\title{
SEXUAL VIOLENCE AMONG A COHORT OF INJECTION DRUG USERS
}

by

\section{PAULA BRAITSTEIN}

B.A., McGill University, 1991

M.A., Simon Fraser University, 1999

A THESIS SUBMITTED IN PARTIAL FULFILMENT OF

THE REQUIREMENTS FOR THE DEGREE OF

\section{MASTER OF SCIENCE}

\author{
in \\ THE FACULTY OF GRADUATE STUDIES \\ THE FACULTY OF MEDICINE \\ Department of Health Care and Epidemiology
}

We accept this thesis as conforming

to the required standard:

Dr. Martin T. Schechter

Senior Thesis Supervisor

Dr. Robert S. Hogg

Thesis Committee Member

Dr. Mark Tyndall

Thesis Committee Member

Dr. Patricia Spittal

Thesis Committee Member

THE UNIVERSITY OF BRITISH COLUMBIA

August 2001

(CPaula Karina Alice Braitstein, 2001 
In presenting this thesis in partial fulfillment of the requirements for an advanced degree at the University of British Columbia, I agree that the Library shall make it freely available for reference and study. I further agree that permission for extensive copying of this thesis for scholarly purposes may be granted by the head of my department or by his or her representatives. It is understood that copying or publication of this thesis for financial gain shall not be allowed without my written permission.

Name: Paula Braitstein

Department of Health Care and Epidemiology The University of British Columbia Vancouver, Canada

Date Angust 31, 2001 


\begin{abstract}
Objectives: To determine the prevalence of and factors associated with sexual violence in childhood, adolescence and adulthood, among injection drug users (IDU). To determine how much of the HIV epidemic among this population is attributable to a history of sexual violence.

Methods: The Vancouver Injection Drug User Study is a prospective cohort of IDU begun in 1996. The analysis included all individuals who completed the baseline questionnaire who responded to the question about sexual assault. Multivariate modeling was used to determine to what extent a history of sexual violence, and at different ages, is predictive of later self-destructive behaviors and health care utilization. Attributable risks were calculated using HIV incidence and prevalence estimates entered into standard attributable risk calculations.
\end{abstract}

Results: There were 1437 eligible individuals, of whom $518(36 \%)$ reported a history of sexual violence. This included $306(21 \%)$ individuals who were at or below age 12 when the first incident occurred. Women were more likely to report a history of sexual violence (AOR: 9.0, 95\% CI: 7.0 - 11.5). After controlling for sociodemographic factors, any history of sexual violence was predictive of ever being in the sex trade (AOR: 3.7, 95\% CI: $2.8-4.9$ ), having knowingly borrowed rigs from $\mathrm{HIV}+$ people (AOR: 1.7, 95\% $\mathrm{CI}: 1.3-2.3$ ), having ever attempted suicide (AOR: $1.7,95 \% \mathrm{CI}: 1.2-2.3$ ), and ever being diagnosed with a mental disorder/disability (AOR: 2.0,95\% CI: 1.6-2.6). A clear gradient of effect was associated depending on the age at onset of abuse, with those experiencing child sexual abuse having the worst outcomes. Childhood sexual abuse (but not other ages) was predictive of using the emergency department in the past six months (AOR 1.8, 95\% CI: $1.3-2.4$ ), and ever being hospitalized for mental illness (AOR 1.5, $95 \% \mathrm{CI}: 1.1-1.9$ ). Approximately $25 \%$ of the HIV prevalence among individuals who have experienced sexual violence can be attributed to their history of sexual violence, and approximately $10 \%$ of the HIV prevalence in all of VIDUS can be attributed to sexual violence.

Conclusions: These data suggest that $36 \%$ of the cohort has ever experienced sexual violence, and $21 \%$ was first experienced in childhood. This history is strongly associated with a plethora of HIV risk and self-destructive behaviors, and can be causally associated in the case of child sexual abuse. Approximately $10 \%$ of the HIV prevalence among this cohort can be attributed to a history of sexual violence. 


$\begin{array}{lc}\text { Abstract } & \text { ii } \\ \text { Table of Contents } & \text { iii } \\ \text { List of Tables } & \text { iv } \\ \text { List of Charts } & \mathbf{v} \\ \text { List of Figures } & \mathbf{v i} \\ \text { List of Appendices } & \mathbf{v i i} \\ \text { Acknowledgements } & \mathbf{v i i i} \\ \text { Dedication } & \text { ix } \\ \text { CHAPTER I: INTRODUCTION } & \\ \text { 1.1 Background } & \mathbf{1} \\ \text { 1.2 Rationale } & \mathbf{4} \\ \text { 1.3 Study Objectives } & \mathbf{5} \\ \text { CHAPTER II: } \quad \text { LITERATURE REVIEW } & \\ 2.1 \text { Prevalence } & 7 \\ 2.2 \text { Consequences of Sexual Violence } & 24 \\ 2.2 .1 \text { Emotional } & 25 \\ 2.2 .2 \text { Cognitive } & \text { Interpersonal } \\ 2.2 .4 \text { Behavioral } & 26 \\ 2.2 .5 \text { Biological } & 28 \\ 2.3 \text { Mediating Factors and the Cause-Effect Relationship } & 32 \\ \end{array}$

\section{CHAPTER III: METHODS}

3.1 Objectives and Hypotheses $\quad 60$

3.2 Data Source 61

3.3 Definition of Sexual Violence $\quad 62$

3.4 Variables

3.5 Analysis $\quad 66$

\section{CHAPTER IV: RESULTS}

4.1 Abuse Characteristics $\quad 72$

4.2 Hypothesis $1 \quad 75$

4.3 Hypothesis $2 \quad 77$

$\begin{array}{ll}4.4 \text { Hypothesis } 3 & \mathbf{8 7}\end{array}$

\section{CHAPTER V: DISCÚSSION}

5.1 Key Results $\quad 89$

5.2 Evidence in Favor and New Findings $\quad 95$

5.3 Strengths of the Study $\quad 99$

$\begin{array}{ll}5.4 \text { Limitations of the Study } & \mathbf{1 0 0}\end{array}$

$\begin{array}{ll}5.5 \text { The Question of Causality } & \mathbf{1 0 4}\end{array}$

CHAPTER VI: $\quad$ CONCLUSIONS AND FUTURE DIRECTIONS 112

$\begin{array}{lr}\text { BIBLIOGRAPHY } & \mathbf{1 1 5}\end{array}$

APPENDIX I Certificate of Ethical Approval, St. Paul's Hospital, University of British Columbia $\quad 124$

$\begin{array}{lll}\text { APPENDIX II } & \text { Tables } 1-36 & \mathbf{1 2 6}\end{array}$ 


\section{List of Tables}

$\begin{array}{ll}\text { Table } & \text { Analysis } \\ \text { Table 1 } & \text { Characteristics of abuse for men and women } \\ \text { Table 2 } & \text { Univariate sociodemographic associations } \\ \text { Table } 3 & \text { Multivariate analysis of sociodemographic factors } \\ \text { Table } 4 & \text { Univariate drug use associations } \\ \text { Table } 5 & \text { Univariate sexual behavior associations } \\ \text { Table 6 } & \text { Univariate medical and health care utilization associations } \\ \text { Table 7 } & \text { Comparison of sociodemographic proportions } \\ \text { Table } 8 & \text { Comparison of drug use proportions } \\ \text { Table 9 } & \text { Comparison of sexual behavior proportions } \\ \text { Table 10 } & \text { Comparison of medical and health care utilization } \\ & \text { proportions }\end{array}$

Table 11 Comparison of sociodemographic unadjusted odds ratios

Table 12 Comparison of drug use unadjusted odds ratios

Table 13 Comparison of sexual behavior unadjusted odds ratios

Table 14 Comparison of medical and health care utilization unadjusted odds ratios

Table 15 Univariate sociodemographic associations

Table 16 Univariate drug use associations

Table 17 Univariate sexual behavior associations

Table 18 Univariate medical and health care utilization associations

Table 19 Univariate sociodemographic associations

Table 20 Univariate drug use associations

Table 21 Univariate sexual behavior associations

Table 22 Univariate medical and health care utilization associations

Table 23 Univariate sociodemographic associations

Table 24 Univariate drug use associations

Table 25 Univariate sexual behavior associations

Table 26 Univariate medical and health care utilization associations

Table 27 Univariate sociodemographic associations

Table 28 Univariate drug use associations

Table 29 Univariate sexual behavior associations

Table 30 Univariate medical and health care utilization associations

Table 31 Univariate sociodemographic associations

Table 32 Univariate drug use associations

Table 33 Univariate sexual behavior associations

Table 34 Univariate medical and health care utilization associations

Table 35 Adjusted odds ratios for HIV risk factors and other self-destructive outcomes

Table 36 Adjusted odds ratios for health care utilization

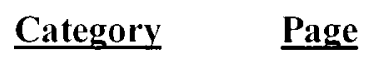

all 127

(ever vs. never) 128

(ever vs. never) 129

(ever vs. never) 130

(ever vs. never) 132

(ever vs. never) 133

across ages $\quad 135$

across ages $\quad 136$

across ages $\quad 137$

across ages $\quad 138$

across ages $\quad 139$

across ages $\quad 140$

across ages $\quad 142$

across ages $\quad 143$

( $\leq 12$ vs. never) $\quad 144$

( $\leq 12$ vs. never) $\quad 145$

( $\leq 12$ vs. never) $\quad 147$

( $\leq 12$ vs. never) $\quad 148$

(13-17 vs. never) 150

(13-17 vs. never) 151

(13-17 vs. never) 153

(13-17 vs. never) 154

$(\leq 12$ vs. $13-17) \quad 156$

$(\leq 12$ vs. 13-17) 157

$(\leq 12$ vs. $13-17) \quad 159$

$(\leq 12$ vs. $13-17) \quad 160$

( $\geq 18$ vs. never) $\quad 162$

( $\geq 18$ vs. never) $\quad 163$

( $\geq 18$ vs. never) 165

( $\geq 18$ vs. never) $\quad 167$

( $\leq 12$ vs. $\geq 13) \quad 169$

$(\leq 12$ vs. $\geq 13) \quad 170$

$(\leq 12$ vs. $\geq 13) \quad 172$

( $\leq 12$ vs. $\geq 13) \quad 173$

across ages $\quad 175$

across ages $\quad 176$ 
Chart 1 Prevalence estimates across general population samples

Chart 2 Prevalence estimates in key populations, by year

Chart 3 Prevalence estimates in key populations, by population 
Figure 1 Relationship of perpetrator to victim, genders combined

p. 74 
Appendix One: Ethics Approval

Appendix Two: Tables $1-3 ; 6$
Page 124

Page 126 


\section{Acknowledgements}

This project would not have been made possible without the assistance and support of numerous people, both friends and colleagues.

First, I must thank my Thesis Committee, Dr.'s Martin Schechter, Bob Hogg, Mark Tyndall, and Patty Spittal, for trying to keep pace with my anxiety levels and tight deadlines, not to mention for providing me with guidance and support.

I would also like to thank Kathy Li, Kevin Craib, Kate Heath, Adrian Levy, Anona Thorne, and Keith Chan for their considerable technical assistance, insight and advice.

I must acknowledge Arn Schilder for his courage and strength in bringing the issue of child sexual abuse to the forefront of the minds of people working in HIV/AIDS, and for making me tea.

I could not have completed this project without the loving support and encouragement of the most important people in my life, my friends. In no particular order, I wish to thank Jac, Evan, Amy, Mike, Larry, Mateen, Glen, Ian, Ken, Melissa, Kath \& Suz, Katrina, Cari and Natalie. Each of you has provided me with inspiration, wisdom and laughter over the past several weeks, and I honestly don't know what I would have done without you.

I must also acknowledge the on-going support and encouragement of the staff, volunteers, and members at the British Columbia Persons with AIDS Society, and particularly the gang in the Treatment Information Program. Thanks, you guys, for letting me have my cake and eat it too.

This degree has been generously supported by the (former) British Columbia Health Research Foundation, and the Canadian Institutes for Health Research (formerly the National Health Research and Development Program). This work has also been supported by the British Columbia Center for Excellence in HIV/AIDS. 


\section{Dedication}

This work is dedicated to the child inside each of us, and to each of our children.

This work is also dedicated to the participants in the Vancouver Injection Drug Users Cohort. I wish this research were not still necessary.

And for C.M., whom I will always remember. 


\section{Chapter 1: Introduction}

\subsection{Background}

Sexual violence is a broad term currently used to describe a spectrum of types of victimization of a sexual nature. Examples of more specific terms that fall under the rubric of sexual violence include sexual abuse, childhood sexual abuse, molestation, sexual assault, sexual coercion, non-consensual sex, and rape. Sexual violence can be perpetrated by anyone, including but not limited to strangers, parents, and spouses.

"At its most fundamental, sexual violence describes the deliberate use of sex as a weapon to demonstrate power over, and to inflict pain and humiliation upon, another human being. Thus, sexual violence does not have to include direct physical contact between perpetrator and victim: threats, humiliation and intimidation may all be considered as sexually violent when they are used with the above purposes." (1)

Early in the $20^{\text {th }}$ century, Freud abandoned his investigation of the relationship between sexual trauma and psychopathology because he was apparently unable to distinguish between true and false memories (2). Freud's doubts so affected mainstream psychiatry that until relatively recently, incest was regarded as a rarity, and the dissociative disorder frequently seen in patients was deemed an artifact created by medical interest (2). In what has become a classic study, Weinberg in 1955 published prevalence estimates that suggested that there was one case of incest per million persons per year in Englishspeaking countries (3). Although case-studies regarding the physical and psychological consequences of sexual violence have been published for several decades (4), it has only been since the 1970's and early 1980's that the topic has received any in-depth attention in the medical and epidemiological literature. The apparent lack of data, combined with Freud's misgivings reinforced the idea that incest and child sexual abuse in general were 
relatively infrequent in .North America, and therefore not a problem (5). However, as more and better quality data have been produced and published, it has become clear that sexual violence, and particularly child sexual abuse, is in fact endemic in the Developed World.

Since the mid-1990's, the Downtown Eastside of Vancouver, British Columbia, has experienced an explosive and ongoing HIV-1 epidemic among injection drug users $(6,7)$. . The neighborhood is among the most impoverished in Canada (8), and the annual HIV-1 incidence rate of $18 \%$ among injection drug users observed in 1997 is among the highest ever documented in the developed world (7). Why and how this epidemic exploded is complex and multifactorial, and inherently political (9). This epidemic was in part the result of poor public policy decision making. The latter created an acute shortage of affordable housing, removed opportunities for addiction and mental health treatment, and concentrated thousands of vulnerable people in an environment where drugs were readily available (9).

It is the question of vulnerability that this thesis explores. There are many ways in which an individual can become vulnerable to HIV infection, meaning that they are predisposed to engaging in behaviors that allow for viral transmission. These behaviors primarily include unprotected sexual activity, and injection drug use. An individual's vulnerability to participating in these behaviors can be the result of concurrent factors, such as being under the influence of alcohol or drugs, or it can be the result of antecedent issues, including mental disability such as schizophrenia, and emotional instability. 
The Vancouver Injection Drug Users Study (VIDUS) is a cohort that was established in 1997 to examine and understand the health and lifestyle of injection drug users. Participants in VIDUS answer questions specifically regarding their history of sexual violence, as well as details regarding HIV risk behaviors, health issues, and medical utilization. To date, the data regarding sexual violence in this cohort has been neither thoroughly examined nor published.

Although it is now well established that the short and long-term effects of sexual violence can be devastating for victims, this has not always been the case. Historically, the question of whether child sexual abuse had any long lasting effects was debated at least since the time of Sigmund Freud, who believed that the stories his female patients recounted to him of sexual experiences with their fathers were fantasy, and that these fantasies were a part of their hysteria (10). A landmark paper in 1962 by Kempe et al. (11) first described the Battered Child Syndrome, but even into the 1980 's, there were authors advocating for the full exploration of children's sexuality, which included exploration by adults (12). Over the past two decades, a substantial number of important publications have confirmed and explored the physical and psychological consequences of sexual violence, in both childhood and adulthood. Chapter 2 of this thesis is a review of the literature on the topic, and will discuss some of the key issues involved, including prevalence estimates, methodological problems in assessing prevalence, and the emotional, cognitive, somatic, behavioral, and interpersonal sequelae of sexual violence, with a particular emphasis on childhood sexual abuse. The literature review will also 
consider whether the relationship between child sexual abuse and later adverse consequences is a causàl one.

\section{I.2 Rationale}

Although the literature on sexual violence is becoming increasingly sound and comprehensive, there are a number of unanswered questions that this project has the potential to explore. There is literature regarding a variety of specific marginalized populations, including homeless women and youth, institutionalized individuals, HIVpositive individuals, people at risk for HIV through sexual activity (e.g. men who have sex with men), and individuals in clinical care. However, one population that has not yet been adequately characterized in terms of sexual violence is the injection drug using community. Therefore, the VIDUS presents an ideal opportunity, because it is a cohort of men and women at high risk for HIV infection and other adverse outcomes by virtue of their drug using behavior. VIDUS collects data on people's history of sexual violence, their drug use and sexual behaviors, and various other health related issues, enabling a thorough investigation. Furthermore, although it is well established that sexual violence is associated with numerous risk taking behaviors and other adverse outcomes, it is not clear from the literature whether childhood sexual abuse in particular is associated with worse outcomes than sexual violence in adolescence or adulthood. In other words, some of the questions which Freud posed earlier in the $20^{\text {th }}$ century have yet to be answered. Because the VIDUS cohort collects data on the age at which sexual violence was first experienced in addition to specific outcomes, and because the sample size is adequately 
large to provide sufficient statistical power, we are presented with an opportunity to explore these critical and as yet unanswered questions.

\subsection{Study Objectives}

The present study has been developed to characterize how sociodemographic factors, HIV risk and other self-destructive behaviors, and utilization of health care services differ between injection drug-using individuals who have experienced sexual violence in their lifetimes and those who have not. This study will also explore how first sexual violence in childhood, adolescence and adulthood specifically affect HIV risk behaviors and clinical outcomes among this injection drug using population. The cohort whose data is forming the basis of the analysis is a group of approximately 1400 male and female individuals who at baseline used injection drugs and were therefore at risk of acquiring HIV infection. Specifically, the primary objectives of this study are:

- To describe the prevalence of and factors associated with a lifetime history of sexual violence among this cohort of injection drug using men and women at high risk of HIV infection.

- To describe how HIV risk behaviors and medical/health care utilization outcomes differ depending on the age at which an individual was first victimized.

- To estimate how much of the HIV epidemic among this population is attributable to a history of sexual violence. 
Chapter 3 will describe in detail the methods used to conduct the analyses. Chapter 4 will present the results of the study, and Chapter 5 will discuss the merits and limitations of the results, and elaborate on the concept of causation in the context of child sexual abuse. Chapter 6 will be the concluding chapter, summarizing what this analysis contributes to the literature, and identifying future directions for research. 


\section{Chapter 2: Literature Review}

\subsection{Prevalence}

Any discussion of the prevalence of sexual violence or childhood sexual abuse must first take into consideration several methodological issues. These issues primarily concern how abuse is defined, sampling and reporting issues (amnesia, disclosure), and the presence of other kinds of violence or abuse as potential confounding factors.

How child sexual abuse or sexual violence is operationally defined varies widely (3-5, 13-15). Roosa (1998) describes the differences such that the definition can be either dichotomous or multilevel in nature (14). Dichotomous outcomes provide respondents the opportunity to say either that any sexual abuse had happened, versus none, as perceived by the respondent (which is the definition in the VIDUS cohort). Finkelhor (1984) alternatively suggests that the definition should include prompted questions about the age of the respondent compared to the age of the perpetrator, for example "Before your 13 th birthday, did you have any sexual relations, consensual or not, with someone 5 years older than you?" (16). This definition captures individuals who may not characterize their experience as abuse or rape, but whom, by law, would be considered as having been violated. This age structure thus takes into account power dynamics that may not be obvious or perceived by the respondents, and it allows for healthy peer sexual experiences. Importantly, however, defining sexual violence in terms of relative age overlooks sexual violence by peers or siblings (3). 
A multilevel definition requires a breakdown of the nature of the abuse: contact or noncontact, intercourse or no intercourse, attempted versus completed. Was the perpetrator a boyfriend or a husband? Were physical threats or force involved? Did the respondent say "no"? Was there only one isolated instance or did the abuse go on for a period of time? At what age do children cease to be children? Some studies use 16 years as the cut-off, some use 17, and many use 18 years. Some consider children to be 12 and under, and over 12 years they become adolescents. As the literature strongly indicates, all of these factors can influence how sexual violence is reported, and how an individual will recover from or respond to sexual violence. Yet these inconsistencies result in differing estimates of both prevalence and potential consequences of sexual violence and make generalizing difficult. For example, a $300 \%$ difference in incidence within one study was found depending on how sexual violence was measured (related mostly to whether a boyfriend was involved or not) (14). However, homogenizing all sexual experiences prevents an adequate understanding of the differential effects of different kinds of abuse, or of appreciating different levels of vulnerability (17).

Obtaining relatively accurate prevalence rates is also key because without them any measurement of their sequelae will be equally inaccurate. Despite this, there is even a debate about what constitutes 'abuse', with some arguing that abuse indicates the presence of harm, and that consequently child sexual abuse may not appropriately describe an adult-child sexual encounter from which no demonstrable harm can be observed (4). Regardless of how sexual violence is defined by the researcher, what constitutes sexual violence to the research participant may be entirely different, thereby 
obfuscating true prevalence. For example, age-specific socialization may alter perceptions of what appropriate behavior is or is not. Individuals who grew up in an earlier era may be more prone to suppress or deny sexually violent experiences, either because of a heightened sense of secrecy and stigmatism associated with sexual victimization, or because the event (eg. date rape, being fondled by an uncle, etc.) was considered normal (and not talked about) at that time (13). Russell (1984) found that older women report less molestation than younger women, leading her to suggest that sexual abuse was increasing over time (18). However, an alternative explanation may simply be a cohort underreporting bias due to less complete memories with the passage of time, embarrassment, or normalization of the event (3). For many gay men, their first homosexual experience was as a child/adolescent, often with someone much older. Many men do not consider this sexual abuse.

Prevalence estimates also depend heavily upon the sample from which they are drawn. Samples used for determining the prevalence of sexual violence have come primarily from four sources $(12,15)$. These are short-term follow-up studies derived from children and parents shortly after abuse has been disclosed (19-21), clinical and/or marginalized populations (20, 22-60), college student samples (61-69) and general population probability samples $(3,70-77)$. There are advantages and disadvantages to each of these sampling populations, such as ability to generalize, sampling and selection bias, establishing a cause-effect relationship and the issue of temporality. Common to all sampling methods are a number of important issues regarding disclosure. 
There are several reasons to be skeptical of currently available prevalence estimates due to disclosure issues. It is very possible that those who respond to surveys or questions about sexual violence experienced either in childhood or adulthood differ in some systematic way from those who don't, and these reasons may even be contradictory. On the one hand, survivors of sexual violence may be reluctant or unwilling to participate in studies of abuse because painful information must be disclosed. On the other hand, survivors may be more motivated to tell their story, thereby increasing their representation in the sample. In a large sample $(n=13,494)$ of $\mathrm{HMO}$ members looking at this question, nearly 10,000 individuals responded to a questionnaire regarding their childhood background. Medical histories prior to this survey were obtainable for all members, including the question of whether they had experienced child sexual abuse. This medical history was therefore available to the investigators whether people responded to the questionnaire or not. Persons with a history of child sexual abuse were somewhat more likely to respond (OR: 1.4, CI: 1.1-1.6, $\mathrm{p}<0.001$ ). Non-respondents who had reported experiencing child sexual abuse were substantially more likely to report current depression and high stress, and to report a higher prevalence of job and family problems (78).

Disclosure may also depend on a variety of other factors, such as the severity of the abuse, its psychological effects, and even whether it is remembered. For example, Smith et al. (2000) sought to determine how long women who had been raped before the age of 18 waited prior to disclosing the incident, whom they disclosed to, and predictors of disclosure. Data were gathered from 3,220 respondents from the National Women's 
Study, a nationally representative telephone survey of women's experiences with trauma and mental health. Of these, 288 reported at least one rape prior to their 18 th birthday. Fully $28 \%$ of child rape victims reported that they had never told anyone about their child rape prior to the research interview; $47 \%$ did not disclose for over 5 years post-rape. Close friends were the most common confidants. Logistic regression revealed that being of a younger age at the time of the rape and knowing the perpetrator were independently predictive of delayed disclosure (79). Finkelhor reported that $50 \%$ of respondents indicate that that research was the first point of disclosure for them (5).

In general, women are most often the victims of sexual violence $(5,23,80)$. Whether this is the result of reporting bias is not clear. Work done by Lab et al. (2000) found that in an evaluation of mental health professionals, the majority do not ask male patients about histories of sexual abuse (81). Furthermore, their understanding of the prevalence and patterns associated with sexual violence against men was highly variable, and most have had no specific training in working with male victims of sexual violence (81). Another important gender-related consideration that may bias much of the available research is homophobia. The overwhelming majority of perpetrators are male (5), and for male victims of sexual violence, homophobia may be an additional barrier to disclosing have been abused or raped, for fear of being labeled gay, or for fear of perhaps being gay. The consistency across all studies which examine prevalence among both men and women strongly suggest that women are the most frequent victims of sexual violence. However, it is also likely that rates among men are underreported. 
Culture as an influential factor in the disclosure of sexual violence has been largely unconsidered. In a review of the literature on childhood sexual abuse in relation to racial, ethnic, and cultural factors, Kenny and McEachern (2000) discuss three ways in which culture is relevant to the topic: 1) how cultural beliefs or attitudes contribute to family climates in which children can be abused, 2) how cultural organization prohibits or hinders disclosure, and 3) how culture plays a role in seeking or accepting social service or mental health assistance (82). Examples of cultural mediating factors are stronger extended family ties, cultural traditions of filial piety and female submissiveness (e.g. Confucian-based cultures), parental respect and obedience, concepts of family unity and family honor, protectiveness of females and stigma attached to abuse, openness to discussing sex, maternal support, and the importance placed on virginity and chastity (82). Importantly, many of these elements are rooted in the traditional fact that the primary unit for survival was the family (52). Language barriers and family isolation can be compounding factors in new immigrant families.

Differential rates of disclosure may also affect estimates of prevalence, and people might not disclose their experience for a variety of reasons. The first time the story is told could be an opening of the floodgates, in which once the abuse is acknowledged, the survivor may be forced to accept and address it. The person may not be psychologically prepared for these consequences, and may therefore not disclose at all. The ramifications of disclosure can also be extreme. A case-series of 38 Palestinian female victims of sexual violence who disclosed their experience found a number of distressing results. In 28 of the 38 cases, the perpetrator was a close male family relative, either the father or brother 
in nearly $90 \%$ of the cases. Pregnancy was the reason for disclosure in nearly half of all cases. Four of the women died as a result of the pregnancy: one due to a botched (illegal) abortion, two when the brother of the victim killed the victim upon finding out about the pregnancy, and one who was killed by her sister (through poisoned food), again because of finding out about the pregnancy (and this last woman was in protective custody at the time). In the 12 cases where the hymen of the victim was perforated, five remained under virtual house arrest to avoid psychological and social derision, one was forced to marry her rapist, one was banished to another country, and the others institutionalized in orphanages or centres for broken families. Of the women whose hymens were still intact, they all disclosed because they went for a medical certification of this fact, which enabled the victim and her family to nullify the abuse. In all cases, disclosure was delayed for a long time following the onset of the abuse (52).

A final factor that must be considered in discussing prevalence is memory. Investigations have overwhelmingly relied on adults' retrospective reports of childhood sexual abuse. There are reports in the literature of people falsely reporting a history of abuse $(13,17)$. There are also cases which go undisclosed because the victim has either forgotten (amnesia) or has dissociated so much from the event that either their memory of the event was distorted, or else in their minds, the event may never have occurred (13). Although controversy exists about the validity of memories of childhood abuse, little is known about memory function in individuals reporting childhood abuse. One study assessed memories for previously presented words, including the capacity for false memory of critical lures not actually present in a word list among 63 individuals. Included in the 
sample were abused women with posttraumatic stress disorder (PTSD), abused women without PTSD, and men and women without abuse or PTSD. Abused women with PTSD had a higher frequency of false recognition memory of critical lures (95\%) than abused women without PTSD (78\%), non-abused women without PTSD (79\%), or non-abused men without PTSD (86\%) (83). Although this research suggests that individuals with a history of abuse have issues with memory in general, it is difficult to interpret in terms of sexual abuse. In another study, the California Verbal Learning Test and the Benton Visual Retention Task were administered to 22 female adult survivors of childhood sexual abuse and to 20 demographically and educationally similar non-victimized women. No evidence was found of explicit memory impairment in the abuse survivors. In this study, neither PTSD severity, dissociative symptom severity, nor extent of preexisting amnesia for childhood trauma contributed to the variance in memory functioning (84).

An alternative method for assessing prevalence has been explored by Finkelhor et al. (85). They sent a national survey to 1000 parents that primarily addressed disciplinary practices and violence toward their children, and the survey included two questions about whether their child had been sexually abused. From these questions, rates of sexual abuse for children currently between 0 and 17 were estimated at $1.9 \%$ in the last year, and $5.7 \%$ ever. The cases making up these rates included a nearly equal number of boys and girls, and no female victims between the ages of 9 and 12. Both these prevalence estimates and the distribution of cases were considerably different from those generally 
obtained in other epidemiologic investigations (85). These results suggest that relying on parents to determine the prevalence of child sexual abuse is not appropriate.

A variety of other methodological problems may also contribute to the large variances in prevalence estimates. The majority of studies are retrospective and cross-sectional in nature, making it difficult to determine cause and effect. Long-term longitudinal studies of the incidence and natural history of child sexual abuse would be ethically challenging, prohibitively expensive, and inherently confounded by intervention and volunteer bias. The effects of sexual violence may wax and wane over time, depending on the life circumstances of the survivor, and these can be very difficult to capture. Measuring certain potentially confounding variables can be extremely difficult in this area of research, in part because of its retrospective nature. Knowing what the pre-molestation functioning of the child or adult is rare, and impossible to know in most instances. Other types of family dysfunction, including alcoholism, physical and/or emotional abuse, family separation/divorce, and a sad multiplicity of other possibilities may significantly impact on how much sexual violence occurs, and whether it is reported. A large proportion of studies utilize samples of convenience, with no appropriate control group. Many use measurement instruments to gauge psychological dysfunction, for example, the validity, accuracy and reproducibility of which are not clear $(12,13)$. In summary, assessing the prevalence of sexual violence is a challenging methodological issue. However, research on this topic is relatively young, and over time many of the key threads will be untangled, and the major pitfalls avoided. 
As a result of all these issues, it is therefore impossible to state categorically the true prevalence of sexual violence, and particularly childhood sexual abuse, in the general population. Data from Statistics Canada (1993) suggests that four out of every ten Canadian women have experienced at least one incident of sexual violence since the age of 16 , and more than half of these women have experienced repeated sexual violence (86). In 1997, there were nearly 11,000 sexual assaults reported in Canada. Children and adolescents made of $60 \%$ of all reported sexual assaults, and family members were responsible for one-third of all of these, girls and boys being victimized in roughly equal proportions (87). Available international data suggest that one in five women in the world has been physically or sexually assaulted at some time in their lives (1). Data from the Centre for Disease Control and Prevention (Atlanta) estimates that there were 71 forcible rapes per 100,000 females reported to United States law enforcement agencies in 1996. Data from the National Women's Study, a longitudinal telephone survey of a national household probability sample of women at least 18 years of age, show 683,000 women are forcibly raped each year and that $84 \%$ of rape victims did not report the offense to the police. Using Uniform Crime Report data for 1994 and 1995, the Bureau of Justice Statistics found that of rape victims who reported the offense to law enforcement, about $40 \%$ were under the age of 18 , and $15 \%$ were younger than $12(88)$.

The most comprehensive and frequently cited reference regarding population estimates of child sexual abuse comes from a meta-analysis performed by Finkelhor et al. (5). This analysis included surveys of child sexual abuse in large non-clinical populations of adults from nineteen countries in addition to the United States and Canada, including ten 
national probability samples. All of the studies revealed sexual abuse histories in at least $7 \%$ of the women and at least $3 \%$ of men, ranging up to $36 \%$ of women in Austria and $29 \%$ of men in South Africa. Most studies found women to be abused 1 to 3 times more frequently than men. They also found that incestual abuse was consistently more common for girls than for boys, constituting approximately one-third to one-half of the abuse of girls experiences (5). Since Finkelhor's publication, several population-based studies have confirmed these results (Chart 1). In marginalized populations, however, or in samples drawn from a targeted or clinical population, estimates are generally much higher, and as summarized in Table 3, there are varying ranges depending on the population (Charts $2 \& 3$ ).

Among those HIV-infected populations who have to date been studied, the lowest prevalence estimate for any sexual violence reported was 20\% (89), and the highest was approximately $65 \%(22)$. For individuals who are at high-risk of HIV infection, estimates are similarly high $(25,47,48)$. In psychiatric and homeless populations, the range is greater, though to some extent harder to measure for a variety of reasons. The lowest reported prevalence in this group was $9 \%(90)$ and the highest was $70 \%$ for homeless adolescent girls (43). Of note, Wenzel reports that $13 \%$ of their homeless adult female sample had been forced to have intercourse (oral, anal or vaginal) at least once in the preceding 12 months (91). The one publication addressing prevalence of sexual violence among female inmates showed that $26 \%$ of women had experienced sexual violence in their childhood or adolescence (44). Among individuals seeking out-patient care (both primary and specialized), estimates range from a low of $25 \%$ (60) to a high of 
$45 \%(50)$. Even among college students, who are presumably of a higher socioeconomic and social functioning level overall, estimates ranged between 6\% (67) and 20\% (66). Two different studies of high school students indicate that between $9 \%$ and $21 \%$ have already experienced and are ready to report having experienced sexual violence $(65,76)$. 
Chart 1. General Population Estimates of the Child Sexual Abuse Prevalence

\begin{tabular}{|c|c|c|}
\hline Author & $\begin{array}{c}\text { Year of } \\
\text { Publication }\end{array}$ & Prevalence \\
\hline $\begin{array}{c}\text { Molnar et al. } \\
\text { National Comorbidity Survey, } \\
\text { U.S. }\end{array}$ & 2001 & $\begin{array}{c}\mathrm{n}=5877 \\
13.5 \% \text { women, } 2.5 \% \text { men } \\
6 \% \text { incest for girls, }<1 \% \text { for boys }\end{array}$ \\
\hline $\begin{array}{c}\text { Bensley et al. } \\
\text { Washington State Behavioral } \\
\text { Risk Factor Surveillance } \\
\text { System, U.S. }\end{array}$ & 2000 & $\begin{array}{c}\mathrm{n}=3473 \\
29 \% \text { women, } 19 \% \text { men }\end{array}$ \\
\hline $\begin{array}{c}\text { Kendler et al. } \\
\text { Virginia Twin Registry, U.S. }\end{array}$ & 2000 & $\begin{array}{c}\mathrm{n}=1411 \text { female adult twins } \\
30 \% \text { overall } \\
42 \% \text { incest } \\
\end{array}$ \\
\hline $\begin{array}{c}\text { Fleming et al. } \\
\text { Australia }\end{array}$ & 1997 & $\begin{array}{c}\mathrm{n}=6000 \text { women } \\
20 \% \text { overall } \\
50 \% \text { incest } \\
\end{array}$ \\
\hline $\begin{array}{l}\text { Romans et al. } \\
\text { New Zealand }\end{array}$ & 1995 & $\begin{array}{c}n=3000 \text { women } \\
16 \% \text { overall } \\
45 \% \text { incest }\end{array}$ \\
\hline
\end{tabular}


Chart 2: Prevalence Estimates of Sexual Violence for Marginalized and Targeted Populations

\begin{tabular}{|c|c|c|c|}
\hline Author & $\begin{array}{l}\text { Year of } \\
\text { Publication }\end{array}$ & Population & Prevalence \\
\hline Zlotnick et al. & 2001 & Depressive out-patients & $25 \%$ (childhood) \\
\hline Thompson et al. & 2001 & $\begin{array}{l}\text { 9th- } 12 \text { th grade girls in } \\
\text { urban/rural Midwest }\end{array}$ & $\begin{array}{l}21 \% \text { (urban) } \\
14 \% \text { (rural) } \\
\end{array}$ \\
\hline Paul et al. & 2001 & $\begin{array}{l}\text { Men who have sex with } \\
\text { men }\end{array}$ & $20 \%$ (childhood) \\
\hline Parillo et al. & 2001 & $\begin{array}{l}\text { Female non-injecting } \\
\text { sex partners of IDUs }\end{array}$ & $\begin{array}{l}33 \% \text { (childhood and } \\
\text { adolescence) }\end{array}$ \\
\hline Noell et al. & 2001 & Homeless adolescents & $38 \%$ (childhood) \\
\hline Gielen et al. & 2001 & HIV-positive women & $41 \%$ (lifetime) \\
\hline Balogh et al. & 2001 & $\begin{array}{l}\text { Adolescent psychiatric } \\
\text { in-patients with } \\
\text { intellectual disabilities }\end{array}$ & $14 \%$ (childhood) \\
\hline Wenzel et al. & 2000 & $\begin{array}{l}\text { Homeless adult women } \\
\text { in L.A. (forced } \\
\text { intercourse only) }\end{array}$ & $13 \%$ in past $12 \mathrm{mths}$ \\
\hline Thakkar, R.R. et al. & 2000 & Female college students & $13 \%$ (under 15$)$ \\
\hline Simoni \& Ng & 2000 & HIV-positive women & $\begin{array}{l}50 \% \text { (childhood) } \\
68 \% \text { (adulthood) } \\
\end{array}$ \\
\hline Rosenberg et al. & 2000 & $\begin{array}{l}\text { High-risk help-seeking } \\
\text { individuals in a medical } \\
\text { facility }\end{array}$ & $45 \%$ (childhood) \\
\hline Petrak & 2000 & $\begin{array}{l}\text { Inner city women } \\
\text { attending a clinic } \\
\text { (U.K.) }\end{array}$ & $26 \%$ (childhood) \\
\hline Pao et al. & 2000 & $\begin{array}{l}\text { HIV-infected } \\
\text { psychiatric adolescent } \\
\text { patients }\end{array}$ & $50 \%$ (childhood) \\
\hline Mullings et al. & 2000 & Female inmates & $\begin{array}{l}26 \% \text { (childhood and } \\
\text { adolescence) }\end{array}$ \\
\hline $\begin{array}{l}\text { Messman-Moore \& } \\
\text { Long }\end{array}$ & 2000 & Female college students & $20 \%$ (childhood) \\
\hline Liebschutz et al. & 2000 & $\begin{array}{l}\text { HIV-positive women in } \\
\text { primary care }\end{array}$ & $\begin{array}{l}68 \% \text { (sexual or } \\
\text { physical) }\end{array}$ \\
\hline Feldhaus et al. & 2000 & $\begin{array}{l}\text { Emergency room } \\
\text { female patients }\end{array}$ & $39 \%$ (lifetime) \\
\hline Humphrey et al. & 2000 & Female college students & $\begin{array}{l}70 \% \text { (lifetime) } \\
36 \% \text { (childhood) }\end{array}$ \\
\hline Heffernan et al. & 2000 & Psychiatric in-patients & $9 \%$ (childhood) \\
\hline Golding et al. & 2000 & $\begin{array}{l}\text { Women seeking } \\
\text { treatment for PMS }\end{array}$ & $\begin{array}{l}95 \% \text { (childhood) } \\
81 \% \text { (penetration) }\end{array}$ \\
\hline Cohen et al. & 2000 & $\begin{array}{l}\text { Women HIV-positive } \\
\text { or at risk }\end{array}$ & $\begin{array}{l}25 \% \text { (childhood } \\
\text { overall) } \\
31 \%(\text { HIV }+ \text { ) } \\
27 \% \text { (HIV-) }\end{array}$ \\
\hline Browne et al. & 2000 & Drug users (Ireland) & $21 \%$ (childhood) \\
\hline
\end{tabular}




\begin{tabular}{|c|c|c|c|}
\hline Banyard et al. & 2000 & Female college students & $25 \%$ (childhood) \\
\hline Beckinsale et al. & 1999 & $\begin{array}{l}\text { Youth seeking primary } \\
\text { care }\end{array}$ & $\begin{array}{l}16 \% \text { (childhood) } \\
6 \% \text { (males) } \\
21 \% \text { (females) }\end{array}$ \\
\hline Young \& Katz & 1998 & $\begin{array}{l}\text { Inner city } 50 \% \\
\text { aboriginal women } \\
\text { attending a clinic } \\
\text { (Winnipeg) }\end{array}$ & $\begin{array}{l}37 \% \text { (lifetime) } \\
27 \% \text { (childhood) }\end{array}$ \\
\hline Schaff \& McCanne & 1998 & Female college students & $6 \%$ (childhood) \\
\hline Molnar et al. & 1998 & $\begin{array}{l}\text { Homeless and runaway } \\
\text { street youth }\end{array}$ & $\begin{array}{l}70 \% \text { (girls) } \\
24 \% \text { (boys) }\end{array}$ \\
\hline Charnaud et al. & 1998 & $\begin{array}{l}\text { Female drug users } \\
\text { (U.K.) }\end{array}$ & \\
\hline $\begin{array}{l}\text { Wingood \& } \\
\text { Diclemente }\end{array}$ & 1997 & $\begin{array}{l}\text { African-American } \\
\text { women living in } \\
\text { poverty }\end{array}$ & $13 \%$ (childhood) \\
\hline McCauley et al. & 1997 & $\begin{array}{l}\text { Adult women in } \\
\text { primary care }\end{array}$ & $\begin{array}{l}22 \% \text { (childhod and } \\
\text { adolescence, physical } \\
\text { and sexual) }\end{array}$ \\
\hline Zierler et al. & 1996 & HIV-positive women & $\begin{array}{l}43 \% \text { (lifetime) } \\
20 \% \text { (childhood) }\end{array}$ \\
\hline Johnsen \& Harlow & 1996 & $\begin{array}{l}\text { Mostly White college } \\
\text { women }\end{array}$ & $9 \%$ (childhood) \\
\hline Lodico \& Diclemente & 1994 & High School students & $\begin{array}{l}9 \% \text { (childhood, } 15 \% \\
\text { females, } 3 \% \text { males) }\end{array}$ \\
\hline Lechner et al. & 1993 & $\begin{array}{l}\text { Women attending } \\
\text { primary care clinic }\end{array}$ & $26 \%$ (childhood) \\
\hline Drossman et al. & 1990 & GI female patients & $\begin{array}{l}44 \% \text { (lifetime physical } \\
\text { or sexual) }\end{array}$ \\
\hline Chu et al. & 1990 & $\begin{array}{l}\text { Female psychiatric in- } \\
\text { patients }\end{array}$ & $\begin{array}{l}63 \% \text { (childhood } \\
\text { physical or sexual) }\end{array}$ \\
\hline Lechner et al. & 1993 & $\begin{array}{l}\text { Adult women in } \\
\text { primary care }\end{array}$ & $26 \%$ (childhood) \\
\hline Allers et al. & 1991 & HIV-infected & $65 \%$ (childhood) \\
\hline Duncan & 1990 & College students & $\begin{array}{l}20 \% \text { (women, lifetime) } \\
5 \% \text { (men, lifetime) } \\
\text { Gay men: } 12 \% \text { (vs. } \\
4 \% \text { ) } \\
\text { Lesbians: } 31 \% \text { (vs. } \\
18 \% \text { ) }\end{array}$ \\
\hline Drossman et al. & 1990 & $\begin{array}{l}\text { Women in a university } \\
\text { based gastroenterology } \\
\text { practice }\end{array}$ & $\begin{array}{l}44 \% \text { (lifetime sexual or } \\
\text { physical) }\end{array}$ \\
\hline Walker et al. & 1988 & $\begin{array}{l}\text { Women with chronic } \\
\text { pelvic pain }\end{array}$ & $64 \%$ (childhood) \\
\hline
\end{tabular}




\section{Chart 3: Prevalence Estimates of Sexual Violence for Marginalized and Targeted}

Populations, grouped by sample type

\begin{tabular}{|c|c|c|c|}
\hline Author & Year of Publication & Population & Prevalence \\
\hline Cohen et al. & 2000 & $\begin{array}{l}\text { Women HIV-positive } \\
\text { or at risk }\end{array}$ & $\begin{array}{l}25 \% \text { (childhood } \\
\text { overall) } \\
31 \% \text { (HIV+) } \\
27 \% \text { (HIV-) }\end{array}$ \\
\hline Gielen et al. & 2001 & HIV-positive women & $41 \%$ (lifetime) \\
\hline Allers et al. & 1991 & HIV-infected & $65 \%$ (childhood) \\
\hline Liebschutz et al. & 2000 & $\begin{array}{l}\text { HIV-positive women in } \\
\text { primary care }\end{array}$ & $\begin{array}{l}68 \% \text { (sexual or } \\
\text { physical) }\end{array}$ \\
\hline Simoni \& $\mathrm{Ng}$ & 2000 & HIV-positive women & $\begin{array}{l}50 \% \text { (childhood) } \\
68 \% \text { (adulthood) }\end{array}$ \\
\hline Zierler et al. & 1996 & HIV-positive women & $\begin{array}{l}43 \% \text { (lifetime) } \\
20 \% \text { (childhood) }\end{array}$ \\
\hline Pao et al. & 2000 & $\begin{array}{l}\text { HIV-infected } \\
\text { psychiatric adolescent } \\
\text { patients }\end{array}$ & $50 \%$ (childhood) \\
\hline Heffernan et al. & 2000 & Psychiatric in-patients & $9 \%$ (childhood) \\
\hline Balogh et al. & 2001 & $\begin{array}{l}\text { Adolescent psychiatric } \\
\text { in-patients with } \\
\text { intellectual disabilities }\end{array}$ & $14 \%$ (childhood) \\
\hline Chu et al. & 1990 & $\begin{array}{l}\text { Female psychiatric in- } \\
\text { patients }\end{array}$ & $\begin{array}{l}63 \% \text { (childhood } \\
\text { physical or sexual) }\end{array}$ \\
\hline Molnar et al. & 1998 & $\begin{array}{l}\text { Homeless and runaway } \\
\text { street youth }\end{array}$ & $\begin{array}{l}70 \% \text { (girls) } \\
24 \% \text { (boys) }\end{array}$ \\
\hline Noell et al. & 2001 & Homeless adolescents & $38 \%$ (childhood) \\
\hline Wenzel et al. & 2000 & $\begin{array}{l}\text { Homeless adult women } \\
\text { in L.A. (forced } \\
\text { intercourse only) }\end{array}$ & $13 \%$ in past $12 \mathrm{mths}$ \\
\hline Mullings et al. & 2000 & Female inmates & $\begin{array}{l}26 \% \text { (childhood and } \\
\text { adolescence) }\end{array}$ \\
\hline Zlotnick et al. & 2001 & Depressive out-patients & $25 \%$ (childhood) \\
\hline Rosenberg et al. & 2000 & $\begin{array}{l}\text { High-risk help-seeking } \\
\text { individuals in a medical } \\
\text { facility }\end{array}$ & $45 \%$ (childhood) \\
\hline Lechner et al. & 1993 & $\begin{array}{l}\text { Adult women in } \\
\text { primary care }\end{array}$ & $26 \%$ (childhood) \\
\hline Petrak & 2000 & $\begin{array}{l}\text { Inner city women } \\
\text { attending a clinic } \\
\text { (U.K.) }\end{array}$ & $26 \%$ (childhood) \\
\hline Feldhaus et al. & 2000 & $\begin{array}{l}\text { Emergency room } \\
\text { female patients }\end{array}$ & $39 \%$ (lifetime) \\
\hline Humphrey et al. & 2000 & Female college students & $\begin{array}{l}70 \% \text { (lifetime) } \\
36 \% \text { (childhood) }\end{array}$ \\
\hline Beckinsale et al. & 1999 & $\begin{array}{l}\text { Youth seeking primary } \\
\text { care } \\
n=3144\end{array}$ & $\begin{array}{l}16 \% \text { (childhood) } \\
6 \% \text { (males) } \\
21 \% \text { (females) }\end{array}$ \\
\hline Young \& Katz & 1998 & Inner city women (44\% & $37 \%$ (lifetime) \\
\hline
\end{tabular}




\begin{tabular}{|c|c|c|c|}
\hline & & $\begin{array}{l}\text { aboriginal) attending a } \\
\text { clinic (Winnipeg) }\end{array}$ & $27 \%$ (childhood) \\
\hline $\begin{array}{l}\text { Wingood \& } \\
\text { Diclemente }\end{array}$ & 1997 & $\begin{array}{l}\text { A frican-American } \\
\text { women living in } \\
\text { poverty }\end{array}$ & $13 \%$ (childhood) \\
\hline Drossman et al. & 1990 & $\begin{array}{l}\text { Women in a university } \\
\text { based gastroenterology } \\
\text { practice }\end{array}$ & $\begin{array}{l}44 \% \text { (lifetime sexual or } \\
\text { physical) }\end{array}$ \\
\hline Golding et al. & 2000 & $\begin{array}{l}\text { Women seeking } \\
\text { treatment for PMS }\end{array}$ & $\begin{array}{l}95 \% \text { (childhood) } \\
81 \% \text { (penetration) }\end{array}$ \\
\hline Walker et al. & 1988 & $\begin{array}{l}\text { Women with chronic } \\
\text { pelvic pain }\end{array}$ & $64 \%$ (childhood) \\
\hline McCauley et al. & 1997 & $\begin{array}{l}\text { Adult women in } \\
\text { primary care }\end{array}$ & $\begin{array}{l}22 \% \text { (childhod and } \\
\text { adolescence, physical } \\
\text { and sexual) }\end{array}$ \\
\hline Lechner et al. & 1993 & $\begin{array}{l}\text { Women attending } \\
\text { primary care clinic }\end{array}$ & $26 \%$ (childhood) \\
\hline Drossman et al. & 1990 & GI female patients & $\begin{array}{l}44 \% \text { (lifetime physical } \\
\text { or sexual) }\end{array}$ \\
\hline Lodico \& Diclemente & 1994 & High School students & $\begin{array}{l}9 \% \text { (childhood, } 15 \% \\
\text { females, } 3 \% \text { males) }\end{array}$ \\
\hline Thompson et al. & 2001 & $\begin{array}{l}\text { 9th-12th grade girls in } \\
\text { urban/rural Midwest }\end{array}$ & $\begin{array}{l}21 \% \text { (urban) } \\
14 \% \text { (rural) }\end{array}$ \\
\hline Johnsen \& Harlow & 1996 & $\begin{array}{l}\text { Mostly White college } \\
\text { women }\end{array}$ & $9 \%$ (childhood) \\
\hline $\begin{array}{l}\text { Messman-Moore \& } \\
\text { Long }\end{array}$ & 2000 & Female college students & $20 \%$ (childhood) \\
\hline Banyard et al. & 2000 & Female college students & $25 \%$ (childhood) \\
\hline Schaff \& McCanne & 1998 & Female college students & $6 \%$ (childhood) \\
\hline Thakkar, R.R. et al. & 2000 & Female college students & $13 \%$ (under 15$)$ \\
\hline Duncan & 1990 & College students & $\begin{array}{l}20 \% \text { (women, lifetime) } \\
5 \% \text { (men, lifetime) } \\
\text { Gay men: } 12 \% \text { (vs. } \\
4 \% \text { ) } \\
\text { Lesbians: } 31 \% \text { (vs. } \\
18 \% \text { ) }\end{array}$ \\
\hline Paul et al. & 2001 & $\begin{array}{l}\text { Men who have sex with } \\
\text { men }\end{array}$ & $20 \%$ (childhood) \\
\hline Parillo et al. & 2001 & $\begin{array}{l}\text { Female non-injecting } \\
\text { sex partners of IDUs }\end{array}$ & $\begin{array}{l}33 \% \text { (childhood and } \\
\text { adolescence) }\end{array}$ \\
\hline Browne et al. & 2000 & Drug users (Ireland) & $21 \%$ (childhood) \\
\hline
\end{tabular}

To summarize, although there a variety of limitations to currently published prevalence estimates of childhood and lifetime sexual violence, one may conclude that sexual 
violence in general and child sexual abuse in particular is unacceptably prevalent in the Developed World, notably North America. While estimates in the general population are approximately $20 \%$, in marginalized populations and individuals accessing health care, these estimates are more like $40 \%$, or even $60 \%$.

\subsection{Consequences of Sexual Violence}

Hendricks-Matthews (1993) has reviewed some of the literature on victimization in general (92). She puts forward a framework developed originally to categorize the consequences of victimization in general, presuming that the effects are basically the same for everyone, whether they have survived a concentration camp, been raped, lived through a war, or some other kind of violent trauma. Whether or not one can universalize the consequences of violent trauma is subject worthy of debate and beyond the scope of this review. However, the framework she uses to conceptualize these sequelae is valuable to understanding the consequences of sexual violence. The five major categories of response to victimization are emotional, cognitive, biologic, behavioral, and interpersonal (92).

As with prevalence studies, outcome studies can have numerous limitations. The studies reviewed below are diverse in terms of their sampling frame, their analytic methods, their hypotheses, the time frame examined, and the types of outcomes. In this respect, most if not all of the studies are hindered by a variety of limitations on their interpretability. These limitations include reporting bias, sampling bias, insufficient power in some cases, 
and inapprópriate statistical methods. Many studies did not examine or consider potentially confounding factors. Therefore, a discussion of the consequences of sexual violence must be framed in light of these limitations. For the sake of brevity, details regarding study methods have not been included in most cases, although key limitations have been noted where appropriate.

\subsubsection{Emotional}

The emotional sequelae of sexual violence can include depression, anxiety, fear, lowered self-esteem, anger, and feelings of guilt and shame. In a recent and important publication of a nationally representative sample of the general population in the United States, Molnar and colleagues (2001) found that $39 \%$ of women who reported a history of child sexual abuse (vs. 19\% who didn't) and 30\% of men who reported a history of child sexual abuse (vs. 11\% who didn't) experienced mood disorders including depression and dysthmia (the difference among the women was statistically significant) (74). Sexually abused women were statistically more likely to experience anxiety disorders such as agoraphobia, panic disorder, and social phobia. Sexually abused men were not statistically more likely to experience any anxiety or depressive disorders, which may be due to lack of statistical power given that only 74 of 2945 (2.5\%) reported child sexual abuse. Particularly deleterious mental health effects of childhood rapes are associated with assaults that caused physical injury (93), and assaults that were incestuous (94). Numerous studies reviewed report increased adverse emotional consequences as a result of sexual violence, particularly depressive and anxiety disorders $(17,19,33,35,72,95$ 98). 
In a group of Australian youth, those who were sexually abused reported twice the level of depression, four times the level of feelings of hopelessness, worthlessness, and powerlessness, and had a significantly higher depression index (24).

Hyun (2000) reports that a childhood history of abuse, in particular sexual abuse, was significantly more frequent in bipolar participants compared with unipolar participants, in both men and women (99). Childhood interpersonal trauma as a whole has also been shown to be highly predictive of both a diagnosis of depersonalization disorder and of scores denoting dissociation, pathological dissociation, and depersonalization. In one study however, emotional abuse, both in total score and in maximum severity, emerged as the most significant predictor both of a diagnosis of depersonalization disorder and of scores denoting depersonalization but not of general dissociation scores, which were better predicted by combined emotional and sexual abuse (53). Other important psychiatric diagnoses have been found to be associated with sexual abuse, including borderline personality disorder, and multiple Axis I diagnoses (46, 60, 100).

\subsubsection{Cognitive}

According to Hendricks-Matthews (92), cognitive responses center on perceptual disturbances. These symptoms can include massive denial, repression, dissociation, and post-traumatic stress disorder. 
Dissociation is defined as an unconscious defense mechanism by which an idea, thought, emotion, or other mental process is separated from the consciousness and thereby loses emotional significance (101). Several important investigations have concluded that survivors of sexual violence experience more and greater degrees of disassociation (26, $27,39,102)$. Interestingly, in an analysis of female sexual assault victims at 4 weeks post-assault, dissociation was predictive of poorer later functioning, while anger expression was predictive of later PTSD severity (103).

Post-Traumatic Stress Disorder (PTSD) is the state of an individual who is experiencing a sustained painful response to overwhelming traumatic events (101). Its critical defining characteristics include re-experiencing the traumatic event through flashbacks, dreams, intrusive thoughts, etc.; confusion, disassociation, amnesia, self-destructive behavior including suicide, substance abuse, difficult interpersonal relationships, development of a phobia, poor impulse control, and explosiveness. There are multiple publications that demonstrate that PTSD can be the result of childhood trauma, including child sexual abuse $(38,39,74,104)$. Many of these publications in fact show a dose-response association between PTSD symptoms and the severity of abuse. In a group of 89 female CSA survivors' current symptoms of PTSD, depression, and dissociation were assessed and found to be strongly related to all three types of symptom severity, such as those who experienced penile penetration, those who believed someone/thing else would be killed, and/or were injured as a result of the abuse. These individuals also exhibited more severe peritraumatic dissociation (39). A study which looked at the differential associations between child sexual abuse, child physical abuse, other adult sexual and 
physical victimization and PTSD, women with a history of child sexual abuse appeared to increased vulnerability to current PTSD (105).

\subsubsection{Interpersonal}

Interpersonal consequences of trauma include sexual dysfunction, problems with intimacy, proneness to revictimization, and transgenerational transmission of violence. There are, unfortunately, numerous examples in the literature of the association between sexual violence and these issues.

Feiring (2000) examined same- and other-sex friendship networks and perceptions of peer competence as functions of stigmatization, defined as shame and a self-blame attributional style among fifty-six sexually abused adolescents who were seen at the time of abuse discovery and 1 year later. Higher self-blame attributional style was related to perceptions of poorer peer acceptance and close friendship and to perceptions of poorer romantic appeal. More shame was related to lower perceptions of peer acceptance and close friendship, and the authors conclude that abuse victims who experience higher levels of shame and self-blame attributional style feel less capable of forming satisfying relationships with peers, friends, and potential romantic partners (19). Sexually abused youth reported having greater difficulty getting along with and feeling unsupported by their parents (24). Fleming (1999) has also reported that women who have experienced childhood sexual trauma experience more problems with low self-esteem, sexual problems, and problems with intimate relationships (97). 
Roy (2001) investigated the relationship between childhood trauma and hostility as an adult, and found that childhood trauma may be a determinant of the personality dimension of hostility as an adult (106). Another study examined child-rearing behavior and found that sexual abuse and its adult sequelae may have negative consequences for the parenting practices of survivors, particularly for survivors' ability to provide their children with appropriate structure, consistent discipline, and clear behavioral expectations (51).

A retrospective case-note review was employed that explored sexual abuse in the lives of intellectually disabled adolescent psychiatric in-patients. Among the $14 \%(n=43)$ individuals who reported sexual abuse, victimization alone occurred in 21 cases, perpetration alone in six cases, and both victimization and perpetration in 16 cases (23). This data suggested a relationship between being a victim and victimizing.

In general, revictimization is defined in the literature as having experienced at least one incident of sexual violence in childhood plus one or more other incidents of sexual violence in either adolescence or adulthood. The issue of revictimization is critical, and could constitute a thesis topic on its own. More sexual victimization after a childhood experience has been frequently reported $(28,64,66,107-109)$.

The National Women's Study was a 2-year, three-wave longitudinal investigation, employing a national probability sample of 3,006 adult women that identified separate 
risk factors for rape and physical assault. In multivariate analysis, past victimization, young age, and a diagnosis of active PTSD increased women's risk of being raped. (110). In another study of women who had experienced child sexual abuse, repeated victimization in adolescence or adulthood was associated with having experienced child sexual abuse involving physical contact, including intercourse and/or penetration. Women with repeated victimization engaged in more self-blame, reported higher levels of post-traumatic symptoms, and reported more high-risk sexual behavior (111).

Banyard (2000) looked at the relationship between the experience of childhood sexual abuse and being a victim of psychological aggression, physical violence, or sexual coercion in a dating relationship in the past year among female college undergraduates. Child sexual abuse was significantly related to having experienced both physical and psychological dating aggression even after controlling for the presence of conflict in the family of origin, but not sexual coercion (61). In another study of revictimization among undergraduate women, victimization before the age of 14 years almost doubled the risk of later adolescent victimization. Furthermore, for those with and without childhood victimization, the risk of an initial sexual assault after the age of 14 years occurred most often in late adolescence, and declined each year thereafter (aged 18-22 years). Sexual victimization among university women was highest for those who had been first assaulted in early adolescence ( 4.6 times more than for non-victims). They also found that the more severe the adolescent experience the greater the risk of collegiate revictimization. Adolescent victims of rape or attempted rape, in particular, were 4.4 times more likely to be as seriously assaulted during their 1st year of college (63). 
In a study of homeless adolescents, it was found that a larger proportion of girls who reported a history of childhood sexual abuse reported recent sexual coercion. (45). Boney-McCoy found that the experience of prior victimization (sexual and nonsexual) was found to increase children's risk for experiencing later child sexual abuse in a national random sample of 2,000 American children aged 10-16 years. Prior victimization predicted subsequent child sexual abuse even when background variables (including the child's gender, race, age, geographic location, quality of relationship with parents, and relative level of violence in the home community) were controlled for. In addition, the prior victimization of a family member also predicted later child sexual abuse. Among children who experienced child sexual abuse, prior victimization increased the level of post-traumatic stress symptomology, even after demographic factors and characteristics of the CSA episode (e.g., severity of the assault, severity of injury, fear of death or serious injury) were included in the model (112).

In a longitudinal study of 113 African-Americans who had been sexually abused as children, brought to a hospital emergency room for treatment at the time, and then reinterviewed as adults, it was found that multiple incidents of child sexual abuse, more than the characteristics of such abuse, was the important predictor of adult heavy alcohol use and binge drinking. These results remained even after controlling for the effects of parental drinking behavior (20). Another but retrospective study of African-American women found that $30 \%$ of those who experienced child sexual abuse were sexually revictimized. In contrast to the previous study, physical force predicted subsequent 
victimization. This study also found that revictimized women reported more involvement in prostitution and partner violence, and revictimized women experienced more problems conceiving, having repeated vaginal infections, sexually transmitted diseases, and painful intercourse (113). Wyatt's data (1992) suggested that unintended pregnancies and abortions were significantly associated with sexual revictimization, and that women who reported more than one sexually violent incident in both childhood and adulthood were also likely to have multiple partnerships and brief sexual relationships (114).

\subsubsection{Behavioral}

Frequent behavioral sequelae of interpersonal trauma such as sexual violence can include aggressive and antisocial behavior, suicidal behaviors, risky sexual behaviors, and substance abuse.

Suicide in particular is a major concern, particularly when examined as a consequence of sexual violence. In a multivariate logistic regression, only marital discord and childhood sexual abuse were risk factors for suicide attempts among African-American women (115). Kisiel (2001) found that a history of sexual abuse was significantly and independently associated with several indicators of mental health disturbance, including risk-taking behavior (suicidality, self-mutilation, and sexual aggression) (102). Beckinsale (1999) reports that sexually abused youth were four times more likely to think about self-harm than others, and to have a significantly higher suicide index (24). Among street youth who were sexually or physically abused, the odds of attempting 
suicide were 1.9 to 4.3 times that of those without a history of sexual or physical abused (43). Thakkar (2000) found that those adults who experienced child sexual abuse had more suicidal ideations, and a less positive outlook on life (68). Conversely, attempted suicide was found not to be statistically associated in other studies $(60,116)$.

Eating disorders and body image problems in general are very common in North America, and can be related to a history of sexual violence (73). One study found that women who had been sexually abused reported more body dissatisfaction and selfconsciousness, less comfort with having sex with the lights on and undressing in front of their sexual partner, increased perception of lack of control over the body, and increased prevalence of eating disorders (117). In another study, data from three separate samples of 9 th-12th graders were used to assess the relationship between child sexual abuse and different forms of weight regulation (76). Logistic regression revealed that sexual victimization was consistently associated with weight regulation in adolescent girls, independent of the effects of physical victimization. In the urban sample, being sexually victimized was associated with an increase of $18 \%$ in the probability of purging relative to not having been sexually victimized. Sexual victimization was associated more strongly with extreme forms of weight regulation and significantly discriminated whether girls would choose multiple weight regulation forms (76). In a separate but related study, dating violence and unwanted sexual contact elevated the probability that girls would report practicing weight control techniques by $6-13 \%$. Controlling for family environment did not eliminate these associations (76). 
There is a large body of literature evaluating the association between risky sexual and drug use behaviors. Risky sexual behavior can be defined as unprotected vaginal or anal sex, multiple sexual partners, casual sexual partners, drug using or male bisexual sexual partners, the use of substances like alcohol or drugs peri-sexually, all factors which may increase the probability of acquiring HIV infection. Risky sexual behavior can be additionally measured through the surrogates of unwanted pregnancies, sexually transmitted infections, and earlier age of onset of sexual activity.

Johnsen (1996) reported that abused women showed more negative attitudes about sexuality, less sexual assertiveness regarding birth control or refusing unwanted sex, less efficacy concerning HIV prevention, more anticipation of a negative response from a partner concerning safer sex, more hard substance use, and more sexual victimization in adulthood (64). Lodico reported that survivors of child sexual abuse were more likely to be sexually active (OR: 1.5, CI: 1.4-1.7), to never or rarely use condoms (OR: 1.3, CI: 1.1 - 1.5), to have gotten a girl pregnant (males) (OR: 5.6, CI: 3.5-8.8), to have been pregnant (females) (OR: 2.4, CI: 1.6-3.8), and to become sexually active before age 12 (OR: 2.7, CI: 1.9-3.7) (65). In a cohort of women who were either HIV-positive or at high risk, childhood sexual abuse was strongly associated with a lifetime history of domestic violence and high-risk behaviors, including having more than 10 male sexual partners and having male partners at risk for HIV infection, and exchanging sex for drugs, money, or shelter (28). In a Canadian study among women attending a primary care clinic, those who reported sexual abuse were younger when they first had intercourse, had multiple partners, and had an increased history of STD's. Aboriginal women, $50 \%$ of the 
participants were Aboriginal, who had been abused were more likely to have abnormal Pap tests (58).

In a group of 165 African American women aged $18-29$, sexually abused women were 1.5 times more likely to have had an abortion, 1.4 times more likely to have an STD, 2.4 times more likely to have had more than 2 STDs, 3.8 times more likely to have a history of anal sex, 2.6 times more likely to worry about acquiring HIV, 3.9 times more likely to believe their partner didn't care about them, twice as likely to doubt the longevity of their relationship, 5.1 times more likely to have had a physically abusive partner within the last 3 months, and 2.6 times more likely to have had a partner who would get abusive when asked to use condoms (57). Among men who have sex with men, Paul (2001) found a dose-response relationship between severity of child sexual abuse as defined by number of coercive experiences, non-primary partner sexual risk, serodiscordant sexual risk, frequent anal sex under the influence of alcohol and/or drugs, to have had a one-night stand in the past year, and to have experienced boyfriend/partner abuse in the past five years (48).

In a group of African-American and Mexican-American women, those who reported sexual abuse were more likely to have lower incomes, earlier first coitus, a history of, STD's, currently abusive partners, new sex partners, to have anal sex, and bleeding with sex (118). Among sexually active adolescents in psychiatric treatment $(n=116)$, those with a history of abuse reported significantly less condom self-efficacy (emotional ability to use condoms), less knowledge of HIV, less impulse control, less frequent use and 
purchase of condoms, and significantly higher rates of sexually transmitted diseases than their peers. Multiple logistic regression indicated that a history of sexual abuse was strongly associated with inconsistent condom use (119). Early and chronic sexual abuse (occurring without non-sexual physical abuse) was associated with more than a 7-fold increase in HIV risk behaviors in women (OR 7.4, 95\% CI 2.4-23.5), and an 8-fold increase for men (OR 7.9, 95\% CI: 1/8-35.1) (70). Sexual abuse as a boy at age 10 years or younger increased the risk of impregnating a teenage girl by $80 \%(\mathrm{OR}: 1.8 ; 95 \% \mathrm{CI}$ : 1.3-2.4); sexual abuse with violence increased the risk by $110 \%$ (OR: $2.1 ; 95 \% \mathrm{Cl}: 1.2-$ 3.4) (120).

In an analysis of HIV risk behaviors among female inmates, Mullings et al. (2000) found that sexually abused women were significantly more likely to have smoked crack cocaine, and to have injected drugs than women who did not report abuse. Abused respondents were also significantly more likely to have engaged in unprotected sex with both injection drug users and crack users, to have had unprotected anal sex, and to have had unprotected sex with multiple partners (44). Women who were sexually abused were also more likely to have unprotected sex while trading sex for drugs or money $(44,47)$. Related to commercial sex work is a study that examined elements of the family histories of sex workers compared to a community sample and found that sex workers reported more child sexual abuse (121).

An interesting representative study of high school students showed that after controlling for related demographics and risk behaviors, sexually abused female students were 
significantly more likely than those without such a history to have had earlier first coitus (OR 2.2, 95\% C.I.: 1.5 - 3.5), to have had three or more sex partners ever (OR 2.5, 95\% C.I.: 1.7 - 3.7), and to have been pregnant (OR 1.9, 95\% C.I.: 1.2 - 2.9). Sexually abused male students were significantly more likely than those without such a history to have ever had multiple partners (OR 3.2, 95\% C.I.: 1.6 - 6.6), to have had multiple sex partners in the past 3 months (OR 2.9, 95\% C.I.: $1.7-3.7$ ), and to have engaged in sex resulting in pregnancy (OR 3.4, 95\% C.I.: 1.5 - 7.3) (122). Compared with married mothers, single mothers reported substantially lower incomes as well as higher rates of childhood abuse and all psychiatric morbidities examined (current and lifetime affective or anxiety disorders and substance use disorders). Childhood abuse had a consistent and significant association with adult mental health, even when other risk variables were controlled (123).

Other older studies also showed that those who experienced childhood sexual abuse were more likely to report earlier onset of sexual activity as well as greater number of lifetime sexual partners (124), to report work as prostitutes and to have multiple sex partners (89). Additionally, abused women were several times more likely to be pregnant by 18 yrs of age, and abused men were twice as likely to be HIV-positive as their non-abused peers (89).

Injection drug use is a well characterized risk factor for HIV infection, as is alcohol consumption. Numerous drug-use factors have been found to be associated with a history of sexual violence, and particularly child sexual abuse. Lodico and DiClemente (1994) 
report relative risks for sexually abused high school students of 4.2 (2.5-7.0) for having ever injected drugs, and 6.9 (3.0-15.6) for having ever shared needles (65). In a large sample of psychiatric in-patients, opiate users were 2.7 times more likely to have a history of childhood sexual and/or physical abuse than non-opiate users, after controlling for sociodemographic and diagnostic variables (37). Jasinski found that multiple incidents of child sexual abuse, more than the characteristics of such abuse, was an important predictor of adult heavy alcohol use and binge drinking, even after controlling for the effects of parental drinking behavior (20). Homeless women who reported rape fared worse than those who did not on every physical and mental health measure but were especially more likely to have used and abused drugs other than alcohol (56). Many other reports confirm a significant relationship between substance use and childhood sexual abuse that will not be summarized here $(25,70,73,97,125,126)$.

\subsubsection{Biological}

Biological response patterns include numerous somatic disturbances. These have major implications for both the patient/survivor, and for the health care system.

Ten years ago, higher rates of medical utilization among individuals who had experienced sexual violence were published (33). Hendricks-Matthews (1993) states that rape victims are high users of medical services in the months and years after the attack. Survivors perceive themselves as less healthy and report seeking medical care more often 
that nonvictims, regardless of the length of time since their sexual assault (92). However, it is only in the past two years that the subject has received further attention. One study looked at whether victimization experience was associated with increases in documented disease and health care utilization among women infected with HIV by comparing two time periods: entire life before study entry and the subsequent two years. At entry, there were no differences found in terms of episodic disease, chronic disease, injuries, emergency department visits, or hospitalizations. After two years, all outcomes were more likely in abused women (41). Despite the limitations of reporting bias, this study did find that childhood sexual abuse was independently associated with risk of episodic disease, sexually transmitted diseases, and chronic pain syndromes (41).

To evaluate the role of physical and/or sexual abuse on chronic pain symptoms and health care utilization in women, 104 consecutive female patients presenting to a multidisciplinary pain center for management of chronic pain were surveyed. The women who reported physical or sexual abuse had increased pain, physical symptoms, anxiety symptoms, and mental health care utilization compared to nonabused women. (127). Chronic pain being strongly associated with a history of child sexual abuse has been reported elsewhere $(50,127-130)$. Finestone's study found that $69 \%$ of the women who had experienced childhood sexual abuse reported a chronic painful condition lasting more than three months, compared to $43 \%$ of the combined control groups. Women who had experienced childhood sexual abuse reported a greater number of painful body areas, more diffuse pain and more diagnoses of fibromyalgia. They had more surgeries, hospitalizations and family physician visits (128). Rosenberg (2000) reports that several 
studies have shown that women who have histories of chronic pelvic pain and severe premenstrual symptoms have higher rates of lifetime abuse (50).

Using medical utilization rates generated from the computerized database of an HMO for nonpsychiatric outpatient, psychiatric outpatient, emergency room (ER), and inpatient admissions, Arnow (1999) found that distressed patients who reported child sexual abuse versus distressed patients who did not report such a history used significantly more nonpsychiatric outpatient visits. These patients had more Emergency Room visits and were more likely to visit the ER for pain-related complaints than other participants. There were no differences among the groups in inpatient utilization rates (131). In a similar study using HMO data, weaker associations were reported between a history of sexual abuse and medical utilization (50). In multivariate analyses, Drossman (1990) found that of abused versus non-abused women in a gastroenterology practice, abused women had significantly more lifetime surgeries (31). In an analysis of the costs to the HMO system, women who reported sexual abuse were found to have median annual health care costs that were $\$ 245$ (95\% confidence interval, $\$ 132.32-\$ 381.93$ ) greater than costs among women who did not report abuse(132). Women with sexual abuse histories had significantly higher primary care and outpatient costs and more frequent emergency department visits than women without these histories (132). Golding et al. (1988) found that women with sexual abuse histories sought medical services twice as often as women reporting no abuse and were twice as likely to seek care for physical pain rather than emotional distress (133). Costs conferred to the system are not limited to the victims'. The economic costs and benefits of pedophile treatment programs in Australia 
incorporating both the tangible and intangible cost of sexual abuse to victims were estimated, and in-prison, cognitive therapy treatment programs for pedophiles were found likely to be of net value to society (134).

Headaches have been found to be associated with a history of sexual violence $(29,135)$. However, one small study examined whether temporomandibular disorder (TMD) patients with sexual versus physical abuse histories differ in their pain report, psychological distress, and somatic symptoms. TMD disorder patients with a history of physical abuse reported significantly more pain, anxiety, and depressive symptoms than did patients with a history of sexual abuse or no history of abuse. Furthermore, the results suggest that TMD patients with a sexual abuse history are not significantly different from patients with no abuse history across the domains studied (136). In an analysis of stress in undergraduate students who reported a history of child sexual abuse compared to those who didn't, during the 5 days preceding a highly stressful day, women in the sexual abuse group reported significantly more physical symptoms than during the 5 days preceding a day of low stress. For the non-abused group, there were no significant differences in reported physical symptoms between high- and low-stress days (69).

Gastrointestinal problems associated with a history of sexual violence have been described. Devroede (2000) details describing a series of cases where severe clinical symptomology is directly related to child sexual abuse (30). In a referral-based gastroenterology practice, to determine whether patients with functional gastrointestinal disorders report greater frequencies of abuse than patients with organic gastrointestinal 
diseases, and to determine whether a history of abuse was associated with more symptom reporting and health care utilization, a consecutive sample of women seen over a 2-month period were asked to complete a brief questionnaire. Of 206 patients, $89(44 \%)$ reported a history of sexual or physical abuse in childhood or later in life; all but 1 of the physically abused patients had been sexually abused. Almost one third of the abused patients had never discussed their experiences with anyone; only 17\% had informed their doctors. Patients with functional disorders were more likely than those with organic disease diagnoses to report a history of forced intercourse (OR 2.08; $95 \% \mathrm{Cl}, 1.03-4.21)$ and frequent physical abuse (OR 11.39; CI, 2.22 - 58.48), chronic or recurrent abdominal pain (OR 2.06; CI, $1.03-4.12$ ), and more lifetime surgeries (2.7 compared with 2.0 surgeries; $\mathrm{p}<0.03$ ). Abused patients were more likely than non-abused patients to report pelvic pain (OR 4.05; CI, 1.41 - 11.69), multiple somatic symptoms (7.1 compared with 5.8 symptoms; $\mathrm{p}<0.001$ ), and more lifetime surgeries ( 2.8 compared with 2.0 surgeries; $\mathrm{p}<0.01)(31)$. There is reason to believe that Irritable Bowel Syndrome (IBS) may be related to a history of child sexual abuse (137).

Chronic pelvic pain is a frequently cited symptom $(29,40,55,135)$. A recent study looked at 36 women with chronic pelvic pain, 23 with chronic low back pain, and 20 healthy women with reference to experience of sexual abuse, physical violence, and emotional neglect in childhood. In terms of experience of sexual abuse in general, the three groups did not differ significantly from one another. However, $22 \%$ of the patients with chronic pelvic pain were sexually abused before their 15 th birthdays, significantly more frequently than the other two groups (chronic low back pain $0 \%, p=.019$, pain-free 
control $0 \%, \mathrm{p}=.028$ ) (138). Sexually transmitted infections are also found more commonly in women reporting a history of child sexual abuse $(49,72,139)$. Wingood found that women who reported a history of child sexual abuse were 1.4 time more likely to have a STD, and 2.4 times more likely to have had more than 2 STDs (57).

A compelling study of sex-specific, age-adjusted risks that were calculated for 11 common chronic medical conditions (10 for each sex: coronary heart disease, hypertension, diabetes, osteoporosis, obesity, asthma, migraine, thyroid disease, and arthritis in all subjects; breast cancer in women; and prostate cancer in men) and confirmed by physical or laboratory examination or review of medical records found that in women, a history of sexual assault was associated with an increased risk of 2 of 10 conditions: arthritis (OR 1.76, 95\% CI: $1.13-2.76)$ and breast cancer (OR 2.21, 95\% CI: 1.12 - 4.33). A "dose-response" effect was observed in that multiple episodes of sexual assault carried a two- to three-fold increased risk of these diseases compared with a single episode. In men, the only statistically significant association was between sexual assault and thyroid disease (OR 4.68, 95\% CI: 1.08 - 20.3) (109). 


\subsection{Mediating Factors and the Cause-Effect Relationship}

Whether there is a cause-effect relationship between sexual violence, particularly in childhood, and some or all of the above discussed outcomes has not yet become a consensus within the literature, and is a difficult principle to establish in part because of the spectrum of mediating effects (17). As Haugaard (2000) states,

"The skewed distribution of the severity of child sexual abuse experiences can distort the estimates of the consequences of child sexual abuse across a sample, because the lack of measurable consequences for the many people in a sample who experienced a single incident of abuse involving little physical invasiveness are likely to obscure the significant consequences experienced by the few people who experienced severe forms of abuse." (4)

There are several potential mediating factors which may influence how severely traumatized an individual is as the result of a sexually violent experience. There are sociodemographic ones, such as the age at which someone was victimized. There are family and social issues, such as whether the victim disclosed and was supported, disclosed and was silenced, and whether relationships with parents were generally strong and loving $(12,72)$.

There are also factors specific to the incident, such as whether it was incestuous or not, whether it was violent, whether there was one single incident or whether the abuse continued for an extended period of time, and whether there was other dysfunction occurring simultaneously (such as an alcoholic parent, or a physically or emotionally abusive environment) (75). 
In the early 1990 's, some important reviews of the literature $(12,140)$ argued that there was no relationship between age of onset of abuse and degree of trauma, nor was there any association between duration of abuse and degree of trauma. Although Sheldrick admitted that there was not, at that time, clear-cut evidence of which pathogenic factors led to negative outcomes, ten years later there is some limited data which suggests that on at least one these two issues she may have been mistaken.

Parillo et al. (2001) recently published work which examined whether sexual abuse involving penetration that occurred in childhood only, in adolescence only, or both childhood and adolescence differently impacted on whether community-recruited women had ever traded sex for money or drugs, how many recent sex partners they had, and the number of times they had engaged in recent unprotected sex. Included in the analysis were 1,490 women recruited from three U.S. sites. For the outcome of trading sex for drugs or money, childhood abuse only was more statistically significant than adolescent abuse only, although the variable of both childhood and adolescent abuse was more significant than either of the other two alone. When looking at number of sexual partners in the past 30 days, the authors found that only the variable of childhood abuse alone was significantly related. There were no significant differences when they looked at age of abuse and recent unprotected vaginal/anal sex (47). Fleming (1999) found that child sexual abuse before the age of 12 (versus $>12)($ AOR: $2.23,95 \% \mathrm{Cl}: 1.06-4.70)$ was independently associated with experiencing rape in adulthood (97). Jasinski (2000) determined that girls who were older at the time of the first sexual assault were more 
likely to engage in heavy drinking. The authors suggested that this may be due to having more recent and therefore more vivid and intrusive recollections of the incident, and the girls use alcohol as a means to self-medicate (20). If sexual abuse in childhood and/or adolescence additionally contributes to whether the victim experiences lasting consequences, then this has important implications for being able to prevent these consequences from happening, and it is surprising that there has not been more work in this area. Interventions designed for children and youth who have experienced sexual abuse could reduce their vulnerability to engaging in risk behaviors for HIV later in life.

There are other reports in the literature about duration or frequency of abuse and its relationship to subsequent consequences. Bensely et al. (2000) found an important relationship between early/chronic abuse (treated by them as one variable) and HIV risk behaviors for women (AOR: 7.7, 95\% Cl 2.4-23.5) (70). Romans et al. (1995) examined a number of abuse characteristics in association with psychiatric morbidity, and found that the only statistically significant association was frequency of abuse (75). Molnar et al. (2001) found that chronic childhood sexual abuse (each of molestation and rape) was significantly associated with experiencing any mood disorder later in life, post-traumatic stress disorder, and any anxiety disorder (74).

The question of incestuous versus non-incestuous abuse as a mediating factor deserves attention, as it is well established that a huge proportion of sexual violence against children and adolescents is perpetrated by victims family members, and that incestuous abuse in general has more severe effects $(5,12)$. Russell (1986) found that among 
women who were sexually abused before age 18, 29\% had been abused by family members, including $4.5 \%$ of the total sample of 930 women who reported having been sexually abused by a father (biological, step, adoptive, or foster) and $4.5 \%$ by an uncle. Russell also found that girls living with a step-father were at increased risk (17\% vs. $2.3 \%$ for biological fathers) (18).

Darves-Bornoz (1999) sought specifically to look for differences in psychological difficulties of incest victims versus victims of non-incestuous sexual violence. In logistic regression analysis adjusted for age, gender, and other characteristics of the trauma, posttraumatic stress disorder, dissociative disorders, agoraphobia, and low self-esteem were all associated with the incest-rape group (94). In Molnar's (2001) recent population-based study, only childhood rape by a step-relative (though not by a relative) was significantly associated with experiencing post-traumatic stress disorder (74).

One of the most challenging issues in ascribing consequences to the effects of having experienced child sexual abuse is the potentially confounding effect of concurrent, nonsexual violence. Fortunately, a number of investigators have undertaken to delineate these effects. For example, Schaff et al. (1998) examined the effects of physical and sexual abuse on future victimization and a diagnosis of post-traumatic stress disorder among 475 female college students (67). It was found that the highest rate of PTSD and adult sexual and/or physical victimization was reported by the group who experienced both physical and sexual violence as children (77\%), followed by the physical abuse in childhood group (50\%). Those who had experienced childhood sexual abuse did not 
differ significantly from those who reported no abuse at all (67). A study published in JAMA by McCauley et al (1997) compared the effects of childhood sexual versus physical versus both sexual and physical abuse on a variety of physical and psychological measures and found no significant differences in symptoms among these groups, except that those who experienced both had slightly higher total number of physical symptoms (42).

Another way of approaching the subject of vulnerability and childhood sexual violence has been through analyses of risk factors for child sexual abuse. Levanthal (1998) summarizes several earlier publications that found risk factors for sexual abuse include being a girl living with a step-father, and being a child with a handicap or developmental delay (141). A larger longitudinal cohort study found that the five major risk factors for being abused were being female (as a victim), marital conflict among parents, poor parental attachment, paternal overprotection, and parental alcoholism or problems with alcohol (141). Other studies examined found that parental drug abuse, a poor parentchild relationship, and a parent with emotional instability were all risk factors for child sexual abuse (141). It is not hard to imagine how many of these factors would put a child in a vulnerable position with regards to being sexually victimized.

Thus far in this review, it has been established that there are substantial methodological obstacles in determining both the prevalence and consequences of sexual violence, particularly that which occurs in childhood. Though there is some conflicting data, in general the literature suggests that child sexual abuse is widespread, and is associated - 
often strongly - with a variety of emotional, interpersonal, cognitive, biological, and behavioral consequences that survivors appear to deal with for many years following an incident. To what degree survivors are impacted depends on a number of abuse and family related factors. When looked at as a whole, is it possible to conclude from the available data that the relationship between child sexual abuse and subsequent adverse effects is a causal one? This discussion of cause and effect must now necessarily focus primarily on the subject of child sexual abuse rather than sexual violence in general because of the issue of temporality. If there is no way of knowing whether the sexual assault or the substance use (or whatever outcome one chooses), the broader discussion can de facto only be theoretical. It is however, possible to establish a temporal relationship between child sexual violence and outcomes later in life, and is therefore open to deeper scrutiny in terms of causation. An advance note of caution must be made because as with all bodies of literature, publication bias and the question of what has not been published must always be kept in mind.

In attempting to determine causality, one must consider the various elements that constitute a causal relationship. Based on Hill's famous criteria, Hennekens and Buring (1987) contend that the criteria for determining whether causality exists are: 1) strength of association, 2) consistency of findings, 3) biologic credibility of the hypothesis, 4) temporal sequence of events, and 5) the presence of a dose-response relationship (142).

There were very few papers reviewed that did not find an association. The majority of papers used multivariate analyses, and many were general population results. Looking at 
Charts 1,2 and 3, it is evident that child sexual abuse is extremely widespread (whether it is an epidemic or endemic is a subject that will not be addressed here) at least across North America, Europe and Australia/New Zealand. If Finkelhor's 1994 meta-analysis is taken to be valid, one in five children can expect to be sexually violated before the age of 14, with far more girls than boys being targeted. In terms of consequences, the literature indicates that in general, notwithstanding methodological issues discussed earlier, data regarding mental health (e.g. depression, anxiety, low self-esteem), physical health (e.g. gastrointestinal and gynecological complications, chronic pain), health care utilization, post-traumatic stress disorder, psychiatry, and HIV risk and other self-destructive behaviors (e.g. suicide) all point to a strong and consistent relationship.

It has also been established that there are mediating factors regarding the abuse itself and the environment in which the abuse takes place that contribute to whether and to what degree people experience severe adverse consequences. Many of these mediating characteristics are related to the abuse circumstances, such as whether it was incest, the frequency of occurrence, any associated physical violence, all of which point to what can be considered (for a lack of a better expression) a dose-response relationship, by virtue of the gradation in the severity of the abuse itself. There are several important publications that strongly suggest such a gradient, although other results are not as clear (48). In an investigation of severity of abuse and post-traumatic stress disorder, Johnson (2001) discusses how strong gradient relationships have been established between severity of abuse (typically operationalized by the presence of penetration and/or number of perpetrators) and dissociation and depression. In her analysis, 89 women who reported 
child sexual abuse used a variety of scales to ascertain the precise nature of the abuse. The three characteristics in the final model for post-traumatic symptoms severity were peritraumatic disassociation (dissociating during the abuse), the degree to which the victims believe they will be killed, and the number of perpetrators (39).

In a population-based sample of 1411 female adult twins, 3 levels of child sexual abuse were assessed by self-report and cotwin report: nongenital, genital, and intercourse. Interviews with twins and parents assessed family background and diagnoses of psychiatric and substance dependence disorders. By self-report, 30.4\% reported any child sexual abuse and $8.4 \%$ reported intercourse. Self-reported child sexual abuse was positively associated with all disorders, though the odds ratios were modest and often non-significant with non-genital abuse and increased with genital contact and especially intercourse, where most OR's exceeded 3.0. Controlling for family background factors and parental psychopathology produced a small to modest reduction in ORs, and co-twins reports followed the same pattern as the self-report (73). -Even in 1986, Browne \& Finkelhor found that most studies they reviewed indicated that abuse characterized by more severe characteristics such as abuse by fathers and stepfathers, experiences involving genital contact, and incidents in which there is the presence of physical force all result in more trauma for the victims (143).

Although not specific to sexual abuse characteristics, there is other literature that suggests a dose-response relationship between various forms of dysfunction and negative outcomes. For example, Kaslow et al. (2000) looked at a variety of family functioning 
variables and their relationship to attempted suicide using a cumulative risk model, and found that the presence of 4 or more of the risk factors increased a woman's likelihood of making a nonfatal suicide attempt (115). Another investigator looked at the relationship between boyhood exposure to physical abuse, sexual abuse, or having a battered mother and the subsequent risk of impregnating a teenage girl. They used HMO questionnaire responses from 4127 men and found a dose-response relationship between the number of types of exposures and the risk of impregnating a teenage girl in that men who reported all 3 types of exposures were more than twice as likely to have been involved than those with no exposures (OR: 2.2; 95\% CI: 1.4-3.5) (120).

There is data that provide biological possibilities of how having experienced child sexual abuse could physiologically contribute to adverse effects later in life. Some have suggested that sexual abuse leads to hyper-arousal, which can lead to heightened physical symptoms (69). Post-traumatic stress disorder (PTSD) and other studies have indicated that severe trauma is associated with a range of physiologic changes, including increased autonomic arousal, stress related over-activation of the neuroendocrine system, most notably through the hypothalamic-pituitary-adrenal (HPA) axis $(37,144,145)$. Some studies were designed to look at the basal functioning of the HPA axis in response to early sexual abuse in girls aged 5 to 7 years. The study found that girls who had been abused within the last couple of months had significantly lower cortisol levels in comparison to control subjects (age, social economic status and race matched) (21). These and other data suggest that children may have an impaired HPA axis after early 
trauma, potentially resulting in symptoms such as exaggerated startle response, hypervigiliance, and irritability (21).

It has also been suggested that the endogenous opiate system is significantly impacted by stressful events. Chronic sympathetic activation due to stress and trauma has been found to lead to decreased levels of cortisol and beta-endorphin, and it has been suggested that reduced levels of beta-endorphin are an indicator of lowered endogenous opiate activity. In addition, heroin and other opioids inhibit the locus cereleus, which has been implicated in fear and anxiety responses, through interaction with opioid receptors. These factors have led trauma researchers to speculate that the use of opiates by traumatized individuals may reflect an attempt to self-medicate or compensate for dysregulation of the noradrenergic and/or endogenous opioid systems (37). It is possible that this physiologic response could biologically prompt survivors of sexual trauma to start using heroin or other opioid drugs.

Elevated corticotropin releasing hormone $(\mathrm{CRH})$ is essential in the activation of the pituitary gland, and is a hormone linked to behavior, notably the 'flight or fight' response. It has been associated with preterm labor, and Horan et al. (2000) developed a hypothesis that early traumatic experiences of childhood sexual abuse may activate corticotropin releasing hormone $(\mathrm{CRH})$ gene expression in the brain, and a vulnerability to elevated CRH gene expression in the placenta. The authors hypothesized that those traumatized by early abuse may be more susceptible to stress vis a vis $\mathrm{CRH}$ dysregulation 
during a major psychosocial stressor, such as pregnancy, or would just be more vulnerable to negative psychological and therefore behavioral effects later on (145).

In addition to biologic plausibility, several theoretical models have been developed to explain how child sexual abuse can cause adverse effects later in life. One of the earliest is called the "Traumagenic Dynamics" model, developed by Finkelhor and Browne in 1985 (146). This model proposes that the experience of sexual abuse can be analyzed in terms of four trauma-causing factors or traumagenic dynamics - traumatic sexualization, betrayal, powerlessness, and stigmatization. Traumatic sexualization refers to a process in which a child's sexuality (including both sexual feelings and sexual attitudes) is shaped in a developmentally inappropriate and interpersonally dysfunctional fashion as a result of sexual abuse. For example, the child may be rewarded by the perpetrator for engaging in inappropriate sexual behavior. Learning to exchange sexual behavior for affection, attention, or other privileges teaches the child to use sexual behavior in order to manipulate others. Thus, traumatic sexualization may be related to the high risk sexual abuse victims have regarding future sexual assaults. Children who have been abused sexually may emerge with inappropriate repertoires of sexual behavior or confusion and misconception regarding their sexual self-concept. This may extend into adulthood, and influence the kinds of situations in which the survivor places and/or finds him or herself.

The second component, betrayal, refers to the dynamic by which children discover that someone on whom they were dependent has caused them harm. Feelings of betrayal are an unsurprisingly common effect found in victims of childhood sexual abuse and cause 
the victims to suffer disillusionment. This can translate into an intense need to regain trust and security. This need may be illustrated by impaired judgment regarding social circles, drug use, and sexual behavior.

A third psychological effect of childhood sexual abuse that causes negative outcomes according to Finkelhor and Browne's model is stigmatization, which is directly related to low self-esteem. Stigmatization refers to the negative connotations (such as 'badness', guilt, shame) that are communicated to or experienced by the child around the experiences, and that then become incorporated into the child's self-image. These feelings could lead to a wide variety of self-damaging behaviors.

Lastly, feelings of powerlessness have been found to be an effect of childhood sexual abuse. Powerlessness has also been called disempowerment, and concerns the victim being rendered powerless. This includes the process in which the child's will, desires, and sense of self-efficacy are continually contravened. Finkelhor and Browne state that having been victimized on repeated occasions, the victim may find it difficult to act without the expectation of being revictimized. This expectation may contribute to absence of preventive action being taken when others are trying to manipulate, control, or harm the victim, leading to revictimization (146).

Another theoretical model was developed specifically to look at how child sexual abuse among girls can cause later HIV risk behaviors, and was developed by Maureen Miller in 1999 (147). Miller proposes four causal pathways: 
(1) Drug Use as Coping: initiation of and/or increasing reliance on drug use as a method of coping with the sexual abuse experience, primarily through individuals using drugs to self-medicate and either numb the emotional and/or physical pain, try to forget the experience, or try not to think about it in general;

(2) Sexual adjustment and sexual risk taking: problems with sexual adjustment related to sexual risk taking, whereby people engage in self-destructive sexual behaviors, often defined as multiple partners, not using condoms, or engaging in sex trade work, because their concept of safety, personal boundaries, and intimacy may have become warped as a result of the abuse;

(3) Emotional psychopathology: such as depression, PTSD, and dissociation which increase the likelihood of an individual participating in HIV risk behaviors like sharing needles with an HIV-positive person; this is linked to a sense of hopelessness, low self-esteem, and a perceived lack of control;

(4) Social network characteristics: such as network membership type, social support, and social isolation, that influence the HIV risk exposure opportunities among women with sexual abuse histories (147).

More recently, Grauerholz et al. (2000) (148) applied an ecological model to the problem of sexual revictimization to advance the understanding of how personal, interpersonal, and sociocultural factors contribute to child sexual abuse victims' increased risk of being sexually victimized later in life. In this theory, the assumption is that individual behavior 
can only be understood by taking into account factors at each of the individual, interpersonal, and sociocultural levels, and understanding how they interact with each other to create the problem. In this model, the ecosystem is considered to be humans and their social environment. This model identifies four levels of analysis:

- ontogenic development: factors in one's personal history that an individual carries with her or himself into future relationships;

- the microsystem: the immediate context in which the victimization occurred or occurs, including immediate family, home environment;

- the exosystem: the informal and formal social structures (extended family, school, work, friends)

- the macrosystem: the cultural beliefs and attitudes which inform our paths in life, and in which child sexual abuse may be fostered. (148)

Jay Paul et al. (2001) (48) applied a social learning model of the child sexual abuse/sexual risk taking behavior specifically to a cohort of men who have sex with men. This model hypothesizes relationships between child sexual abuse and emotional, cognitive, and interpersonal outcomes that impact directly or indirectly upon two key components of HIV sexual risk-taking:

- the appraisal of potential risk, and

- the capacity to enact behaviors necessary to reduce risk. 
The authors conceptualize child sexual abuse as a painful experience on numerous levels, and that the experience arouses a Fight or Flight response. The fact that the situation is one in which the victim is able neither to fight back nor to escape, and is often within the home by trusted people leads to feelings of powerlessness, learned helplessness, and low self-efficacy. These feelings create a negative self-image and prevent the individual from adopting appropriate health promoting sexual practices (48).

There are many similarities and strengths among these models. Primarily, they all recognize that individual, family, and the general social environment play strong and interacting roles in determining whether the conditions are conducive to sexual victimization of a child, and in determining how and to what extent a survivor will cope with the consequences of childhood abuse. Of interest, in 1999, the World Health Organization adopted the theoretical model of individual/child - family - community society in terms of understanding risk factors for child abuse (149)

Returning to the question of causation, the theoretical elements of a causal relationship have been cursorily applied to the question of causation between child sexual abuse and later adverse effects such as HIV risk behaviors.

- Is there consistency among the findings?

Basically, yes.

- Is there strength of association?

Yes.

- Did the cause precede the effect?

Yes.

- Is there biological plausibility?

Yes.

- Is there a dose-response relationship?

Yes. 
The limitation of the principles set out by Hill and refined by Hennekens and Buring (142) is that they assume that the causative agent has one mechanism of action or is unifactoral, and they assume that the environment into which the agent is placed is sterile and/or in a vacuum. Evidently this is not the case with human societies, as each of these described models affirm, and child sexual abuse is unquestionably multifactoral in nature and effect. As a result, however, it is impossible to say with the same degree of certainty or clarity that child sexual abuse causes later problems in the same way one could say that HIV causes AIDS. If we think of our societies ecologically, our lives are like intertwined, constantly changing, and interdependent webs located within other webs, located within yet other webs. It is time to move away from a "magic bullet" idea that a specific sexual event invariably leads to a specific outcome or syndrome (17). An ecological analysis requires an ecological question, and so the question of whether child sexual abuse causes significant individual, social, and environmental (not to mention medical) problems in the future may not be the most appropriate. Rather, the questions should be framed as how much of the problems (notably HIV risk behaviors and other self-destructive actions) that we see today are attributable to childhood sexual abuse? Although there is currently a substantial body of literature to suggest that child sexual abuse can cause mild, moderate and severe physical and psychological effects later in life, there are nonetheless a number of important questions that are still not adequately understood. These include:

- What are the differential effects of age of first victimization?

- What are the differential effects of physical vs. emotional vs. sexual violence?

- How are men and women differentially affected in terms of later life consequences (eg. HIV risk behaviors, suicide, etc.)? 


\section{Chapter 3: Methods}

\subsection{Objectives and Hypotheses}

The present study set out to characterize how sociodemographic factors, HIV risk behaviors, and health-related outcomes differ between injection drug-using individuals who have experienced sexual violence in their lifetimes versus those who have not. This study also explores how sexual violence that first occurred in childhood affects HIV risk behaviors and health outcomes compared to sexual violence that first occurred in adolescence or adulthood. Specifically, the primary objectives and hypotheses of this study are:

1. To describe the prevalence of and factors associated with a lifetime history of sexual violence among this cohort of injection drug using men and women at high risk of HIV infection. The primary hypothesis associated with this objective is that that there will be a high prevalence of sexual violence in this cohort of injection drug users, and that those individuals who have survived sexual violence will have a higher HIV risk behavior profile and a higher prevalence of other self-destructive behaviors than those who have not. The secondary hypothesis is that individuals who have experienced any sexual violence in their lifetimes will report increased health care utilization.

2. To describe how HIV risk behaviors and other self-destructive behaviors differ depending on the victim's age when they were first victimized. The primary hypothesis associated with this objective is that people who experienced sexual violence in childhood will have a higher risk profile for HIV than either those who experienced 
sexual violence in adolescence, adulthood or those who report never having experienced sexual violence at all. The secondary hypotheses for this analysis are that individuals who have experienced sexual violence in their childhoods will report more health care utilization than individuals who experienced sexual violence either in adolescence or adulthood, and more than individuals who report never having experienced any sexual violence at all.

3. To estimate how much of the HIV epidemic among this population is attributable to a history of sexual violence. The hypothesis for this objective is that $10 \%$ of the HIV epidemic experienced by injection drug users in the VIDUS cohort will be attributable to sexual violence.

\subsection{Data Source}

Beginning in May 1996, persons who had injected illicit drugs in the previous month were recruited into the Vancouver Injection Drug User Study (VIDUS). Data collection for the project is conducted in a storefront office. Over 1400 study participants were recruited through self-referral and street outreach. Individuals were eligible if they had injected illicit drugs at least once in the previous month, resided in the greater Vancouver region, and provided written informed consent. Ethical approval for the project was provided by the University of British Columbia. Ethical approval for this thesis was provided by St. Paul's Hospital Research Ethics Board (see Appendix A). Evidence of recent injection drug use was required by inspection of needle tracks. At baseline and then semi-annually, participants provide blood samples and complete an interviewer- 
administered questionnaire by a trained interviewer. The baseline questionnaire elicited demographic data including age, gender, and place of residence, as well as detailed drug use characteristics and drug use history, detailed sexual behavior with each of regular and casual partners, as well as sex trade clients, and other issues including suicide, mental health, and sexual violence. Self-reported data is also collected for this cohort on sexually transmitted diseases, and accidental overdoses. Blood is drawn at each semiannual interview, and tested for HIV and Hepatitis $\mathrm{C}$ infection. HIV and Hepatitis $\mathrm{C}$ test results are linked with the Provincial Registry of the British Columbia Centre for Disease Control, and mortality data are collected through the Coroner's office. All data is updated and maintained in a database at the British Columbia Center for Excellence in HIV/AIDS. All data for this project (except HIV cumulative incidence) was obtained from the baseline questionnaire.

\subsection{Definition of Sexual Violence}

On the baseline questionnaire, there were several questions regarding sexual violence. The first asked a dichotomous question (yes/no) of whether the participant had ever been forced to have sex against their will. Subsequent questions asked about the age of the respondent when the first incident of sexual violence happened, who perpetrated the act the first time, whether there had been any subsequent victimization, when the last time the respondent was raped, whether they had disclosed their experiences prior to the baseline interview, and whether they had ever received any counseling to address their experiences. 
As described in the Literature Review of this thesis, there are many important and complicated issues in defining sexual violence, and there are limitations with the relative open-endedness of this question. These could include people who were enticed into sexual relations with someone much older or a family member, but who considers that they gave consent for whatever reason. It could also include individuals who were not sexually penetrated, and who therefore do not consider themselves as having been forced to "have sex". However, the advantage of the relatively vague nature of the question is that it provides the opportunity for the respondent to say they were sexually violated, if in their opinion or understanding, they were. In many ways, whether someone feels violated is the bottom line in defining sexual violence, and therefore for the purposes of this analysis, this definition was considered to be acceptable.

\subsection{Variables}

\section{Hypothesis \#1 Variables}

To assess the prevalence of lifetime sexual violence among the cohort, the number of people who responded in the affirmative as to whether they had ever been forced to have sex against their will was divided by the number of people in the cohort who answered the question either way.

The primary outcome or dependent variable for the univariate analyses was whether or not individuals report having ever been forced against their will to have sex. Independent variables that were hypothesized to be significantly associated with having a history of 
sexual violence were broken down into sociodemographic characteristics, drug use characteristics, sexual behavior factors, and health care utilization/medical outcomes.

The sociodemographic variables examined were gender (with transgendered individuals being classified as women), if the respondent was married or common-law, whether they were born in Canada, were living in unstable housing (, relied on government income assistance (welfare) as their main source of income, whether they were employed, their ethnicity (Aboriginal vs. other), and whether they had completed high school. Drug use variables examined were age at first injection, use of various substances including alcohol, cocaine, heroin, crack and tobacco, frequency of cocaine and heroin use, ever and currently borrowing rigs/needles, borrowing rigs/needles from known HIV-positive individuals, lending rigs/needles, needing help injecting, having ever accidentally overdosed, and bingeing. Sexual behavior variables analyzed were the number of lifetime sexual partners (dichotomized into greater than or less than 20), age at first consensual sexual intercourse, having a regular or casual opposite sex sexual partner, condom use for vaginal intercourse with regular and casual partners, ever being a commercial sex worker, being in the sex trade during the prior 6 months, age at which the respondents were first paid for sex, and condom use with clients. The health related variables analyzed were General Practitioner (GP) utilization, emergency room utilization, overnight hospital admissions, ambulance utilization, drug/alcohol treatment ever, current drug/alcohol treatment, current methadone use, seriously thinking about suicide, attempted suicide, ever having been diagnosed with a mental disability/disorder, and ever having been hospitalized for a mental disorder including suicide. 


\section{Hypothesis \#2 Variables}

Age categories were determined using commonly understood definitions for child, adolescent and adult. Thus, the first grouping (child) was of individuals whose first experience of sexual violence occurred at or before the age of twelve. The second category, adolescence, was defined as individuals who experienced their first sexual violence between the ages of thirteen and seventeen, inclusively. Individuals were considered to have experienced their first sexual violence as adults if they reported being eighteen or over at the time.

Thus, four different age outcomes were used for each series of analyses. The first was limited to only individuals who had ever experienced sexual violence, and was dichotomized between those who were aged 12 or less, and those who were 13 and older. The advantage of this categorization was that it allowed for comparisons only among those who had been abused. However, the disadvantage of this categorization is that it presumes that sexual violence experienced in adolescence and adulthood are associated with the same effects. In addition, by not comparing it to individuals who were never sexually assaulted, the possibility of effect dilution is strong. Therefore, the outcomes were more specifically defined as those who experienced their first incident of sexual abuse at or before the age of 12 years (childhood sexual abuse) versus never, those who experienced their first incident in adolescence (between and including 13 and 17 years of age) compared to never, and those who experienced it first in adulthood (at or over 18) 
compared to individuals who reported never experiencing sexual violence. A subsequent analysis was also performed to specifically compare the effects of childhood versus adolescent first abuse, using twelve and under versus thirteen to seventeen (inclusive) as the outcome. Univariate analyses for each of these five outcomes involved the same independent variables as in Hypothesis \#1.

\section{Hypothesis \#3 Variables}

Cumulative HIV incidence was calculated using individuals whom, in the course of being a participant in the cohort, had tested HIV-I antibody negative, and then subsequently tested HIV-1 antibody positive, since cohort inception. Cumulative incidence was calculated using Kaplan-Meier method, and is therefore expressed as a probability (percent). Prevalence was calculated using the number of individuals HIV-seropositive as of August 15,2001, divided by the number of people in the cohort. To determine the population attributable risk, the dependent variable was a) cumulative HIV incidence, and b) cumulative HIV prevalence. The independent variables were having ever experienced any sexual violence in one's lifetime, or not.

\subsection{Analyses}

\section{Hypotheses 1\& 2}

Statistical power for a two-direction result was considered prior to beginning the analyses. The total sample size was 1,437 , and it was determined that there were 518 individuals who reported ever having been sexually victimized, including 306 who were 
at or under the age of twelve when it first happened, 117 who were inclusively between the ages of thirteen and seventeen, and a further 95 individuals who were eighteen or over when the first incident occurred. Thus, these analyses had more than $95 \%$ power to detect a $10 \%$ difference (s.d. $2 \%$ ) in any given outcome among the smallest of these groupings $(n=95)$.

Univariate comparisons of categorical and dichotomous variables between individuals who reported a history of sexual violence and those that did not were conducted using Pearson's chi-squared test and Fishers Exact methods, depending on the numbers within the cells. Non-normal continuous data was analyzed using the Wilcoxon rank-sum test, and normally distributed continuous data was analyzed using Student's t-test.

\section{Hypothesis I \& 2: Multivariate Analyses}

Multivariate logistic regression was used to determine sociodemographic factors independently associated with ever experiencing sexual violence. All univariately significant $(p<0.05)$ sociodemographic variables were entered into the model, using the Enter method.

Multivariate logistic regression analysis was used to identify whether sexual violence (ever, and at each different age category) was independently associated with the following outcomes:

- Age entered sex trade (dichotomized at the median)

- Age at first injection (dichotomized at the median) 
- Ever being in the sex trade

- Ever borrowing rigs/needles from known HIV-positive people

- Ever attempted suicide

- Ever accidentally overdosed

- Ever diagnosed with a mental disorder/disability

- Ever borrowed rigs/needles

- Use cocaine at least once daily

- Need help injecting

Each of these outcomes was a priori determined based on their significance level $(\mathrm{p}<0.05)$ in univariate analyses at some or all of the age categories, and because each one represents an important self-destructive behavior (including HIV risk behaviors). Separate models were built for each outcome, and each age category (including ever versus never) was analyzed separately. Each model was controlled for fixed sociodemographic characteristics (gender, age at baseline, education level at baseline, ethnicity, and place of birth). There were therefore forty separate controlled analyses conducted.

Both the literature and this data suggest that health care utilization is increased among individuals who have experienced sexual violence. A second series of multivariate analyses was therefore conducted specifically examining health care utilization. The following five outcomes were applied, with each age category being entered into a model for each outcome, including ever experienced sexual violence versus never, and each model was again controlled for fixed sociodemographic characteristics (gender, age at baseline, education at baseline, ethnicity, place of birth):

- General Practitioner consultation in previous six months 
- Ambulance use in previous six months

- Emergency Department use in previous six months

- Overnight hospital admission in previous six months

- Ever hospitalized for a mental disorder/disability

These represented an additional twenty controlled multivariate analyses. All logistic regressions were done using the Enter method.

Relevant assessments for collinearity were explored, including between accidental overdoses, needing help injecting and cocaine frequency; suicide and cocaine frequency, being in the sex trade and needing help injecting, sex trade and number of lifetime partners, among others. Interaction terms were explored when results warranted them (e.g. child sexual abuse and gender for outcome of accidental overdoses and age entered the sex trade). All statistical tests were two-sided, and therefore all p-values are twosided. All regressions were performed using the Enter method.

\section{Analysis, Hypothesis 3}

Attributable risks were calculated based on both cumulative incidence and prevalence data. Attributable risk based on incidence is useful for knowing how much of the recent epidemic (i.e. since the inception of the VIDUS cohort which coincided with the HIV epidemic among this population) is attributable to sexual violence. The attributable risk based on prevalence is useful for understanding how much of all the HIV in the cohort can be attributed to a history of sexual violence. More discussion on how and why 
prevalence was used in these calculations, including its limitations, can be found in the Discussion section of this paper.

The analyses included all individuals who completed a baseline questionnaire and responded to the question of sexual violence and for whom there was data on HIV serostatus. Cumulative HIV incidence was calculated based on the number of new HIV seroconversions observed among the cohort since its inception, and then categorized according to whether the respondents indicated they had ever experienced sexual violence. Prevalence was calculated as the total number of individuals in the cohort who are currently HIV-positive. An attributable risk is defined as the proportion of disease incidence that can be attributed to an exposure, in this case sexual violence.

Statistical power was considered a priori to undertaking these analyses using a standard power calculation for a two-tailed test. The assumptions were that the expected difference in HIV incidence between those who have ever experienced sexual violence and those who have not would be 0.05 , the sample size was 1437 , the standard deviation was set at 0.01 , and the alpha at 0.05 . From this calculation, it was determined that there was over $95 \%$ power to detect a $10 \%$ difference in cumulative HIV incidence between abused versus non-abused groups. The attributable risks were not calculated specifically for individuals who first experienced sexual violence in childhood because of lack of power. 
However, it was subsequently determined that the difference in cumulative incidence between exposed and unexposed groups was only $1.47 \%$, which was a posteriori calculated to result in insufficient power. Therefore, attributable risks were calculated based on prevalence data, for which there was sufficient power.

The absolute attributable risk was then calculated using the standard equation:

Prevalence of HIV in exposed group - Prevalence of HIV in non-exposed group $=$ Amount of HIV prevalence attributable to sexual violence in those who experienced it

Similarly, an attributable risk percent was calculated for the exposed group:

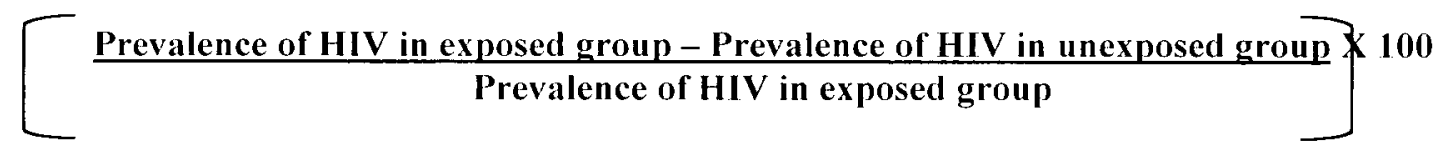

A similar calculation was also performed to determine what proportion of the HIV prevalence in the total population of VIDUS participants can be attributed to sexual violence. The absolute population attributable risk was calculated as follows:

Prevalence of HIV in total population of VIDUS - Prevalence of HIV non-abused = Amount of HIV in VIDUS that is attributable to sexual violence

To be able to express this as a percentage, the population attributable risk percent was calculated as follows:

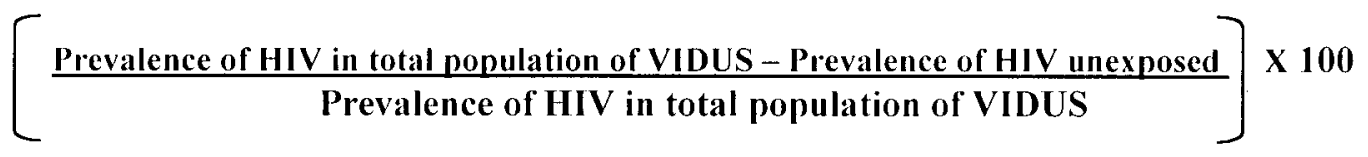




\section{Chapter 4: Results}

There were 1,437 individuals eligible for analysis, including $932(65 \%)$ men, $503(35 \%)$ women, and 2 transgendered individuals who were included among women for the purposes of this analysis. The majority of the cohort is Caucasian $(n=865,60 \%)$, while $362(25 \%)$ are Aboriginal, and the remaining $210(15 \%)$ are classified as "other ethnicity". Among the entire cohort, the mean age is 33.9 years, and the median is 34.2 years. Of the 1,437 participants, $1244(85 \%)$ have at least one follow-up visit. At baseline, there were $518(36 \%)$ individuals who responded that they had ever experienced sexual violence, plus 20 people who reported either being unsure or preferring not to answer. These latter individuals were excluded from all analyses.

\subsection{Abuse Characteristics:}

Of the 518 individuals who had ever experienced sexual violence, $345(67 \%)$ were women, and $173(33 \%)$ were men. Table 1 summarizes the characteristics of abuse for men and women.

Among the 313 women for whom the data was available, $167(53 \%)$ reported that their first incident of sexual violence occurred at or below age $12 ; 85(27 \%)$ reported the first incident to have taken place when they were inclusively between the ages of 13 and 17; and the remaining $61(19 \%)$ reported being at least 18 years of age when the first incident occurred. The mean age at onset of abuse for women was 12.9 years (s.d. 8), and the median was 12.0 years (IQR: $6-17)$. 
Among the men, the mean age at onset of abuse was substantially lower, at 11 years (s.d. 7), and the median was 10 years (IQR: 6-15). For the 162 men for whom there is data, $113(70 \%)$ reported that their first incident of sexual violence was at or below age $12 ; 32$ (20\%) reported being aged 13 through 17, and the remaining $17(10 \%)$ reported being adults at the first occurrence.

There were also varying distributions of perpetrators between men and women. Among women, $31 \%$ reported that a male relative had been the first perpetrator; $26 \%$ reported that it was a known male; $15 \%$ reported that it was a female stranger; and the remaining perpetrators included pimps, female dates, female relatives, and male stranger. Surprisingly, no women reported that a male date or male client had been the perpetrator at first occurrence. There were 8 women $(2 \%)$ who refused to say who the perpetrator was, $5(1 \%)$ stated that the perpetrator was "other", and $3(<1 \%)$ reported being unsure of who the perpetrator was at first occurrence.

For men, $5 \%$ reported that the perpetrator was a male relative, $8 \%$ reported that the perpetrator was a known male, $4 \%$ reported it being a female stranger. The remainder of the responses were distributed in small percentages across female relative, male stranger, dates (male and female), male client, and pimp. No men reported being unsure of who the perpetrator was, and no men refused to answer the question. Six men reported that the perpetrator was "other". 


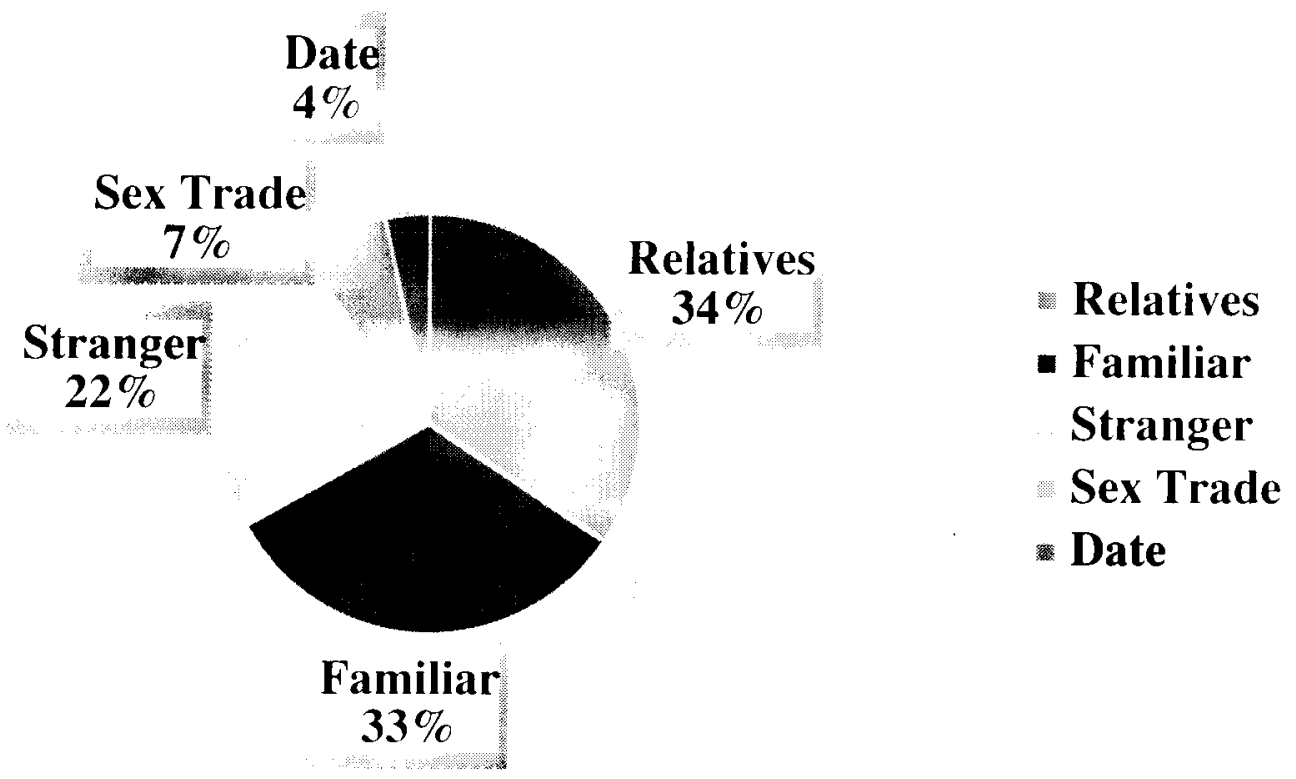

Figure 1: Relationship of perpetrators to victims, genders combined

The data regarding disclosure. counseling, and revictimization is compelling. Among women, $45 \%$ reported that they had never disclosed the sexual violence prior to the interview. Only $16 \%$ had ever received any counseling. Over $50 \%$ of women had been revictimized at least once since the first incident. For men, the overwhelming majority $(87 \%)$ had never disclosed the abuse prior to the interview. This is particularly noteworthy since the majority of them experienced the sexual abuse in childhood. Only $5 \%$ of men had ever received counseling. In contrast to women, $9 \%$ had since been revictimized. 
For men and women combined (for both perpetrators and victims), Figure 1 summarizes the relationship of the perpetrator to the victim:

\subsection{Results, Hypothesis 1:}

\section{Ever vs. Never}

Table 2 summarizes the sociodemographic characteristics examined, and those factors statistically associated with a history of any lifetime sexual violence. Two thirds of individuals who reported any sexual violence were women $(67 \%$ vs. $33 \%, p<0.001)$, despite making up only one-third of the entire population. Compared to individuals who reported not experiencing sexual violence, individuals who reported being assaulted or abused at some point in their lifetime were statistically more likely to be younger (median age 33, IQR $26-39$ vs. 35 , IQR $27-41$ ), born in Canada ( $92 \%$ vs. $82 \%, \mathrm{p}<0.001$ ), Aboriginal ( $32 \%$ vs. $21 \%, \mathrm{p}<0.001$ ), married or common-law ( $30 \%$ vs. $20 \%, \mathrm{p}<0.001$ ), and less likely to be employed ( $3 \%$ vs. $7 \%, p<0.001$ ). Sociodemographic variables which were non-significant $(p>0.05)$ were having less than a high school education, relying on welfare as one's main source of income, and living in unstable housing. In a multivariate model of sociodemographic characteristics, the only significant and independent associations with having experienced any sexual violence were being a woman (AOR 9.5, 95\% Cl: 7.2 - 12.4), and being born in Canada (AOR 1.6, 95\% Cl: $1.1-2.4$ ) (Table 3). 
There were many highly statistically significant bivariate associations between having ever experienced sexual violence and drug use characteristics (Table 4). People who reported ever experiencing sexual violence were statistically younger when they first 'fixed' (median age 18, IQR $15-23$ vs. 19, IQR $16-25, \mathrm{p}<0.001$ ). In addition, they were more likely to have ever borrowed needles from someone they knew to be HIVpositive ( $11 \%$ vs. $4 \%, p<0.001)$, to smoke cigarettes $(96 \%$ vs. $93 \%$, $p=0.003)$, to have ever accidentally overdosed ( $62 \%$ vs. $47 \%, \mathrm{p}<0.001)$, to have ever lent needles ( $45 \%$ vs. $32 \%, \mathrm{p}<0.001$ ), to be currently borrowing needles ( $46 \%$ vs. $34 \%, \mathrm{p}<0.001$ ), to have ever borrowed needles ( $71 \%$ vs. $62 \%, p<0.001$ ), to need help injecting ( $49 \%$ vs. $37 \%$ ), and to use cocaine more than once per day $(50 \%$ vs. $41 \%)$. The variables which were not bivariately significant at the 0.05 cut-off were using heroin in the past 6 months, using heroin more than once per day, using cocaine in the past six months, using crack in the past six months, using alcohol and bingeing.

In a series of bivariate analyses examining sexual behavior characteristics associated with a reported history of sexual violence (Table 5), variables more likely to be associated were median age at first commercial sex interaction ( 17 yrs, IQR $14-22$ vs. 19 yrs, IQR $16-24, p<0.001$ ), engaging in the sex trade in the previous six months ( $50 \%$ vs. $14 \%$, $p<0.001$ ), ever being in the sex trade (63\% vs. $23 \%, p<0.001$ ), using condoms with opposite sex clients ( $46 \%$ vs. $17 \%$, $p<001$ ), having more than 20 lifetime sexual partners ( $74 \%$ vs. $62 \%, p<0.001)$, and having a regular opposite partner ( $47 \%$ vs. $39 \%, p<0.001)$. 
Table 6 describes the health and health care utilization variables that were bivariately analyzed. People who had ever experienced sexual violence were statistically more likely to have ever been hospitalized due to a mental disorder or disability including suicide ( $33 \%$ vs. $12 \%, \mathrm{p}<0.001$ ), to have seriously thought about suicide ( $74 \%$ vs. $45 \%$, $\mathrm{p}<0.001$ ), to have attempted suicide ( $75 \%$ vs. $51 \%, \mathrm{p}<0.001$ ), to have ever had a sexually transmitted disease ( $61 \%$ vs. $40 \%, \mathrm{p}<0.001$ ), to have consulted a General Practitioner in the previous six months $(84 \%$ vs. $71 \%, \mathrm{p}<0.001)$, to have ever been diagnosed with a mental disorder or disability ( $31 \%$ vs. $19 \%, p<0.001)$, to have ever received any drug/alcohol treatment ( $82 \%$ vs. $69 \%, p<0.001$ ), to have been admitted to hospital at least overnight in the previous six months ( $28 \%$ vs. $17 \%, p<0.001)$, to be currently on methadone ( $15 \%$ vs. $8 \%, \mathrm{p}<0.001)$, to have required ambulance attention in the past six months ( $34 \%$ vs. $27 \%, p=0.003)$, to be currently in drug/alcohol treatment $(26 \%$ vs. $17 \%$, $\mathrm{p}<0.001$ ), and to have gone to the hospital emergency department in the previous six months ( $50 \%$ vs. $42 \%, \mathrm{p}=0.002)$.

\subsection{Results, Hypothesis 2:}

Comparisons of proportions for key sociodemographic, drug use, sexual behavior, and medical/health care utilization variables across all age groups (including ever and never) are presented in Tables 7, 8, 9, and 10. The unadjusted odds ratios across the age categories and for all variables are summarized in Tables $11,12,13$, and 14 .

First Abuse at Age 12 or Under versus No Sexual Violence 
Of the 518 individuals who reported experiencing any sexual violence, 306 (59\%) reported being at or below the age of 12 years when the first incident occurred. Among this group of injection drug users, therefore, there is $21 \%$ prevalence of childhood sexual abuse when "child" is defined as being aged twelve or under. The remaining 212 reported being 13 and over when the first incident occurred, including 117 (23\%) who were inclusively aged 13 to 17 years, and $95(18 \%)$ being 18 or over when they first experienced sexual violence.

Table 15 summarizes the sociodemographic characteristics of individuals who experienced sexual violence first as children (age 12 and under versus never). Compared to those who had never experienced sexual violence, those who experienced childhood sexual abuse were more likely to be female $(61 \%$ vs. $17 \%, p<0.001)$, born in Canada ( $92 \%$ vs. $82 \%$, p $<0.001)$, Aboriginal ( $33 \%$ vs. $21 \%$, p $<0.001)$, married or common-law $(27 \%$ vs. $20 \%, p=0.014)$, to have less than a high school education $(23 \%$ vs. $17 \%$, $p=0.030)$, and less likely to be employed ( $2 \%$ vs. $7 \%, p=0.003)$. Not statistically significant sociodemographic variables $(p>0.05)$ were relying on welfare as one's primary source of income, and being in unstable housing.

In terms of drug use characteristics, compared to individuals who had never experienced sexual violence, those who were first sexually abused in childhood were more likely to have first fixed at a younger age (median 17, IQR $14-22$, vs. 19, IQR $16-25, \mathrm{p}<0.001$ ), to have ever accidentally overdosed ( $67 \%$ vs. $47 \%, \mathrm{p}<0.001$ ), to have ever knowingly 
- borrowed needles/rigs from someone who was known to be HIV-positive (12\% vs. $4 \%$, $\mathrm{p}<0.001$ ), to have ever lent needles ( $46 \%$ vs. $32 \%, p<0.001$ ), to be currently borrowing needles $(49 \%$ vs. $35 \%, \mathrm{p}<0.001)$, to have ever borrowed needles ( $72 \%$ vs. $62 \%$, $p<0.001)$, to use cocaine at least once per day ( $53 \%$ vs. $41 \%, p<0.001)$, to need help injecting ( $47 \%$ vs. $37 \%, p=0.002)$, and to currently smoke cigarettes $(97 \%$ vs. $93 \%$, $p=0.010)$. Non-significant $(p>0.05)$ variables examined were heroin use in the last six months, daily frequency of heroin use, cocaine use in the last six months, crack use in the last six months, bingeing, and alcohol use (Table 16).

Sexual behavior characteristics examined are summarized in Table 17. Those who first experienced sexual abuse in childhood compared to those who never experienced it were more likely to have entered the sex trade at a younger age (median 16, IQR $14-21$, vs. 19, IQR $16-24, p<0.001)$, to have been in the sex trade in the previous six months $(50 \%$ vs. $14 \%, \mathrm{p}<0.001)$, to have ever been in the sex trade $(61 \%$ vs. $24 \%, \mathrm{p}<0.001)$, to use condoms with sex trade clients ( $47 \%$ vs. $17 \%, \mathrm{p}<0.001)$, and to have had more than twenty sexual partners over one's lifetime $(75 \%$ vs. $62 \%$, p $<0.001)$. Non-significant variables $(p>0.05)$ were having a regular opposite sex partner, having a casual opposite sex partner, using condoms with either one's regular or casual opposite sex partners, and age at first consensual intercourse.

Of the medical and health care utilization variables examined, compared to those who reported never experiencing sexual violence those who were twelve or under were statistically more likely to have ever been hospitalized for a mental disorder or disability 
( $38 \%$ vs. $12 \% ; p<0.001$ ), to have seriously thought about suicide ( $77 \%$ vs. $45 \%$, $\mathrm{p}<0.001$ ), to have attempted suicide ( $76 \%$ vs. $52 \%, \mathrm{p}<0.001$ ), to have ever had any sexually transmitted diseases ( $64 \%$ vs. $40 \%, \mathrm{p}<0.001)$, to have ever been diagnosed with a mental disorder or disability ( $36 \%$ vs. $19 \%, \mathrm{p}<0.001)$, to have ever been in drug/alcohol treatment ( $84 \%$ vs. $69 \%, p<0.001)$, to have consulted a General Practitioner in the prior six months ( $85 \%$ vs. $71 \%, \mathrm{p}<0.001)$, to have been admitted to hospital at least overnight in the prior six months ( $28 \%$ vs. $17 \%, \mathrm{p}<0.001)$, to be currently in drug/alcohol treatment ( $24 \%$ vs. $17 \%, p=0.007$ ), to have used a hospital Emergency Department in the past six months ( $49 \%$ vs. $42 \%, p=0.017)$, and to have required ambulance attention in the

previous six months ( $33 \%$ vs. $27 \%, p=0.030$ ). The only statistically non-significant health related variable was currently being on methadone ( $12 \%$ vs. $8 \%, p=0.076)$ (Table 18).

\section{First Abuse in Adolescence versus No Sexual Violence}

The profile of sociodemographic, drug use, sexual behavior, and medically related characteristics for individuals who reported their first abuse occurring when they were adolescents (ages 13-17 inclusive) compared to never was not dissimilar from those who first experienced abuse in childhood, although generally not as extreme.

Sociodemographically, compared to those who never experienced sexual violence, people who were first sexually violated in their adolescence were more likely to be female ( $73 \%$ vs. $17 \%, p<0.001$ ), born in Canada ( $95 \%$ vs. $82 \%, p<0.001)$, Aboriginal ( $31 \%$ vs. $21 \%$, 
$\mathrm{p}<0.018$ ), and to be married or common-law ( $34 \%$ vs. $20 \%, \mathrm{p}<0.001$ ). Not statistically significant sociodemographic variables $(\mathrm{p}>0.05)$ were relying on welfare as one's primary source of income, being in unstable housing, having less than a high school education, and employment status (Table 19).

In terms of drug use characteristics, compared to individuals who had never experienced sexual violence, those who were first victimized in adolescence were more likely to have first fixed at a younger age (median 18, IQR $15-23$, vs. 19 , IQR $16-25$, p=0.014), to have ever accidentally overdosed ( $60 \%$ vs. $47 \%, \mathrm{p}<0.001)$, to need help injecting $(52 \%$ vs. $37 \%, p<0.001$ ), to have ever knowingly borrowed needles/rigs from someone who was known to be HIV-positive ( $9 \%$ vs. $4 \%, \mathrm{p}=0.017$ ), and to have ever lent needles ( $41 \%$ vs. $32 \%, \mathrm{p}=0.047$ ). Non-significant variables were currently borrowing needles, having ever borrowed needles, using cocaine at least once per day, heroin use in the last six months, daily frequency of heroin use, cocaine use in the last six months, crack use in the last six months, bingeing, and alcohol use (Table 20).

Sexual behavior characteristics examined for adolescents are summarized in Table 21. Those who first experienced sexual abuse in adolescence compared to those who never experienced it were more likely to have entered the sex trade at a younger age (median 15 , IQR $14-20$, vs. 19 , IQR $16-24, \mathrm{p}<0.001$ ), to have been in the sex trade in the previous six months ( $50 \%$ vs. $14 \%, \mathrm{p}<0.001)$, to have ever been in the sex trade $(61 \%$ vs. $24 \%, \mathrm{p}<0.001$ ), to use condoms with sex trade clients ( $42 \%$ vs. $17 \%, \mathrm{p}<0.001$ ), and to have a regular opposite sex partner ( $50 \%$ vs. $39 \%, p=0.016)$. Non-significant variables 
were having had more than twenty sexual partners over one's lifetime, having a casual opposite sex partner, using condoms with either one's regular or casual opposite sex partners, and age at first consensual intercourse.

Of the medical and health care utilization variables examined, compared to those who reported never experiencing sexual violence those who were between the ages of thirteen and seventeen (inclusive) were statistically more likely to have ever been hospitalized for a mental disorder or disability ( $21 \%$ vs. $12 \%, \mathrm{p}=0.009)$, to have seriously thought about suicide $(69 \%$ vs. $45 \%, p<0.001)$, to have attempted suicide ( $68 \%$ vs. $52 \%, p=0.007)$, to have ever had any sexually transmitted diseases ( $56 \%$ vs. $40 \%, p<0.001)$, to be currently on methadone $(18 \%$ vs. $8 \%, p<0.001)$, to be currently in drug/alcohol treatment $(28 \%$ vs. $17 \%, \mathrm{p}=0.003$ ), to have been admitted to hospital at least overnight in the prior six months ( $28 \%$ vs. $17 \%, \mathrm{p}=0.005)$, and to have consulted a General Practitioner in the prior six months ( $79 \%$ vs. $71 \%, p=0.048)$. Non-significant variables were having ever been diagnosed with a mental disorder or disability, having ever been in drug/alcohol treatment, have used a hospital Emergency Department in the past six months, and to have required ambulance attention in the previous six months (Table 22).

\section{Childhood Sexual Abuse versus First Abuse in Adolescence}

Tables $23,24,25$, and 26 show a series of univariate comparisons between those who first experienced sexual violence in childhood, compared to those who were adolescents at the time. As seen, women were more likely to report first abuse in adolescence ( $73 \%$ 
vs. $61 \%$ ), while men were more likely to experience first abuse at or under the age of twelve (39\% vs. $28 \%, p=0.027$ ). There were no differences between the two groups in terms of drug use or sexual behavior characteristics, and the only statistically significant difference among medical and health care utilization characteristics was that individuals first abused at or under the age of twelve were more likely to have ever been hospitalized for a mental disability or disorder (including suicide) (38\% vs. 20\%, p<0.001), compared to those who first experienced sexual violence in adolescence.

First Abuse in Adulthood versus No Sexual Violence

Individuals who reported first being sexually assaulted in adulthood (aged 18 and over) compared to those who reported never having experienced sexual violence were more likely to be women $(77 \%$ vs. $17 \%, p<0.001)$, married or common law $(37 \%$ vs. $20 \%$, $\mathrm{p}<0.001$ ), born in Canada (90\% vs. 82\%, p=0.033), Aboriginal (32\% vs. 21\%, p=0.019), and to rely on Welfare as one's main source of income $(83 \%$ vs. $71 \%, p=0.011)$. Non significant sociodemographic variables were employment status, education level, and housing stability (Table 27).

The only statistically significant drug use characteristics among individuals who reported first sexual violence in adulthood compared to never were having lent needles ( $45 \%$ vs. $32 \%, p=0.008)$, and needing help injecting ( $52 \%$ vs. $37 \%, p=0.003)$ (Table 28$)$. 
Significant sexual behavior characteristics among this group were slightly older age at first consensual intercourse (median 15, IQR 14 - 17, vs. 15, IQR 13 - 16), sex trade in the last six months ( $51 \%$ vs. $14 \%$, p $<0.001)$, sex trade ever $(68 \%$ vs. $23 \%, p<0.001)$, using condoms with one's sex trade clients ( $46 \%$ vs. $17 \%, \mathrm{p}=0.020)$, and having a regular opposite sex sexual partner ( $53 \%$ vs. 39\%, $\mathrm{p}=0.009)$ (Table 29).

Interestingly, among individuals who reported first sexual violence as adults compared to those who never experienced it, all the medical and health care utilization characteristics examined were statistically significant. These individuals were more likely to have ever been hospitalized for a mental disorder or disability (including suicide) ( $32 \%$ vs. $12 \%$ ), to have seriously thought about suicide ( $72 \%$ vs. $45 \%, p<0.001)$, to have attempted suicide ( $78 \%$ vs. $51 \%$, p $<0.001$ ), to have consulted a GP in the past six months ( $86 \%$ vs. $71 \%$, $\mathrm{p}<0.001$ ), to be currently on methadone ( $20 \%$ vs. $8 \%, p<0.001)$, to be currently in any drug/alcohol treatment $33 \%$ vs. $17 \%, p<0.001$ ), to have ever had a sexually transmitted disease ( $57 \%$ vs. $40 \%, \mathrm{p}=0.002$ ), to ever have been diagnosed with a mental disorder or disability $(29 \%$ vs. $19 \%, p=0.011)$, to have ever been in any drug/alcohol treatment $(80 \%$ vs. $69 \%, p=0.027)$, to have required ambulance attention in the past six months ( $38 \%$ vs. $27 \%, \mathrm{p}=0.023$ ), and to have used the Emergency Department of a hospital in the last six months ( $55 \%$ vs. $42 \%, \mathrm{p}=0.014$ ) (Table 30 ).

12 and under versus 13 and over 
The analysis was then restricted to the population of people who had ever experienced any sexual violence, and then individuals who reported being children (12 and under) at the time of the first abuse were compared to those who were 13 or older. Those who were 12 and under were more likely to be male (61\% vs. $39 \%, p<0.001$ ), to have ever accidentally overdosed ( $67 \%$ vs. $56 \%, p=0.011)$, to binge ( $53 \%$ vs. $44 \%, p=0.046)$, to have ever been hospitalized due to mental illness including suicide (38\% vs. $25 \%$, $p=0.002)$, and to have ever been diagnosed with a mental illness ( $36 \%$ vs. $25 \%, p=0.01)$. They were less likely to be currently on methadone ( $12 \%$ vs. $19 \%, p=0.025)$, to be married or common-law $(27 \%$ vs. $35 \%, p=0.037)$, and to rely on welfare as one's main source of income $(65 \%$ vs. $74 \%, p=0.039)$ (Tables $31,32,33,34)$.

\section{Multivariate Models Across Ages}

The multivariate models are summarized in Tables 35 and 36. These data, combined with the univariate comparisons across age groups (see Tables 7 - 10) are strongly suggestive of a dose-response relationship between younger age at onset of abuse and more severe outcomes later in life.

After controlling for fixed sociodemographic characteristics, having first experienced sexual violence at or before age 12 was predictive of entering the sex trade at age 15 or less (AOR 1.6, 95\% CI: 1.1 - 2.2); ever being in the sex trade (AOR 4.1, 95\% CI: $3.0-$ 5.8); borrowing needles from a known HIV-positive person (AOR 2.0, 95\% CI: $1.4-$ 2.8); ever having attempted suicide (AOR 1.6, 95\% CI: $1.1-2.3$ ); ever having 
accidentally overdosed (AOR 1.4, 95\% CI: $1.0-1.9$ ); and ever having been diagnosed with a mental disorder or disability (AOR: $2.3,95 \% \mathrm{CI}: 1.7-3.1$ ).

Having first experienced sexual violence in adolescence was predictive, after controlling for fixed sociodemographic factors, of ever being in the sex trade (AOR: $2.7,95 \% \mathrm{Cl}: 1.8$ - 4.3); having ever attempted suicide (AOR: 2.0, 95\% CI: $1.2-3.3$ ), and ever having been diagnosed with a mental disorder/disabiltiy (AOR: 1.6, 95\% CI: $1.1-2.5$ ).

Having first experienced sexual violence in adulthood was only predictive, after controlling for fixed sociodemographics, of ever being in the sex trade (AOR: 2.7, 95\% CI: $1.6-4.7)$.

Ever borrowing needles/rigs, using cocaine at least once daily, and needing help injecting all became non-significant after controlling for fixed sociodemographic variables in all age categories.

Health care utilization was also examined across the age groups, adjusting in each case for gender, age at baseline, education level, ethnicity, and place of birth. As described in Table 36, having experienced sexual violence in childhood was the only age category predictive of increased health care utilization. These individuals were more likely to have used a hospital emergency department in the previous six months (AOR: 1.9, 95\% CI: $1.3-2.9)$, and to have ever been hospitalized for a mental disorder/disability (including suicide) (AOR: 1.7, 95\% CI: 1.2 - 2.4). Having ever experienced sexual 
violence was predictive of having consulted a General Practitioner over the previous six months (AOR: $1.9,95 \% \mathrm{CI}: 1.1-3.5$ ), but this outcome was non-significant when stratified by age at onset of abuse.

\subsection{Results, Hypothesis \#3:}

Among those 1,238 individuals who were HIV-antibody negative at baseline, $111(9 \%)$ of them have become HIV-positive since. The cumulative incidence rate of HIV-1 in the VIDUS cohort is $13.51 \%$ (s.e. 0.013 ). Among those who have never experienced sexual violence, the cumulative HIV incidence is $12.97 \%$ (s.e. $0.015: 12.95,12.99$ ), and among those who ever experienced sexual violence it is $14.44 \%$ (s.e. $0.022: 14.42,14.46$ ). Using the log-rank test, this difference was not statistically significant $(\mathrm{p}=0.833)$, despite the fact that the standard errors do not overlap.

As of August 14,2001, the prevalence of HIV among the entire cohort is $21.4 \%$. Broken down by exposed versus unexposed, those who ever experienced sexual violence have a $25.3 \%$ HIV prevalence, while in the unexposed the prevalence is $19.1 \%(\mathrm{p}=0.006)$. Exposure is defined as having ever experienced sexual violence.

Therefore the absolute Attributable Risk (prevalence of HIV in exposed minus prevalence in unexposed) is $6.2 \%$, and the Attributable Risk percent is $24.5 \%$, theoretically meaning that nearly $25 \%$ of the HIV among individuals who have ever experienced sexual violence can be attributed to their history of sexual violence. 
The absolute Population Attributable Risk (prevalence of HIV in all of VIDUS minus prevalence in unexposed) is $2.3 \%$, and the Population Attributable Risk percent is $10.7 \%$, meaning that more than one in ten cases of HIV infection among injection drug users in VIDUS can, in theory, be attributed to their histories of sexual violence. 


\section{Chapter 5: Discussion}

\subsection{Summary of key results:}

There are several results emerging from this analysis that must be emphasized. Clearly, there is a very high prevalence of lifetime sexual violence among this cohort of injection drug users, at $36 \%$. In multivariate analysis controlling for other sociodemographic variables, women were nine times more likely to have ever experienced sexual violence. After controlling for sociodemographic characteristics, a history of sexual violence was predictive of several self-destructive behaviors, including ever having been in the sex trade, ever having knowingly borrowed rigs/needles from HIV-positive people, having ever attempted suicide, and having ever been diagnosed with a mental disorder or disability.

A clear dose-response relationship was evident in both univariate and multivariate analyses between younger age at onset of abuse and self-destructive behaviors. First experience of sexual violence as an adult was only predictive of ever having been in the sex trade. First experience of sexual violence as an adolescent was predictive of ever being in the sex trade, attempting suicide, and having been diagnosed with a mental disorder/disability. Being aged 12 or under at the time of the first incident of sexual violence was predictive of ever being in the sex trade, entering the sex trade at an earlier age, having ever borrowed needles/rigs from a known HIV-person, having attempted suicide, having ever accidentally overdosed, and having been diagnosed with a mental disorder or disability. 
Similarly, first experience of sexual violence as a child was predictive of using the Emergency Department of a hospital in the prior six months and having ever been hospitalized for a mental illness. No other age groups were significant for any of the health care utilization outcomes.

The adjusted odds ratios were strongly significant across the age groups for having ever been in the sex trade. Both sexual violence first in adolescence and adulthood were predictive by nearly three times of ever being in the sex trade. The child sexual abuse group were over four times as likely to have ever been in the sex trade suggesting a strong increased risk over the other age categories. Child sexual abuse was the only age group that was predictive of entering the sex trade at or below the age of fifteen, reinforcing a dose-response relationship between age at onset of sexual violence and being in the sex trade. An interaction between gender and child sexual abuse was examined for age entering the sex trade, but it was non-significant. It is important to consider that being in the sex trade in and of itself is probably a risk factor for experiencing sexual violence, and that being in the sex trade may not be a consequence of sexual violence, with the possible exceptions of the childhood and adolescent groups. Of note, using condoms with sex trade clients was strongly univariately associated with experiencing sexual violence in the analyses of sexual behavior characteristics, and this may be the result of being raped as the result of insisting on condom use with clients $(150)$. 
There appears to be a gradient of effect evident between younger age at abuse onset and ever having attempted suicide, as well as having ever been diagnosed with a mental illness. People who experienced sexual abuse first in childhood or adolescence, but not adulthood, are twice as likely to attempt suicide, suggesting a causative relationship. Similarly, those who first experienced sexual abuse first in childhood and adolescence, bot not adulthood, were more far more likely to have ever been diagnosed with a mental illness. If each age group was significant in relation to this outcome one could have hypothesized that sexual predators may be attracted to individuals who are already vulnerable by virtue of being mentally disabled in some way, resulting in a strong association. However, the fact that this outcome was only significant for those who experienced sexual violence in childhood or adolescence reinforces the literature that sexual violence causes a plethora of mental health disturbances.

Having ever accidentally overdosed was only significant in the childhood sexual violence group, suggesting a much stronger effect as a result of child sexual abuse. Indeed, this became further apparent when an interaction term was created between gender and child sexual abuse. When entered into the model, the child sexual abuse variable increased in significance (AOR: 1.9, 95\% CI: $1.2-2.9$ ), and the interaction term was also significant, though inversely (AOR: $0.52,95 \% \mathrm{CI}: 0.28-0.95$ ), suggesting that gender has a modifying effect on child sexual abuse in the context of accidental overdoses.

Taken altogether, these data suggest a strong trend that the younger one's age at the first incident of sexual violence, particularly in childhood, one's most vulnerable years, the 
worse the outcomes later in life - notably; entering the sex trade early, borrowing needles from HIV-positive people, attempting suicide, accidentally overdosing, having a mental disability, and using more health care services. Supporting these data, are the two agespecific univariate comparisons $(\leq 12$ vs. $>12$, and $\leq 12$ vs. $13-17$ ). Although in general both sets of analyses showed fewer differences, this is probably due to effect dilution, since experiencing sexual violence at any age appears to be associated with a broad plethora of adverse effects. Despite effect dilution, in the case of the at and under twelve versus over twelve, those who were at or under twelve were more likely to have ever accidentally overdosed, to ever have been hospitalized with a mental disorder/disability, and to have ever been diagnosed with a mental disorder/disability, all of which were highly significant in the adjusted age analyses ${ }^{\prime}$. The effects are even more diluted by comparing the childhood group to the adolescent group, as evidenced by the even smaller number of significant differences. However, a review of the univariate percents (Tables 7 - 10) and unadjusted odds ratios (Tables $11-14$ ) across the groups demonstrates how being sexually assaulted for the first time either in childhood or adolescence is associated in a dose response fashion with a broad array of adverse outcomes. Some of these must be related to sociodemographic variables, given that once sociodemographics are controlled for, many of the effects fall away.

\footnotetext{
It should be noted that it is unrealistic to expect that people who experience sexual violence first in adolescence or first in adulthood will be same, and therefore a cautionary note on the interpretation of these findings should be stated. One may assume that those first assaulted in adulthood may be qualitatively different from the others, either by virtue of their more advanced stage of maturity, or even the nature of the incident. For example, it is more likely that in the adult group, their experience of sexual violence is the result of their lifestyle (being in the sex trade, living on the street), whereas for the group first abused in adolescence, their sexual violence may indeed have led to their lifestyle.
} 
As previously mentioned, gender was the factor most strongly associated with experiencing sexual violence. In all analyses which compared those who experienced any sexual violence at each age category including childhood to those who never experienced sexual violence, women were at a minimum $7.5(95 \% \mathrm{CI}: 5.7-9.8)$ times more likely to experience sexual violence (see Table 29). However, in the analyses which were restricted to the population of people who had ever experienced sexual violence, males were more vulnerable at or before the age of twelve compared to other age categories (see Tables $23 \& 31$ ). Girls however, still comprised two-thirds of those who experienced child sexual abuse. Boys may be more vulnerable early because they are physically better able to defend themselves after they hit puberty, or it may be a preferential indication on the part of sexual predators (i.e. they may prefer young boys). One can see from Table 7 a clear trend suggesting that the older the age at first incident, the more likely the victim is to be female. The younger the age, the more likely the victim is male. Again however, women consistently represented the majority of victims, regardless of age at onset.

There are other important results regarding gender and the specific characteristics regarding the abuse. Women were significantly more likely to have been assaulted by a male relative ( $31 \%$ vs. $5 \%$ ) or a male known to them (26\% vs. $8 \%$ ). They were also more likely to be assaulted by a female stranger ( $15 \%$ vs. $4 \%$ ). It is shocking that $45 \%$ of women and $87 \%$ of men only disclosed their history of sexual violence at the time of the interview. This suggests that there may be huge underreporting issues regarding sexual violence, particularly among men. Similarly only $5 \%$ of men and $16 \%$ of women have 
ever received counseling addressing the abuse. Over half of the women (51\%) were ever " sexually revictimized, while less than $10 \%$ of men were. Notwithstanding reporting bias, it appears that although males are at heightened vulnerability early in childhood, the risk of sexual violence stays high for girls and women, whereas it decreases sharply for men as they grow older. It is unknown why there are so many data missing in terms of perpetrators for male victims. However, among women, $15 \%$ of perpetrators were female strangers; this pattern has not been reported before, and is both surprising and cause for alarm. All of these data have important implications for the prevention and treatment of child sexual abuse.

Attributable Risk is a well-described epidemiological method of assessing how much disease can be attributed to a particular exposure $(151,152)$, and is generally used in describing a causal relationship. It is a crude measure, and involves many contentious assumptions (151-153), yet it is one means of understanding the relationship between exposure and disease. Despite its limitations conceptually, to be further discussed in the section below on limitations, the Attributable Risk results are interesting, and contribute to the description of the role of sexual violence in influencing the epidemic of HIV-1 infection among Vancouver's injection drug users. Although the effect of sexual violence on cumulative HIV incidence was not statistically significant, the incidence rates standard errors did not overlap by $1.5 \%$, and can therefore be considered different depending on whether the individuals had a history of sexual violence. The reason that the difference in incidence rates may not have been significant is because people who have experienced sexual violence have probably been engaging in self-destructive 
(including HIV risk) behaviors for longer than the time of the cohort, and therefore may have seroconverted prior to the inception date of the cohort. Considering that the effect between sexual violence and HIV infection is an indirect one (through the mediating factors of sharing needles, unprotected sexual activity, etc.), the fact that there is a difference even just in incidence rates is significant. This difference becomes significantly and statistically more pronounced when HIV prevalence is examined $(\mathrm{p}=0.006)$. In this cohort, according to the Attributable Risk calculations for the exposed population and for the whole population, $25 \%$ of the HIV among individuals who have ever experienced sexual violence can be attributed to their history of sexual violence, and $10 \%$ of the overall VIDUS cohort can attribute their HIV-positive serostatus to a history of sexual violence.

\subsection{Supporting Evidence in the Literature and New Findings:}

The lifetime prevalence estimate for sexual violence in this cohort is $36 \%$, and $21 \%$ for that occurring first in childhood. Among women, the lifetime prevalence is $68 \%$, and the childhood sexual abuse prevalence is 33\%. Among men, 19\% ever experienced sexual violence, and 12\% experienced child sexual abuse. Our findings suggest that injection drug users are approximately as likely to have experienced sexual violence as many other marginalized populations, including the homeless $(43,45,91)$, the incarcerated (44), and a variety of clinical and college samples $(24,31,32,36,40,42,48,49,55,57,60-68$, 76). In relation to other populations at risk for HIV or infected with HIV, our prevalence estimates are about average $(22,28,35,41,46,53,59)$. Most of the published estimates 
are in populations of women at risk for or infected with HIV, and our results are aggregated for gender, compounding already existing limitations in direct prevalence comparisons, but making an important contribution for exactly that reason. However, our results are not surprising. A notable reference for another Canadian inner-city (Winnipeg) which investigated sexual violence among women (50\% Aboriginal) attending a primary care clinic suggested that there was a lifetime prevalence of sexual violence of $37 \%$, and a prevalence of child sexual abuse of $27 \%$ (58). Though a more homogeneous population than VIDUS, the similarity in results to the present study is striking. Browne et al. (2000) have also reported a prevalence of child sexual abuse of $21 \%$ among Dublin's injection drug users (sample size unknown) (25). The present study is nonetheless among the first to establish prevalence estimates among injection drug users, and to do so within a large and stable cohort of both men and women at high risk for HIV infection.

The literature, perhaps surprisingly (given the intuitively obvious nature of the fact that being sexually abused in childhood will be particularly bad for you above and beyond experiencing any other sexual violence) contains conflicting data regarding differential age effects. In the early 1990's, some important reviews of the literature $(12,140)$ argued that there was no relationship between age of onset of abuse and degree of trauma. Parillo et al. (2001) recently published work which examined whether sexual abuse involving penetration that occurred in childhood only, in adolescence only, or both childhood and adolescence differently impacted on whether women had ever traded sex for money or drugs, how many recent sex partners they had, and the number of times they had engaged 
in recent unprotected sex. In terms of sex trade, childhood abuse only was more statistically significant than adolescent abuse only, although the variable of both childhood and adolescent abuse was more significant than either of the other two alone. When looking at number of sexual partners in the past 30 days, the authors found that only the variable of childhood abuse alone was significantly related. There were no significant differences when they looked at age of abuse and recent unprotected vaginal/anal sex (47). Fleming (1999) found that child sexual abuse before the age of 12 (versus > 12) (AOR: 2.23,95\% Cl: 1.06-4.70) was independently associated with experiencing rape in adulthood (97). Jasinski (2000) determined that girls who were older at the time of the first sexual assault were more likely to engage in heavy drinking. The authors suggested that this may be due to having more recent and therefore more vivid and intrusive recollections of the incident, and the girls use alcohol as a means to self-medicate (20). Our results therefore appear to be the most rigorous and comprehensive data thus far in the literature which point to childhood sexual abuse being worse than experiencing sexual violence at other ages.

Our data strongly indicates, and is supported in the literature, that experiencing sexual violence is strongly associated with a variety of mental disabilities and disorders, including being hospitalized as a result of them $(17,19,24,33,35,46,53,60,72,74,93$ 100). Our data suggests that this association may in fact be causal.

Our data regarding health care utilization in general is supported by the literature, and reaffirms that people who experience sexual violence generally require increased levels 
of health care utilization than those who have not $(31,33,41,50,92,127,128,131)$. The literature on this topic includes those who experienced childhood sexual abuse and those who experienced kinds of sexual violence, but does not compare among them. This data therefore, appears to be among the first to demonstrate that younger age at onset of abuse is predictive of increased health care utilization.

Our analysis did not specifically examine post-traumatic stress disorder as an outcome. However, the literature on the subject suggests that many of the apparently selfdestructive behaviors which the present data found, including borrowing needles, borrowing from HIV-positive people, accidental overdoses, and attempted suicide, are included among the defining features of this syndrome. There is currently a body of literature which suggests a strong relationship between sexual violence, especially in childhood, and post-traumatic stress disorder $(38,39,74,104,105)$, and our data strengthens this relationship even further. Based on these findings, it would not be an overstatement to say that there is an epidemic of post-traumatic stress disorder occurring among Vancouver's injection drug users.

The present study makes a number of other unique contributions to the literature in addition to being in a population of injection drug users, identifying that males may be more vulnerable as small children, finding that there is probably massive underreporting of sexual violence among men in general, and particularly finding a clear dose-response relationship between age at onset of abuse and self-destructive behaviors. First, the literature does not appear to contain a quantitatively determined risk of HIV attributable 
to sexual violence. Though limited, these calculations help to quantify the magnitude of the effect. Of note, the application of attributable risk calculations using prevalence data appears to be novel. Second, and most importantly, the literature appears blocked in its ability to consciously argue for a causative effect of child sexual abuse $(17,73)$. This study addresses the issue in some detail (in both the Literature Review, and in an upcoming section in the Discussion), and draws the conclusion that child sexual abuse can most certainly cause a variety of self-destructive and generally adverse outcomes later in life.

\subsection{Strengths of this Analysis}

There are several important strengths worth noting regarding this study. First, this analysis involved a relatively large open cohort of individuals, who by entry criteria into the cohort, are at high risk for HIV infection. It is population specific, and is among the first studies to determine prevalence estimates in injection drug users. However, it is also a broad spectrum population, in that it involves men, women, and the transgendered, across different age groups, using different kinds of drugs to differing degrees, and engaging in a variety of risky and self-destructive behaviors, also to varying degrees. Thus, it has allowed for a comprehensive analysis of how sexual violence affects many of these important factors. The size of the cohort and the number of people who report having experienced sexual violence provided the analysis with sufficient power to perform these analyses and control for potential confounders. 
The fact that the question regarding sexual violence was open-ended and subjective was a strength of the analysis, because it allowed participants to determine whether, in their opinion, they had ever experienced sexual violence. Only a small number of people chose not to answer the question, and these individuals were excluded from all analyses. The fact that the question asked the age at which the first incident of sexual violence happened is an important and unique feature of this analysis. It has allowed for an analysis of the differential distribution of outcomes based on age at onset of sexual violence, and has enabled a clear and direct link to be established between childhood sexual abuse and a spectrum of self-destructive outcomes.

Another strength of this analysis is that it investigated a range of behaviors and outcomes, each of which has important health, quality of life, and cost related implications. As a result, it provides considerable justification for the establishment of counseling and treatment programs, prevention and intervention initiatives, specifically geared at reducing the incidence of childhood sexual abuse, and of addressing the adolescent and adult sequelae of it.

\subsection{Limitations}

As with any epidemiological analysis, there are a number of limitations to this study. First, except HIV serostatus, all the data is self-reported, and is therefore subject to reporting bias. Underreporting may have specifically impacted on the reported prevalence of sexual violence among men, either because of homophobia (men were most likely abused by other men, raising issues of homosexuality), or because of a 
socially learned and engendered predisposition to being less able to emotionally cope with and communicate about the presence and effects of sexual violence, which could increase the probability that men would be less likely to admit to having been abused. A second limitation of this analysis is that because entry criteria into the cohort involved having injected in the previous month, the question of injection drug use could not be specifically considered. This may in fact have accounted for why neither cocaine nor heroin use in the last six months were significant in any of the analyses. Third, this population of injection drug users may not be representative of all injection drug users, particularly those living in a rural or suburban environment, and therefore generalizability to all injection drug users is limited. A fourth limitation is that most of the data, being collected from the baseline questionnaire, was collected in 1997. Therefore, the variables involving "current" issues, such as current drug/alcohol treatment, or current methadone use, and even variables involving activities in the prior six months, were not at all current to this analysis. There have been a variety of new programs and initiatives established in the community since the time when these questions were originally asked, and these programs may influence some of these variables. Of note, however, there are still long waiting lists to enter drug/alcohol treatment or rehabilitation, and it is very difficult due to lack of resources for individuals to get free, ongoing, high quality mental health counseling in this community.

Other limitations of this analysis include the fact that the VIDUS cohort does not collect participants Personal Health Numbers (PHN), preventing us from validating the health care utilization data with health care utilization records. We were not able to separate out 
different kinds of victimization other than sexual (i.e. physical abuse, emotional abuse, neglect, etc.), and we were not able to control for other family background factors (e.g. alcoholism, divorce, etc.). The literature indicates that there is often overlap between types of abuse among victims, and our measures of sexual violence may in fact be measuring some kind of aggregated abuse variable unintentionally. However, our results regarding HIV risk and other self-destructive behaviors are strongly supported by the literature regarding sexual violence, and given the dose response effect we have found regarding age at onset of abuse, the extent to which this limitation should be considered can be minimized.

The question of the utility, applicability, and generalizability of the attributable risk calculations are best addressed within the context of limitations to the analysis. Population attributable risk is a notoriously crude method for assessing the relationship between exposure and outcome. It is generally used to assess the absolute and relative differences in incidence rates among the exposed and unexposed in relation to the development of a disease, and is a commonly used and widely accepted tool among epidemiologists (142).

This analysis was examining the relationship between sexual violence and HIV risk behaviors, and ideally, therefore, the attributable risks would have been calculated for the risk behaviors. Unfortunately, there is no incidence data available for these behaviors, and therefore HIV seroconversion was used as an indirect measure of whether sexual violence actually, ultimately, makes a difference, if one considers that HIV 
seroconversion is the final "so what" (which is arguable, given that the lives of VIDUS participants are clearly in more immediate danger from attempted suicide, drug overdoses, and many other factors). As previously indicated, while the incidence rates were different, they were not so different as to warrant attributable risk calculations. The prevalence estimates, however, were. The literature regarding attributable risk that was reviewed for this analysis $(142,151,152)$ never discussed why incidence specifically is used, and why prevalence specifically is not. The use of incidence rates in attributable risk originally comes from its development using relative risk, which is a calculation dependent on incidence $($ Attributable fraction $=$ [population exposure rate $(\mathrm{f}) *(\mathrm{RR}$ 1)]/[1+f(RR-1)], and was originally described by Levin 1953 (151). As Rothman (1998) states, incidence is generally a better way of assessing etiologic associations. Since prevalence reflects both the incidence rate and the probability of surviving with disease, studies of prevalence or studies based on prevalent cases yield associations that reflect the determinants of survival with disease, just as much as the causes of disease. However, for diseases in which there is a long pre-clinical phase, as is the case of HIV infection, it is considered acceptable to use prevalence data instead (152). We were not interested in measuring the effect of sexual violence on time to development of disease, but rather the relationship of sexual violence to being HIV-positive, supporting the application of prevalence in this situation. In addition, the relevant question for this analysis was based on population effects, and was about how much HIV in this cohort can be attributed to sexual violence; not, how much HIV since the cohort started is attributable to sexual violence. For each of these reasons, the use of prevalence was 
considered acceptable. It does appear to be a novel application of the"concept of attributable risk.

\subsection{The Question of Causality}

We must now return to the thorny issue of causation, raised first in the conclusion of the Literature Review of this paper.

The cause-effect relationship in epidemiological theory is a crucial and complex concept, widely discussed and debated $(152,153)$. For this reason, it is beyond the scope of this paper to thoroughly review its many facets and long history of development. However, the results of this analysis, combined with the generally strong and consistent associations in the literature that this analysis reinforces, are sufficiently strong to warrant an argument in favor of causation regarding the topic of sexual violence.

Principles of causation have been reasoned out and defined in several different ways since the European Enlightenment (152). As the practice of medicine and the field of epidemiology have evolved over time, the causative principles have become increasingly more relevant to humans, and to human populations. Epidemiologists generally prefer not to talk about causation, preferring terms such as risk factors, determinants, and exposures (153). In an attempt to simplify the issue, causes have been categorized in different ways, including necessary or sufficient, direct or indirect, single or multiple (153). The topic of causation is huge, and impossible to do justice to here. However, 
there are a number of conceptualizations of causation that have been developed for epidemiological applications, which can be useful in facilitating the discussion regarding sexual violence $(152,153)$.

As children, we observe one-to-one associations everywhere. If the light switch gets flicked, the light goes on, therefore the switch causes the light to go on. Thus we are conditioned early into thinking about causation in a singular and linear fashion. A definition of cause that is based on such one-to-one associations is:

"an antecedent event, condition, or characteristic that was necessary for the occurrence of the disease at the moment it occurred, given that other conditions are fixed." (Rothman: p.8)

This definition is problematic for epidemiological applications for several reasons. One is that it assumes that one can isolate a specific event, condition, or characteristic as the causative factor, and that this cause will be exactly the same every time (since one of the inherent assumptions about causality is that the results be reproducible). Seldom in human populations are events or characteristics repeated exactly the same way twice. Consequently, the second problem with the definition is the assumption of a fixed effect. This concept of specificity is most evident in Koch's postulates and one of Hill's proposed causative principles as well, with the idea that if one adds a specific agent to a fixed environment, the same effect will be seen every time the experiment is repeated $(152,153)$. Clearly, human societies and individuals - and the agents that affect us - are not controllable in this way, and therefore the assumption that the cause and effect of a disease will be so predictable is an inappropriate approach to such a human science as 
epidemiology. This is most evident in environmental epidemiology, as there are innumerable interacting, confounding, and unpredictable (not to mention unmeasurable) variables. As a result, cancer epidemiologists now refer to initiators and promoters of disease.(152), rather than causes.

This reluctance to say 'cause' appears to be exactly the obstacle facing the literature on sexual violence (and child sexual abuse in particular); despite all the evidence, researchers appear unwilling to actually come out and say that child sexual abuse causes a variety of self-destructive behaviors (17). This may be rooted in the conspiracy of silence that has surrounded the topic up until fairly recently (154). It may be because, if the prevalence estimates in the general population are accurate, many researchers (and journal editors) have probably themselves experienced child sexual abuse and for their own complicated personal reasons are not willing to acknowledge its potentially devastating effects. It may also be that epidemiologists are, with reason, conservative about drawing firm conclusions about causation except under the most controlled and predictable of circumstances (i.e. the randomized, double-blind, controlled clinical trial). These are all legitimate reasons, but this conservatism can also mean that, like climate change, the wait for the identification of a "true cause", if one exists, can be too long.

Rothman (1998) generally rejects most currently applied concepts of causation, and prefers to refer to causal components, and causal complements (152). Returning to his example of the lightbulb, the flick of the switch is one component among several necessary in order to cause the light to go on; the others being a current of electricity, a 
working bulb, and so on. Thus a cause can be considered sufficient, or minimal, if there is a minimal but necessary set of conditions that inevitably produces the effect. There is a tendency, however, for epidemiologists to assume that if there can be multiple components to the cause of any given disease, these components will necessarily add up to $100 \%$. This is probably the biggest flaw in the concept of attributable risk (whether incidence is the basis of it or not); it apportions components in a percent scale, and does not take into account interactive, random, or unknown effects. According to Rothman, the fraction of a disease that can be attributed to all or any of the component causes has no upper limit (152).

Susser (1991) has suggested a Pragmatic approach to untangling the web of causation (153). In this approach, all determinants serve as causes, and their essential properties are considered to be association, time order, and direction. In the Pragmatic perspective, a cause is something that makes a difference.

"Insofar as epidemiology is a science which by definition aims to discover the causes of health states, the search includes all determinants of a health outcome. These may be both active agents such as are embodied by interventions and similar activity and static conditions such as the attributes of persons and places. This concept of determinants enjoins a model of multiple causes." (Susser: p. 637)(153)

Susser's Pragmatic definition is based on but is slightly broader than some of Hill's famous principles, originally put forward in a 1964 Surgeon General's Report regarding smoking, and used to assess causation in the Literature Review of this paper. In contrast to Susser, although Rothman recognizes the utility of such causal criteria, he generally 
concludes that no causal criteria can attain the certainty of causation to the same degree as logical deduction, and that these criteria are essentially used for convenience (152).

"With such criteria, all the concerns about the logic or lack thereof in causal inference could be forgotten: It would only be necessary to consult the checklist of criteria to see if a relation were causal. [] Nevertheless, lists of causal criteria have become popular, possibly because they seem to provide a road map through complicated territory." (Rothman: p.24) (152)

Epidemiology is fundamentally a practical science, and was developed for practical reasons. So despite Rothman's many cogent arguments, which generally support the problematic described regarding sexual abuse and causation in the Literature Review, there do not appear to be other alternatives to the epidemiologist than to rely on the five causal, if perhaps convenient, criteria developed originally by Hill (i.e. association, consistency, temporality, biological plausibility, dose-response) (142).

To consider the question of sexual violence and the causation of self-destructive behaviors therefore, we must first narrow the concept to child sexual abuse, in part because it is hypothesized that child sexual abuse is associated with more adverse outcomes, and largely because it allows us, in the context of this project, to account for the question of temporality. We can therefore say that within this project, one of the five key causal criteria is automatically met.

According to the data generated from this project, we can also confirm that it meets the criteria of strength of association. In most self-destructive behaviors examined through 
controlled multivariate analysis, child sexual abuse was consistently and significantly associated.

The consistency of this data with the increasingly large body of literature on the topic is impressive, and can be said to meet the criteria of consistency of association.

Perhaps the most telling of all the causal criteria in the context of this project is that of a gradient of effect with severity of abuse, if in this case, severity of abuse is defined as that which occurred first in childhood compared to other ages. It was hypothesized that child sexual abuse would be more strongly associated with adverse effects than any of first experience of sexual violence in adolescence, adulthood, or never, and it was. These associations and interactions were confirmed through multivariate analysis, and are strongly indicative of a more severe effect if someone was first abused in childhood. The literature, as reviewed earlier, additionally supports this contention.

The literature contains numerous references regarding the biologic plausibility of someone who has experienced sexual trauma at an early age being vulnerable to many devastating effects later in life, including a variety of self-destructive behaviors. Although none of these were able to be tested in VIDUS participants, there is clearly theoretical and preliminary evidence that there are biological mechanisms that explain how someone who has experienced trauma, sexual or otherwise, would be predisposed to ending up as an active injection drug user in the Downtown Eastside. As described in more detail in the Literature Review of this thesis, these possible mechanisms include an 
over-activation of the neuroendocrine system, particularly the hypothalmic-pituitaryadrenal (HPA) axis $(37,144,145)$, hyperarousal (69), suppression of corticotropin releasing hormone (CRH) (145), suppressed cortisol levels (21), and lowered endogenous opiate activity (37).

The fact that not all of the VIDUS participants reported a history of sexual violence is not surprising. Sexual violence is only one kind of trauma, out of hundreds, and the effects can be mediated by several factors (e.g. disclosing and being supported). These mediating factors and other kinds of trauma, perhaps experienced by participants, were not considered in this analysis due to lack of existing VIDUS data on the topics, but are worthy of greater exploration. Further, if we can now say that child sexual abuse can cause these self-destructive and generally adverse effects (sorry, Rothman), and if we can say that these effects can be mitigated to some extent, then there is a social responsibility incumbent on each of us and our governments to intervene.

How does attributable risk contribute to the discussion of causation? Despite its limitations, including its upper limit attributable of $100 \%$, the attributable risk calculations suggest that, as per the hypothesis initially presented in this thesis, approximately $10 \%$ of the HIV among VIDUS participants can attribute their HIV to their history of sexual violence, and about $25 \%$ of those who have experienced sexual violence can attribute their HIV to this history. This is in a population of individuals where over one of three of whom have ever experienced sexual violence, and to one in five of whom it happened at or before the age of twelve. The prevalence estimates alone 
are unacceptably high, and in a population for whom a highly risky lifestyle (in terms of HIV) is their defining feature, this $10 \%$ excess risk is considerable. This is particularly notable given that the relationship between child sexual abuse and sexual violence is an indirect relationship. The attributable risk therefore simply adds weight to the strength of this analysis, the consistency of the literature, and the other causal criteria, all of which have been met. 


\section{Conclusions and Future Directions .}

The first hypothesis of this project was that there would be a high prevalence of lifetime sexual violence in this cohort of injection drug users, and that those individuals who have survived sexual violence would have a higher HIV risk behavior profile and a higher prevalence of other self-destructive behaviors than those who have not. The lifetime prevalence of sexual violence in this cohort is $36 \% ; 68 \%$ for women, and $19 \%$ for men. Those individuals who have survived sexual violence are, after controlling for sociodemographic factors, more likely to have been in the sex trade, to knowingly share needles/rigs with HIV-positive people, to have attempted suicide, and to have been diagnosed with a mental disorder/disability. The null hypothesis of no association can therefore be rejected.

The second hypothesis was that individuals who have experienced any sexual violence in their lifetimes would report increased health care utilization. A lifetime history of sexual violence was predictive of having consulted a General Practitioner in the past six months, to have used a hospital emergency department in the past six months, and to have ever been hospitalized for a mental disorder/disability, after controlling for sociodemographic variables. Again, the null hypothesis of no association can be rejected.

The third hypothesis was that people who experienced sexual violence in childhood would have a higher risk profile for HIV than either those who experienced sexual violence in adolescence, adulthood or those who report never having experienced sexual 
violence at all. The prevalence of child sexual abuse in this cohort is $21 \% ; 33 \%$ for women, and $13 \%$ for men. The first incident of sexual abuse occurring in childhood was predictive of entering the sex trade at a younger age, ever being in the sex trade, to have knowingly borrowed needles/rigs from HIV-positive people, to have attempted suicide, to have ever accidentally overdosed, to have been diagnosed with a mental disorder/disability. First experience of sexual violence in adolescence was predictive of ever being in the sex trade, having ever attempted suicide, and being diagnosed with a mental illness. First experience of sexual abuse in adulthood was only associated with ever being in the sex trade.

The fourth hypothesis in this analysis was that individuals who have experienced sexual violence in their childhoods would report more health care utilization than individuals who experienced sexual violence either in adolescence or adulthood, and more than individuals who report never having experienced any sexual violence at all. Indeed, the data strongly suggests that individuals who were first sexually abused in childhood utilize more health care services, including being twice as likely to have ever been hospitalized for a mental disorder or disability.

The final objective of this project was to determine how much of the HIV epidemic among this population is attributable to a history of sexual violence. The hypothesis for this objective was that $10 \%$ of the HIV epidemic experienced by injection drug users in the VIDUS cohort could be attributed to sexual violence. Interestingly, this was almost precisely the population attributable risk percent calculated. Further, approximately 25\% 
of those in the cohort who have ever experienced sexual violence can attribute their HIV serostatus to their history of sexual violence.

Despite these important findings, there are several more investigations required of this data, in order to complete a thorough evaluation of the issue of sexual violence in this group of injection drug users. These are listed in their descending order of importance:

- Stratification of the data by gender.

- A test for trend across the age groups for each self-destructive and/or HIV risk behavior.

- The differential and/or interactive effects of physical and sexual violence.

- The level of revictimization among individuals who experienced childhood and adolescent sexual abuse.

Despite the body of literature that is accumulating pointing to the causative and devastating effects of child sexual abuse, clearly it is still widely prevalent. Until there is no more sexual victimization of children, more and better research must be used and applied to finding solutions, and breaking the cycles of violence and pain that are becoming increasingly evident. 
1. Gordon P, Crehan K. Dying of sadness: gender, sexual violence and the HIV epidemic. In:: United Nations Development Program; 2000.

2. Nurcombe B. Child sexual abuse I: psychopathology. Aust N Z J Psychiatry 2000;34(1):85-91.

3. Russell DEH. Incidence and Prevalence of Intrafamilial and Extrafamilial Sexual Abuse of Female Children. Child Abuse \& Neglect 1983;7:133-46.

4. Haugaard JJ. The challenge of defining child sexual abuse. Am Psychol 2000;55(9):1036-9.5. Finkelhor D. The International Epidemiology of Child Sexual Abuse. Child Abuse \& Neglect 1994;18(5):409 - 17.

6. Strathdee SA, D.M. P, al. ACPe. Social determinants predict needle-sharing behaviour among injection drug users in Vancouver, Canada. Addiction 1997;92(10):1339-47.

7. Wood E, Schechter MT, Tyndall MW, Montaner JS, O'Shaughnessy MV, Hogg RS. Antiretroviral medication use among injection drug users: two potential futures. AIDS 2000;14(9): 1229-35.

8. Canada S. Population Census. Ottawa: Government of Canada; 1996.

9. O'Shaughnessy MV, Schechter MT. Death by Public Policy. In: Canadian Association for HIV Research; 1998 April 1998; Quebec City; 1998.

10. Freud S. The etiology of hysteria. In: Strachley J, editor. The Complete Psychological Works of Sigmeund Freud. London: Hogarth; 1962.

11. Kempe CH, Silverman FN, Steele BF, al. e. The battered child syndrome. Journal of the American Medical Association 1962;181:17-24.

12. Sheldrick C. Adult Sequelae of Child Sexual Abuse. British Journal of Psychiatry 1991;158(suppl. 10):55 - 62.

13. Finkelhor D, Hotaling GT. Sexual abuse in the National Incidence Study of Child Abuse and Neglect: an appraisal. Child Abuse \& Neglect. 1984;8(1):23-32.

14. DiLillo D. Interpersonal functioning among women reporting a history of childhood sexual abuse: empirical findings and methodological issues. Clin Psychol Rev 2001;21(4):553-76.

15. Briere J. Methodological Issues in the Study of Sexual Abuse Effects. Journal of Consulting and Clinical Psychology 1992;60(2):196 - 203.

16. Russell DE. The secret trauma: Incest in the lives of girls and women. New York: Basic Books; 1986.

17. Wyatt GE, Peters SD. Issues in the definition of child sexual abuse in prevalence research. Child Abuse \& Neglect 1986;10:231-40.

18. Feiring C, Rosenthal S, Taska L. Stigmatization and the development of friendship and romantic relationships in adolescent victims of sexual abuse. Child Maltreat 2000;5(4):311-22.

19. Jasinski JL, Williams LM, Siegel J. Childhood physical and sexual abuse as risk factors for heavy drinking among African-American women: a prospective study. Child Abuse Negl 2000;24(8):1061-71. 
20. King JA, Mandansky D, King S, Fletcher KE, Brewer J.- Early sexual abuse and low cortisol. Psychiatry Clin Neurosci 2001;55(1):71-4.

21. Allers CT, Benjack KJ. Connections between childhood abuse and HIV infection. Journal of Counselling and Development 1991(70):309 - 13.

22. Balogh R, Bretherton K, Whibley S, Berney T, Graham S, Richold P, et al. Sexual abuse in children and adolescents with intellectual disability. J Intellect Disabil Res 2001;45(Pt 3):194-201.

23. Beckinsale $P$, Martin G, Clark S. Sexual abuse and suicidal issues in Australian young people. An interim report. Aust Fam Physician 1999;28(12):1298-303.

24. Browne R, O'Connor J. Child abuse and the clinical course of drug misuse. Br J Psychiatry 2000;177:469.

25. Butzel JS, Talbot NL, Duberstein PR, Houghtalen RP, Cox C, Giles DE. The relationship between traumatic events and dissociation among women with histories of childhood sexual abuse. J Nerv Ment Dis 2000;188(8):547-9.

26. Chu JA, Dill DL. Dissociative Symptoms in Relation to Childhood Physical and Sexual Abuse. American Journal of Psychiatry 1990;147(7):887-92.

27. Cohen M, Deamant C, Barkan S, Richardson J, Young M, Holman S, et al. Domestic violence and childhood sexual abuse in HIV-infected women and women at risk for HIV. Am J Public Health 2000;90(4):560-5.

28. Cunningham J. PT, Pearce P. Childhood Sexual Abuse and Medical Complaints in Adult Women. Journal of Interpersonal Violence 1988;3(2):131-44.

29. Devroede G. Early life abuses in the past history of patients with gastrointestinal tract and pelvic floor dysfunctions. Prog Brain Res 2000;122:131-55.

30. Drossman DA, Leserman J, Nachman G, Li ZM, Gluck H, Toomey TC, et al. Sexual and physical abuse in women with functional or organic gastrointestinal disorders. Annals of Internal Medicine 1990;113(11):828-33.

31. Feldhaus KM, Houry D, Kaminsky R. Lifetime sexual assault prevalence rates and reporting practices in an emergency department population. Ann Emerg Med 2000;36(1):23-7.

32. Felitti VJ. Long-term Medical Consequences of Incest, Rape, and Molestation. Southern Medical Journal 1991;84(3):328-31.

33. Fiorentine R, Pilati ML, Hillhouse MP. Drug treatment outcomes: investigating the long-term effects of sexual and physical abuse histories. J Psychoactive Drugs 1999;31(4):363-72.

34. Gielen AC, McDonnell KA, Wu AW, O'Campo P, Faden R. Quality of life among women living with HIV: the importance violence, social support, and self care behaviors. Soc Sci Med 2001;52(2):315-22.

35. Golding JM, Taylor DL, Menard L, King MJ. Prevalence of sexual abuse history in a sample of women seeking treatment for premenstrual syndrome. J Psychosom Obstet Gynaecol 2000;21(2):69-80.

36. Heffernan K, Cloitre M, Tardiff K, Marzuk PM, Portera L, Leon AC. Childhood trauma as a correlate of lifetime opiate use in psychiatric patients. Addictive Behaviors 2000;25(5):797-803.

37. Jenkins MA, Langlais PJ, Delis DA, Cohen RA. Attentional dysfunction associated with posttraumatic stress disorder among rape survivors. Clin Neuropsychol 2000;14(1):7-12. 
38. Johnson DM, Pike JL, Chard KM. Factors predicting PTSD, depression, and dissociative severity in female treatment-seeking childhood sexual abuse survivors. Child Abuse Negl 2001;25(1):179-98.

39. Lechner M.E. VME, Garcia-Shelton L.M., Leichter J.L., Steibel K.R. Selfreported medical problems of adult female survivors of childhood sexual abuse. The Journal of Family Practice 1993;36(6):633-8.

40. Liebschutz JM, Feinman G, Sullivan L, Stein M, Samet J. Physical and sexual abuse in women infected with the human immunodeficiency virus: increased illness and health care utilization. Arch Intern Med 2000;160(11):1659-64.

41. McCauley J, Kern DE, Kolodner K, Dill L, Schroeder AF, DeChant HK, et al. Clinical characteristics of women with a history of childhood abuse: unhealed wounds [see comments]. Jama 1997;277(17):1362-8.

42. Molnar BE, Shade SB, Kral AH, Booth RE, Watters JK. Suicidal behavior and sexual/physical abuse among street youth. Child Abuse \& Neglect 1998;22(3):213-22.

43. Mullings JL, Marquart JW, Brewer VE. Assessing the relationship between child sexual abuse and marginal living conditions on HIV/AIDS-related risk behavior among women prisoners. Child Abuse Negl 2000;24(5):677-88.

44. Noell'J, Rohde P, Seeley J, Ochs L. Childhood sexual abuse, adolescent sexual coercion and sexually transmitted infection acquisition among homeless female adolescents. Child Abuse Negl 2001;25(1):137-48.

45. Pao M, Lyon M, D'Angelo LJ, Schuman WB, Tipnis T, Mrazek DA. Psychiatric diagnoses in adolescents seropositive for the human immunodeficiency virus. Archives of Pediatrics \& Adolescent Medicine 2000;154(3):240-4.

46. Parillo KM, Freeman RC, Collier K, Young P. Association between early sexual abuse and adult HIV-risky sexual behaviors among community-recruited women. Child Abuse Negl 2001;25(3):335-46.

47. Paul JP, Catania J, Pollack L, Stall R. Understanding childhood sexual abuse as a predictor of sexual risk-taking among men who have sex with men: The Urban Men's Health Study. Child Abuse Negl 2001;25(4):557-84.

48. Petrak J, Byrne A, Baker M. The association between abuse in childhood and STD/HIV risk behaviours in female genitourinary (GU) clinic attendees. Sex Transm Infect 2000;76(6):457-61.

49. Rosenberg HJ, Rosenberg SD, Wolford GL, 2nd, Manganiello PD, Brunette MF, Boynton RA. The relationship between trauma, PTSD, and medical utilization in three high risk medical populations. Int J Psychiatry Med 2000;30(3):247-59.

50. Ruscio AM. Predicting the child-rearing practices of mothers sexually abused in childhood. Child Abuse Negl 2001;25(3):369-87.

51. Shalhoub-Kevorkian N. The politics of disclosing female sexual abuse: a case study of Palestinian society. Child Abuse \& Neglect 1999;23(12):1275-93.

52. Simeon D, Guralnik O, Schmeidler J, Sirof B, Knutelska M. The role of childhood interpersonal trauma in depersonalization disorder. Am I Psychiatry 2001;158(7):1027-33.

53. Talbot NL, Duberstein PR, King DA, Cox C, Giles DE. Personality traits of women with a history of childhood sexual abuse. Compr Psychiatry 2000;41(2):130-6. 
54. Walker E. KW, Harrop-Griffiths J., Holm L., Russo J., Hickok L.R. Relationship of Chronic Pelvic Pain to Psychiatric Diagnoses and Childhood Sexual Absue. American Journal of Psychiatry 1988;145(1):75-80.

55. Wenzel SL, Leake BD, Gelberg L. Health of homeless women with recent experience of rape. J Gen Intern Med 2000;15(4):265-8.

56. Wingood GM, DiClemente RJ. Child Sexual Abuse, HIV Sexual Risk, and Gender Relations of African-American Women. American Journal of Preventive Medicine 1997;13(5):380-4.

57. Young TK, Katz A. Survivors of sexual abuse: clinical, lifestyle and reproductive consequences. Canadian Medical Association Journal 1998;159(4):329 - 34.

58. Zierler S, Witbeck B, Mayer K. Sexual Violence Against Women Living with or at Risk for HIV Infection. American Journal of Preventive Medicine 1996;12(5):304-10.

59. Zlotnick C, Mattia J, Zimmerman M. Clinical features of survivors of sexual abuse with major depression. Child Abuse Negl 2001;25(3):357-67.

60. Banyard VL, Arnold S, Smith J. Childhood sexual abuse and dating experiences of undergraduate women. Child Maltreatment 2000;5(1):39-48.

61. Duncan D. Prevalence of sexual assault victimization among heterosexual and gay/lesbian university students. Psychological Reports 1990;66:65-6.

62. Humphrey JA, White JW. Women's vulnerability to sexual assault from adolescence to young adulthood. J Adolesc Health 2000;27(6):419-24.

63. Johnsen LW, Harlow LL. Childhood sexual abuse linked with adult substance use, victimization, and AIDS-risk. AIDS Education and Prevention 1996;8(1):44-57.

64. Lodico MA, DiClemente RJ. The Association Between Childhood Sexual Abuse and Prevalence of HIV-Related Risk Behaviors. Clinical Pediatrics 1994(August):498 502.

65. Messman-Moore TL, Long P.J, Siegfried NJ. The revictimization of child sexual abuse survivors: an examination of the adjustment of college women with child sexual abuse, adult sexual assault, and adult physical abuse. Child Maltreat 2000;5(1):18-27.

66. Schaaf K.K. MTR. Relationship of childhood sexual, physical, and combined sexual and physical abuse to adult victimization and posttraumatic stress disorder. Child Abuse \& Neglect 1998;22(11):1119-33.

67. Thakkar RR, Gutierrez PM, Kuczen CL, McCanne TR. History of physical and/or sexual abuse and current suicidality in college women. Child Abuse Negl 2000;24(10):1345-54.

68. Thakkar RR, McCanne TR. The effects of daily stressors on physical health in women with and without a childhood history of sexual abuse. Child Abuse Negl 2000;24(2):209-21.

69. Edwards VJ, Anda RF, Nordenberg DF, Felitti VJ, Williamson DF, Wright JA. Bias assessment for child abuse survey: factors affecting probability of response to a survey about childhood abuse. Child Abuse Negl 2001 ;25(2):307-12.

70. Smith DW, Letourneau EJ, Saunders BE, Kilpatrick DG, Resnick HS, Best CL. Delay in disclosure of childhood rape: results from a national survey. Child Abuse Negl 2000;24(2):273-87.

71. Gentilello LM, Rivara FP, Donovan DM, Villaveces A, Daranciang E, Dunn CW, et al. Alcohol problems in women admitted to a level I trauma center: a gender-based comparison. Journal of Trauma-Injury Infection \& Critical Care 2000;48(1):108-14. 
72. Lab DD, Feigenbaum JD, De Silva P. Mental health professionals' attitudes and practices towards male childhood sexual abuse. Child Abuse Negl 2000;24(3):391-409.

73. Kenny MC, McEachern AG. Racial, ethnic, and cultural factors of childhood sexual abuse: a selected review of the literature. Clin Psychol Rev 2000;20(7):905-22.

74. Bremner JD, Shobe KK, Kihlstrom JF. False memories in women with selfreported childhood sexual abuse: an empirical study. Psychol Sci 2000;11(4):333-7.

75. Stein MB, Hanna C, Vaerum V, Koverola C. Memory functioning in adult women traumatized by childhood sexual abuse. Journal of Traumatic Stress 1999;12(3):527-34.

76. Finkelhor D, Moore D, Hamby SL, Straus MA. Sexually abused children in a national survey of parents: methodological issues. Child Abuse \& Neglect 1997;21(1):19.

77. Statistics C. Violence Against Women Survey. Ottawa: Government of Canada; 1993.

78. Canada S. Family Violence in Canada: A Statistical Profile. Ottawa: Government of Canada; 1999. Report No.: 85-224-X1E.

79. Control CfD. Rape. In:: National Center for Injury Prevention and Control; 2001.

80. Zierler S. FL, Laufer D. et al. Adult survivors of childhood sexual abuse and subsequent risk of HIV infection. American Journal of Public Health 1991(81):572 - 5.

81. Heffernan K, Cloitre M. A comparison of posttraumatic stress disorder with and without borderline personality disorder among women with a history of childhood sexual abuse: etiological and clinical characteristics. J Nerv Ment Dis 2000;188(9):589-95.

82. Wenzel SL, Koegel P, Gelberg L. Antecedents of physical and sexual victimization among homeless women: a comparison to homeless men. Am J Community Psychol 2000;28(3):367-90.

83. Thompson KM, Wonderlich SA, Crosby RD, Mitchell JE. Sexual violence and weight control techniques among adolescent girls. Int J Eat Disord 2001;29(2):166-76.

84. Hendricks-Matthews MK. Survivors of abuse. Health care issues. Primary Care; Clinics in Office Practice 1993;20(2):391-406.

85. Molnar BE, Buka SL, Kessler RC. Child sexual abuse and subsequent psychopathology: results from the National Comorbidity Survey. Am J Public Health 2001;91(5):753-60.

86. Hanson RF, Saunders B, Kilpatrick D, Resnick H, Crouch JA, Duncan R. Impact of childhood rape and aggravated assault on adult mental health. Am J Orthopsychiatry 2001;71(1):108-19.

87. Darves-Bornoz JM, Berger C, Degiovanni A, Gaillard P, Lepine IP. Similarities and differences between incestuous and nonincestuous rape in a French follow-up study. J Trauma Stress 1999;12(4):613-23.

88. Bodden-Heidrich R, Kuppers V, Beckmann MW, Rechenberger I, Bender HG. Chronic pelvic pain syndrome (CPPS) and chronic vulvar pain syndrome (CVPS): evaluation of psychosomatic aspects. Journal of Psychosomatic Obstetrics \& Gynecology $1999 ; 20(3): 145-51$.

89. Desai HD, Jann MW. Major depression in women: a review of the literature. J Am Pharm Assoc (Wash) 2000;40(4):525-37.

90. Fleming J, Mullen PE, Sibthorpe B, Bammer G. The long-term impact of childhood sexual abuse in Australian women. Child Abuse \& Neglect 1999;23(2):145-59. 
“91. Hill J, Davis R, Byatt M, Burnside: E, Rollinson L, Fear S. Childhood sexual abuse and affective symptoms in women: a general population study. Psychol Med 2000;30(6):1283-91.

92. Stewart KE, Ross D. Severe adverse life events and depressive symptoms among women with or at risk of HIV infection. Aids 1999;13(17):2477-8.

93. Hyun M, Friedman SD, Dunner DL. Relationship of childhood physical and sexual abuse to adult bipolar disorder. Bipolar Disord 2000;2(2):131-5.

94. Zanarini MC. Childhood experiences associated with the development of borderline personality disorder. Psychiatr Clin North Am 2000;23(1):89-101.

95. Mosby. Mosby's Medical Dictionary. Fifth ed; 1999.

96. Kisiel CL, Lyons JS. Dissociation as a mediator of psychopathology among sexually abused children and adolescents. Am J Psychiatry 2001;158(7):1034-9.

97. Feeny NC, Zoellner LA, Foa EB. Anger, dissociation, and posttraumatic stress disorder among female assault victims. J Trauma Stress 2000;13(1):89-100.

98. Ruggiero KJ, McLeer SV, Dixon JF. Sexual abuse characteristics associated with survivor psychopathology. Child Abuse Negl 2000;24(7):951-64.

99. Nishith P, Mechanic MB, Resick PA. Prior interpersonal trauma: the contribution to current PTSD symptoms in female rape victims. J Abnorm Psychol 2000;109(1):20-5.

100. Roy A. Childhood trauma and hostility as an adult: relevance to suicidal behavior. Psychiatry Res 2001;102(1):97-101.

101. Flanagan AS, Furman WC. Sexual victimization and perceptions of close relationships in adolescence. Child Maltreat 2000;5(4):350-9.

102. Krahe B, Scheinberger-Olwig R, Waizenhofer E, Kolpin S. Childhood sexual abuse and revictimization in adolescence. Child Abuse Negl 1999;23(4):383-94.

103. Stein MB, Barrett-Connor E. Sexual assault and physical health: findings from a population-based study of older adults. Psychosom Med 2000;62(6):838-43.

104. Acierno R, Resnick H, Kilpatrick DG, Saunders B, Best CL. Risk factors for rape, physical assault, and posttraumatic stress disorder in women: examination of differential multivariate relationships. J Anxiety Disord 1999;13(6):541-63.

105. Arata CM. From child victim to adult victim: a model for predicting sexual revictimization. Child Maltreat 2000;5(1):28-38.

106. Boney-McCoy S, Finkelhor D. Prior victimization: a risk factor for child sexual abuse and for PTSD-related symptomatology among sexually abused youth. Child Abuse Negl 1995;19(12):1401-21.

107. West CM, Williams LM, Siegel JA. Adult sexual revictimization among black women sexually abused in childhood: a prospective examination of serious consequences of abuse. Child Maltreat 2000;5(1):49-57.

108. Wyatt GE, Guthrie D, Notgrass CM. Differential effects of women's child sexual abuse and subsequent sexual revictimization. J Consult Clin Psychol 1992;60(2):167-73.

109. Kaslow NJ, Thompson MP, Brooks AE, Twomey HB. Ratings of family functioning of suicidal and nonsuicidal African American women. J Fam Psychol 2000;14(4):585-99.

110. Vajda J, Steinbeck K. Factors associated with repeat suicide attempts among adolescents. Aust N Z J Psychiatry 2000;34(3):437-45. 
111. Kendler KS, Bulik CM, Silberg J, Hettema JM, Myers J, Prescott CA. Childhoód sexual abuse and adult psychiatric and substance use disorders in women: an epidemiological and cotwin control analysis. Arch Gen Psychiatry 2000;57(10):953-9.

112. Kearney-Cooke A, Ackard DM. The effects of sexual abuse on body image, selfimage, and sexual activity of women. J Gend Specif Med 2000;3(6):54-60.

113. Champion JD, Shain RN, Piper J, Perdue ST. Sexual abuse and sexual risk behaviors of minority women with sexually transmitted diseases. West J Nurs Res 2001;23(3):241-54.

114. Brown LK, Lourie KJ, Zlotnick C, Cohn J. Impact of sexual abuse on the HIVrisk-related behavior of adolescents in intensive psychiatric treatment. Am J Psychiatry 2000;157(9):1413-5.

115. Bensley LS, Van Eenwyk J, Simmons KW. Self-reported childhood sexual and physical abuse and adult HIV-risk behaviors and heavy drinking. Am J Prev Med 2000;18(2):151-8.

116. Anda RF, Felitti VJ, Chapman DP, Croft JB, Williamson DF, Santelli J, et al. Abused boys, battered mothers, and male involvement in teen pregnancy. Pediatrics 2001;107(2):E19.

117. Potter K, Martin J, Romans S. Early developmental experiences of female sex workers: a comparative study. Australian \& New Zealand Journal of Psychiatry 1999;33(6):935-40.

118. Raj A, Silverman JG, Amaro H. The relationship between sexual abuse and sexual risk among high school students: findings from the 1997 Massachusetts Youth Risk Behavior Survey. Matern Child Health J 2000;4(2):125-34.

119. Lipman EL, MacMillan HL, Boyle MH. Childhood abuse and psychiatric disorders among single and married mothers. Am J Psychiatry 2001;158(1):73-7.

120. Wyatt GE. The relationship between child sexual abuse and adolescent sexual functioning in Afro-American and white American women. Annals of the New York Academy of Science 1988(528):111 - 22.

121. Lynch DA, Krantz S, Russell JM, Hornberger LL, Van Ness CJ. HIV infection: a retrospective analysis of adolescent high-risk behaviors. J Pediatr Health Care 2000;14(1):20-5.

122. Marcenko MO, Kemp SP, Larson NC. Childhood experiences of abuse, later substance use, and parenting outcomes among low-income mothers. Am J Orthopsychiatry 2000;70(3):316-26.

123. Green CR, Flowe-Valencia $\mathrm{H}$, Rosenblum L, Tait AR. Do physical and sexual abuse differentially affect chronic pain states in women? Journal of Pain \& Symptom Management 1999;18(6):420-6.

124. Finestone HM, Stenn P, Davies F, Stalker C, Fry R, Koumanis J. Chronic pain and health care utilization in women with a history of childhood sexual abuse. Child Abuse Negl 2000;24(4):547-56.

125. Goldberg RT, Goldstein R. A comparison of chronic pain patients and controls on traumatic events in childhood. Disabil Rehabil 2000;22(17):756-63.

126. Gurvits TV, Gilbertson MW, Lasko NB, Tarhan AS, Simeon D, Macklin ML, et al. Neurologic soft signs in chronic posttraumatic stress disorder. Arch Gen Psychiatry 2000;57(2):181-6. 
127. Arnow BA, Hart S, Scott C, Dea R, O'Connell L, Taylor CB. Childhood sexual abuse, psychological distress, and medical use among women. Psychosomatic Medicine 1999;61(6):762-70.

128. Walker EA, Unutzer J, Rutter C, Gelfand A, Saunders K, VonKorff M, et al. Costs of health care use by women HMO members with a history of childhood abuse and neglect. Archives of General Psychiatry 1999;56(7):609-13.

129. Golding JM, Stein JA, Siegel JM, Burnam MA, Sorenson SB. Sexual assault history and use of health and mental health. American Journal of Community Psychology 1988;16:625-44.

130. Shanahan M, Donato R. Counting the cost: estimating the economic benefit of pedophile treatment programs. Child Abuse Negl 2001;25(4):541-55.

131. Glod CA. Long-term Consequences of Childhood Physical and Sexual Abuse. Archives of Psychiatric Nursing 1993;7(3 (June)):163 - 73.

132. Campbell LC, Riley JL, 3rd, Kashikar-Zuck S, Gremillion H, Robinson ME. Somatic, affective, and pain characteristics of chronic TMD patients with sexual versus physical abuse histories. J Orofac Pain 2000;14(2):112-9.

133. Tynes LL, Gibson RL. Irritable bowel syndrome: overview of diagnosis and treatment. J La State Med Soc 1999;151(2):76-81.

134. Lampe A, Solder E, Ennemoser A, Schubert C, Rumpold G, Sollner W. Chronic pelvic pain and previous sexual abuse. Obstet Gynecol 2000;96(6):929-33.

135. Pitzner JK, McGarry-Long J, Drummond PD. A history of abuse and negative life events in patients with a sexually transmitted disease and in a community sample. Child Abuse Negl 2000;24(5):715-31.

136. Beitchman JH, Zucker KJ, Hood JE, daCoasta GA, Akman D, Cassavia E. A review of the long-term effects of child sexual abuse. Child Abuse and Neglect 1992;16:101-18.

137. Romans SE, Martin JL, Anderson JC, O'Shea ML, Mullen PE. Factors that mediate between child sexual abuse and adult psychological outcome. Psychological Medicine 1995;25:127 - 42.

138. Levanthal JM. Epidemiology of sexual abuse of children: Old problems, new directions. Child Abuse \& Neglect 1998;22(6):481 - 91.

139. Hennekens $\mathrm{CH}$, Buring JE. Epidemiology in Medicine. Boston/Toronto: Little, Brown and Company; 1987.

140. Browne A, Finkelhor D. Initial and long-term effects: a review of the research. In: Finkelhor D, editor. A Sourcebook on Child Sexual Abuse. London: Sage Publications; 1986. p. 143-79.

141. De Bellis MD, Chrousos GP, Dorn LD, Burke L, Helmers K, Kling MA; et al. Hypothalamic-pituitary-adrenal axis dysregulation in sexually abused girls. Journal of Clinical Endocrinology and Metabolism 1994;7:249-55.

142. Horan DL, Hill LD, Schulkin J. Childhood sexual abuse and preterm labor in adulthood: an endocrinological hypothesis. Womens Health Issues 2000;10(1):27-33.

143. Finkelhor D, Browne A. The traumatic impact of child sexual abuse: A conceptualization. American Journal of Orthopsychiatry 1985;55:530-41.

144. Miller M. A model to explain the relationship between sexual abuse and HIV risk among women. AIDS Care 1999;11(1):3-20. 
145. Grauerholz L. Ań ecological approach to understanding sexual revictimization: linking personal, interpersonal, and sociocultural factors and processes. Child Maltreat 2000;5(1):5-17.

146. Djeddah C, Facchin P, Ranzato C, Romer C. Child abuse: current problems and key public health challenges. Social Science and Medicine 2000;51:905-15.

147. Garcia-Moreno C, Watts C. Violence against women: its importance for HIV/AIDS. Aids 2000;14(Suppl 3):S253-65.

148. Adams MJ, Khoury MJ, James LM. The use of attributable fraction in the design and interpretation of epidemiologic studies. Journal of Clinical Epidemiology 1989;42(7):659-62.

149. Rothman KJ, Greenland S. Modern Epidemiology. 2nd ed: Lippincott Williams \& Wilkins; 1998.

150. Susser M. What is a cause and how do we know one? A grammar for Pragmatic Epidemiology. American Journal of Epidemiology 1991;133(7):635-48.

151. Finkelhor D. Sexually Victimized Children. New York: Free Press; 1979. 
Appendix One

St. Paul's Hospital, University of British Columbia Ethics Approval 
Appendix Two

Tables 1- 36 
Table 1 Abuse Characteristics by Gender

$\begin{array}{cc}\underset{n=345 / 505}{\text { Female }} & \text { Male } \\ n=173 / 932\end{array}$

First Incident

Childhood (12 and under)

Adolescence (13 - 17)

Adulthood (18 and over)

Mean Age at Onset (s.d.)

Median Age at Onset (IQR)

Perpetrator at First Incident

Male relative

Female relative

Known male

Male stranger

Female stranger

Male date

Female date

Male client

Male pimp

Other

Unsure

Refuse to answer

Ever Disclosed Prior to Interview

Never Disclosed Prior to Interview

Ever Received Counseling

Ever Been Revictimized
$167(54 \%)$

$85(27 \%)$

$61(19 \%)$

$13(8)$

$12(6-17)$

$31 \%$

$<1 \%$

$26 \%$

$<1 \%$

$15 \%$

$0 \%$

$4 \%$

$0 \%$

$7 \%$

$1 \%$

$<1 \%$

$2 \%$

$55 \%$

$45 \%$

$16 \%$

$51 \%$
$113(70 \%)$

$32(20 \%)$

$17(10 \%)$

$11(7)$

$10(6-15)$
$5 \%$

$1 \%$

$8 \%$

$3 \%$

$4 \%$

$<1 \%$

$<1 \%$

$<1 \%$

$1 \%$

$<1 \%$

$0 \%$

$0 \%$

$13 \%$

$87 \%$

$5 \%$

$9 \%$ 
Table 2 Univariate analyses comparing sociodemographic characteristics of individuals reporting any lifetime sexual violence versus those who report no lifetime sexual violence $(n=1437)$.

\section{Sexual Violence}

$\begin{array}{lllll}\text { Never } & \text { Ever } & \text { Unadjusted } & & \\ \mathbf{n},(\%) & \mathbf{n},(\%) & \text { Odds Ratio } & (95 \% \text { C.I. }) & \text { p-value } \\ \mathbf{n}=919 & \mathbf{n = 5 1 8} & & & \end{array}$

\section{Gender}

Male

$759(83 \%) \quad 173(33 \%)$

Female

$160(17 \%)$

$345(67 \%)$

9.5

$(7.5-12.0)$

$<0.001$

Age (years)

33

$26-39$
Median

IQR

35

$27-41$

$752(82 \%)$

$725(79 \%)$

$194(21 \%)$

Aboriginal

Yes
$167(18 \%)$

\section{Ethnicity}

Married or Common Law

$$
\text { No }
$$

Yes

$734(80 \%)$

$185(20 \%)$

$857(93 \%)$

$62(7 \%)$

No

Yes

$<0.001$

$40(8 \%)$

$478(92 \%)$

2.7

$(1.9-3.8)$

$<0.00$ I

$350(68 \%)$

$168(32 \%)$

1.8

$(1.4-2.3)$

$<0.001$

$361(70 \%)$

$157(30 \%)$

1.7

$(1.4-2.2)$

$<0.001$

Employment

$\begin{array}{lllllll}\text { No } & 857(93 \%) & 505(97 \%) & 0.4 & (0.2-0.6) & <0.001 \\ \text { Yes } & 62(7 \%) & 13(3 \%) & & & \end{array}$

Less than High School Education

No

$760(83 \%)$

Yes
$408(79 \%)$

$110(21 \%)$

1.3

$(1.0-1.7)$

0.066

Welfare as Main Income

No

Yes
$268(29 \%)$

$651(71 \%)$
$163(32 \%)$

$355(69 \%)$

0.9

$(0.7-1.1)$

0.360

Housing

Stable

Unstable

$361(39 \%) \quad 197(38 \%)$

$558(61 \%) \quad 321(62 \%)$
1.1

$(0.8-1.3) \quad 0.640$ 
Table 3 Logistic regression analysis* of sociodemographic factors associated with lifetime sexual violence

\begin{tabular}{|c|c|c|}
\hline Variable & $\begin{array}{l}\text { Adjusted } \\
\text { Odds ratio }\end{array}$ & $\begin{array}{c}95 \% \\
\text { Confidence Interval }\end{array}$ \\
\hline
\end{tabular}

\section{Gender}

(Female versus male)

9.0

$(7.0-11.5)$

Born in Canada

(Yes versus No)

1.6

$(1.1-2.4)$

All sociodemographic variables significant at the 0.05 cut-off were offered to the model. 
Table 4 Univariate analyses of drug use characteristics associated with a reported history of sexual violence $(n=1437)$.

\section{Sexual Violence}

\begin{tabular}{lcccc} 
Never & Ever & Unadjusted & & \\
$n,(\%)$ & $n,(\%)$ & Odds Ratio & $(95 \%$ C.I. $)$ & p-value \\
$\mathbf{n = 9 1 9}$ & $\mathbf{n = 5 1 8}$ & & & \\
\hline
\end{tabular}

Age when first fixed (years)

$\begin{array}{lll}\text { Median } & 19 & 18\end{array}$
IQR
$16-25$
$15-23$
$<0.001$

Ever Knowingly Borrowed Needles from HIV-positive Person
No
$879(96 \%)$
$463(89 \%)$
Yes
$40(4 \%)$
$55(11 \%)$
2.6
$(1.7-3.9)<0.001$

Currently Smoke Cigarettes

$\begin{array}{lccccc}\text { No } & 68(7 \%) & 18(4 \%) & & & \\ \text { Yes } & 851(93 \%) & 500(96 \%) & 2.2 & (1.3-3.7) & 0.003\end{array}$

Ever Accidentally Overdosed

$\begin{array}{llllll}\text { No } & 489(53 \%) & 196(38 \%) & & & \\ \text { Yes } & 430(47 \%) & 322(62 \%) & 1.9 & (1.5-2.3) & <0.001\end{array}$

Ever Lent Needles

$\begin{array}{llllll}\text { No } & 626(68 \%) & 286(55 \%) & & & \\ \text { Yes } & 293(32 \%) & 232(45 \%) & 1.7 & (1.4-2.2) & <0.001\end{array}$

Currently Borrowing Needles

$\begin{array}{llllll}\text { No } & 604(66 \%) & 282(54 \%) & & & \\ \text { Yes } & 315(34 \%) & 236(46 \%) & 1.6 & (1.3-2.0) & <0.001\end{array}$

Ever Borrowed Needles

$\begin{array}{llllll}\text { No } & 350(38 \%) & 148(29 \%) & & & \\ \text { Yes } & 569(62 \%) & 370(71 \%) & 1.5 & (1.2-1.9) & <0.001\end{array}$

Need Help Injecting

$\begin{array}{lllllll}\text { No } & 580(63 \%) & 264(51 \%) & & & \\ \text { Yes } & 339(37 \%) & 254(49 \%) & 1.6 & (1.3-2.0) & <0.001\end{array}$

Cocaine Use Frequency
$<1 /$ day
$542(59 \%) \quad 259(50 \%)$
$>1 /$ day $\quad 377(41 \%) \quad 259(50 \%)$
$1.4 \quad(1.2-1.8) \quad<0.001$ 
Heroin Use in Last $6 \mathrm{mths}$
No
$243(26 \%)$
$131(25 \%)$
Yes
$676(74 \%) \quad 387(75 \%)$
$1.1 \quad(0.8-1.4) \quad 0.633$

Heroin Use Frequency

$<1$ per day $545(59 \%) \quad 295(57 \%)$

$>1$ per day $374(41 \%) \quad 223(43 \%)$

$1.1 \quad(0.9-1.4) \quad 0.385$

Cocaine Use in Last 6 mths
No
$155(17 \%)$
$80(15 \%)$
Yes
$764(83 \%)$
$438(85 \%)$
1.1
$(0.8-1.5) \quad 0.484$

Crack Use in Last 6 mths
No
$527(57 \%)$
$281(54 \%)$
Yes
$392(43 \%) \quad 237(46 \%)$
1.1
$(0.9-1.4) \quad 0.256$

Alcohol

No $\quad 536(58 \%) \quad 312(60 \%)$

Yes

$383(42 \%) \quad 206(40 \%)$

0.9

$(0.7-1.2) \quad 0.480$

Bingeing

No

$472(51 \%) \quad 261(50 \%)$

Yes

$447(49 \%) \quad 257(50 \%)$

1.0

$(0.8-1.3)$

0.723 
Table 5 Univariate analyses of sexual behaviors associated with a reported history of lifetime sexual violence versus none $(n=1437)$.

\section{Sexual Violence}

\begin{tabular}{lcccc} 
Never & Ever & Unadjusted & & \\
$\mathbf{n},(\%)$ & $\mathbf{n},(\%)$ & Odds Ratio & $(95 \%$ C.I. $)$ & p-value \\
$\mathbf{n}=919$ & $\mathbf{n = 5 1 8}$ & & \\
\hline
\end{tabular}

Age when respondent was first paid for sex (years)

$\begin{array}{lcc}\text { Median } & 19 & 17 \\ \text { IQR } & 16-24 & 14-22\end{array}$

$<0.001$

Sex trade in last 6 months
No
$792(86 \%) \quad 257(50 \%)$
Yes
$127(14 \%) \quad 261(50 \%)$
6.3
$(5.0-8.1)<0.001$

Sex trade ever
No
$704(77 \%) \quad 194(37 \%)$
Yes
$215(23 \%) \quad 324(63 \%)$
5.5
$(4.4-6.9)<0.001$

Condoms with opposite sex client
No
$766(83 \%) \quad 280(54 \%)$
Yes
$153(17 \%) \quad 238(46 \%)$
$4.3 \quad(3.4-5.4) \quad 0.001$

Number of lifetime sexual partners

$\begin{array}{llllll}<20 & 353(38 \%) & 136(26 \%) & & & \\ >20 & 566(62 \%) & 382(74 \%) & 1.8 & (1.4-2.2) & <0.001\end{array}$

Regular opposite sex sexual partner
No
$562(61 \%) \quad 272(53 \%)$
Yes
$357(39 \%) \quad 246(47 \%)$
1.4
$(1.1-1.8)<0.001$

Casual opposite sex sexual partner
No
$604(66 \%) \quad 364(70 \%)$
Yes
$315(34 \%) \quad 154(30 \%)$
0.8
$(0.6-1.0) \quad 0.078$

Condoms with regular opposite sex sexual partner
No
$738(80 \%) \quad 401(77 \%)$
Yes
$181(20 \%)$
$117(23 \%)$
1.2
$(0.9-1.5)$
0.194

Condoms with casual opposite sex sexual partner
No
$690(75 \%) \quad 406(78 \%)$
Yes
$229(25 \%) \quad 112(22 \%)$
0.8
$(0.6-1.1)$
0.158

Age at first consensual intercourse (years)
Median
15
14.5

IQR

$13-16$

$13-16$

0.116 
Table 6 Univariate analyses of health issues and medical utilization associated with a reported history of sexual violence $(n=1437)$.

Sexual Violence

Never Ever Unadjusted

$n,(\%) \quad n,(\%) \quad$ Odds Ratio $\quad(95 \%$ C.I. $) \quad$ p-value $\mathrm{n}=\mathbf{9 1 9} \quad \mathrm{n}=\mathbf{5 1 8}$

Ever hospitalized for a mental disability (including suicide)
No $\quad 809(88 \%) \quad 347(67 \%)$
Yes $110(12 \%) \quad 171(33 \%)$
3.6
$(2.8-4.7) \quad<0.001$

Seriously thought about suicide
No $509(55 \%) \quad 133(26 \%)$
Yes $410(45 \%) \quad 385(74 \%)$
3.6
$(2.9-4.5) \quad<0.001$

Attempted suicide

$\begin{array}{lcccccc}\text { No } & 199(49 \%) & 97(25 \%) & & & \\ \text { Yes } & 211(51 \%) & 288(75 \%) & 2.8 & (2.1-3.8) & <0.001\end{array}$

Ever any sexually transmitted diseases

$\begin{array}{lllllll}\text { No } & 548(60 \%) & 204(39 \%) & & & \\ \text { Yes } & 371(40 \%) & 314(61 \%) & 2.3 & (1.8-2.8) & <0.001\end{array}$

GP consult in past $6 \mathrm{mths}$

$\begin{array}{lcccccc}\text { No } & 269(29 \%) & 83(16 \%) & & & \\ \text { Yes } & 650(71 \%) & 435(84 \%) & 2.2 & (1.7-2.8) & <0.001\end{array}$

Ever diagnosed with a mental disability/disorder

$\begin{array}{llllll}\text { No } & 748(81 \%) & 355(69 \%) & & & \\ \text { Yes } & 171(19 \%) & 163(31 \%) & 2.0 & (1.6-2.6) & <0.001\end{array}$

Drug/Alcohol treatment ever

$\begin{array}{lllllll}\text { No } & 284(31 \%) & 93(18 \%) & & & \\ \text { Yes } & 635(69 \%) & 425(82 \%) & 2.0 & (1.6-2.7) & <0.001\end{array}$

Overnight Hospital Admission in past $6 \mathrm{mths}$
No $\quad 759(83 \%) \quad 372(72 \%)$
Yes $\quad 160(17 \%) \quad 146(28 \%)$
1.9
$(1.4-2.4) \quad<0.001$

Currently on methadone
No $\quad 842(92 \%) \quad 442(85 \%)$
Yes $77(8 \%) \quad 76(15 \%)$
1.9
$(1.3-2.6)<0.001$ 
Ambulance attention in past $6 \mathrm{mths}$

$$
\text { No } \quad 672(73 \%) \quad 340(66 \%)
$$

Yes $247(27 \%) \quad 178(34 \%)$

1.8

$(1.1-1.8)$

0.003

\section{Current Drug/Alcohol treatment}

$\begin{array}{llllll}\text { No } & 764(83 \%) & 381(74 \%) & & & \\ \text { Yes } & 155(17 \%) & 137(26 \%) & 1.8 & (1.4-2.3) & <0.001\end{array}$

Emergency Dept. in past $6 \mathrm{mths}$

No $537(58 \%) \quad 258(50 \%)$

Yes $\quad 382(42 \%) \quad 260(50 \%)$

1.4

$(1.1-1.8) \quad 0.002$ 
Table 7 - Sociodemographic Characteristics (proportions) at Baseline Across Age Groups

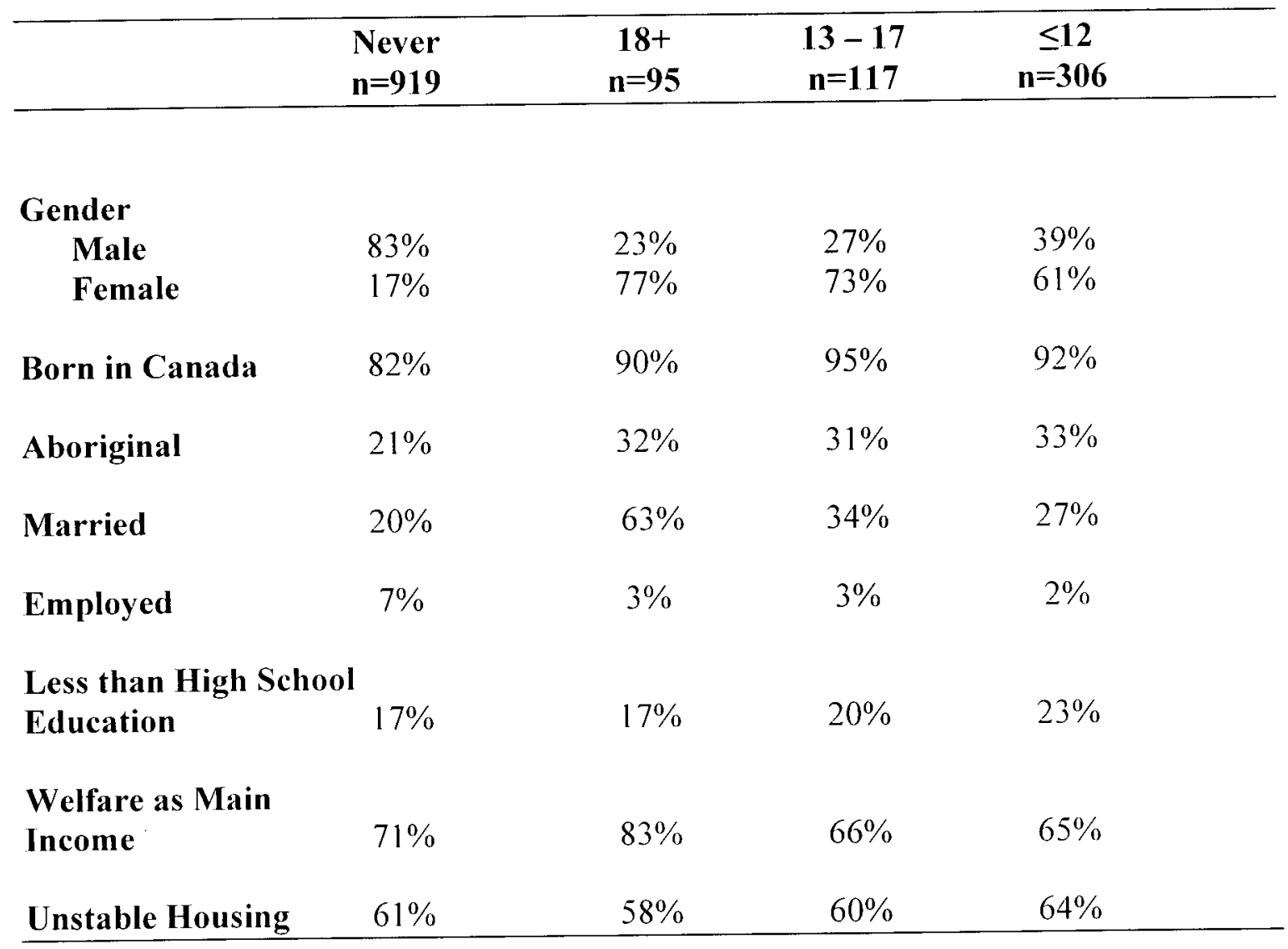


Table 8 Drug Use Characteristics (proportions) at Baseline Across Age Groups

$\begin{array}{cccc}\text { Never } & 18+ & 13-17 & \leq 12 \\ n=919 & n=95 & n=117 & n=306\end{array}$

Age First Fixed

(median, IQR)

$19(16-25)$

$20(17-26) \quad 18(15-23)$

$17(14-22)$

Ever Borrowed from

HIV+ Person

$4 \%$

$8 \%$

$9 \%$

$12 \%$

Smoke Cigarettes

$93 \%$

$95 \%$

$97 \%$

$97 \%$

Ever Accidentally

Overdosed

$$
47 \%
$$

$50 \%$

$60 \%$

$67 \%$

Ever Lent Needles

$$
32 \%
$$

$45 \%$

$41 \%$

$46 \%$

Ever Borrowed

Needles

$$
62 \%
$$

$71 \%$

$70 \%$

$72 \%$

Need Help

Injecting

$37 \%$

$52 \%$

$52 \%$

$47 \%$

Use Cocaine At

Least Once Daily

$41 \%$

$48 \%$

$44 \%$

$53 \%$ 
Table 9 Sexual Behavior Characteristics (proportions)' at Baseline Across Age Groups

\begin{tabular}{cccc}
\hline Never & $18+$ & $13-17$ & $\leq 12$ \\
$n=919$ & $n=95$ & $n=117$ & $n=306$ \\
\hline
\end{tabular}

Age First Paid to

Have Sex

(median, IQR)

$19(16-24)$

$20(17-27)$

$15(14-20) \quad 16(14-21)$

Ever in Sex Trade

$23 \%$

$68 \%$

$61 \%$

$61 \%$

Condoms with

Opposite Sex Client

$17 \%$

$46 \%$

$42 \%$

$47 \%$

At Least 20 Lifetime

Sexual Partners

$62 \%$

$74 \%$

$70 \%$

$75 \%$

Regular Opposite Sex

Partner

$39 \%$

$53 \%$

$50 \%$

$45 \%$ 
". Table 10 Medical and Health Care Utilization Characteristics (proportions) at Baseline Across Age Groups

\begin{tabular}{cccc}
\hline Never & $18+$ & $13-17$ & $\leq 12$ \\
$n=919$ & $n=95$ & $n=117$ & $n=306$ \\
\hline
\end{tabular}

Ever Hospitalized for Mental Illness

$12 \% \quad 32 \% \quad 21 \% \quad 38 \%$

Seriously Thought

About Suicide

$45 \%$

$72 \%$

$69 \%$

$77 \%$

Attempted Suicide

$51 \%$

$78 \%$

$68 \%$

$76 \%$

Ever Have a STD

$40 \%$

$57 \%$

$56 \%$

$64 \%$

GP Consult in Past

Six Months

$71 \%$

$86 \%$

$79 \%$

$85 \%$

Diagnosed with a

Mental IIlness

$19 \%$

$29 \%$

$22 \%$

$36 \%$

Ever Drug/Alcohol

Treatment

$69 \%$

$80 \%$

$78 \%$

$84 \%$

Overnight Hospital

Admissions in

Past Six Months

$17 \%$

$27 \%$

$28 \%$

$28 \%$

Ambulance Attention in Past Six Months

$27 \%$

$38 \%$

$34 \%$

$33 \%$

Emergency Dept. Use in Past Six Months

$42 \%$

$55 \%$

$49 \%$

$49 \%$ 
Table 11 Comparison of unadjusted sociodemographic odds ratios among different categories of age at first incident of sexual violence

$\begin{array}{lcc}\leq 12 \text { vs. never } & \mathbf{1 3}-\mathbf{1 7} \text { vs. never } & \geq \mathbf{1 8} \text { vs. never } \\ (U O R, 95 \% \mathrm{CI}) & (U O R, 95 \% \mathrm{CI}) & (U O R, 95 \% \mathrm{CI})\end{array}$

\section{Gender}

(Female vs. male) $\quad 7.5(5.7-9.8) \quad 12.6(8.7-18.3) \quad 15.7(10.4-23.8)$

Born in Canada

(Yes vs. no) $\quad 2.5(1.6-3.8) \quad 4.1(1.9-8.9) \quad 2.1(1.1-4.2)$

\section{Ethnicity}

(Aboriginal vs. other) $1.9(1.4-2.5) \quad 1.7(1.1-2.5) \quad 1.7(1.1-2.7)$

Married or Common Law

(Yes vs. no) $\quad 1.5(1.1-2.0) \quad 2.1(1.4-3.1) \quad 2.3(1.5-3.6)$

\section{Employment}

(Yes vs. no)

$$
0.3(0.2-0.7)
$$

ns

ns

$<$ High School Education

(Yes vs. no) $\quad 1.4(1.0-2.0)$

ns

ns

Welfare as Main Income

(Yes vs. no)

ns

ns

$2.0(1.2-3.5)$

\section{Housing}

(Unstable vs. stable)

ns

ns

ns 
Table 12 Comparison of unadjusted drug use odds ratios among different categories of age at first incident of sexual violence

$\begin{array}{lcc}\leq 12 \text { vs. never } & \mathbf{1 3 - 1 7} \text { vs. never } & \geq \mathbf{1 8} \text { vs. never } \\ (U O R, 95 \% C I) & (U O R, 95 \% C I) & (U O R, 95 \% C l)\end{array}$

Age when first fixed $0.97(0.96-0.99) \quad$ ns ns

(per year decrement)

Ever Knowingly Borrowed Needles from HIV-positive Person

(Yes vs. no) $\quad 2.9(1.9-4.6) \quad 2.3(1.2-4.5) \quad$ ns

Currently Smoke Cigarettes

$\begin{array}{llll}\text { (Yes vs. no) } \quad 2.4(1.2-4.6) & 3.0(1.0-2.2) & \text { ns }\end{array}$

Ever Accidentally Overdosed

$\begin{array}{lll}\text { (Yes vs. no) } \quad 2.3(1.7-3.0) & 1.7(1.2-2.5) & \text { ns }\end{array}$

Ever Lent Needles

$\begin{array}{llll}\text { (Yes vs. no) } & 1.8(1.4-2.4) & 1.5(1.0-2.2) & 1.8(1.2-2.7)\end{array}$

Currently Borrowing Needles

(Yes vs. no) $\quad 1.8(1.4-2.4)$

ns $\quad$ ns

Ever Borrowed Needles

(Yes vs. no)

$1.6(1.2-2.1)$

ns

ns

Need Help Injecting

(Yes vs. no)

$1.5(1.2-1.9)$

$1.9(1.3-2.7)$

$1.9(1.3-2.9)$

Cocaine Use Frequency

$(\geq 1$ /day vs. less $) \quad 1.6(1.2-2.1)$

ns

ns

Heroin Use in Last 6 mths

(Yes vs. no)

Heroin Use Frequency

$(\geq 1 /$ day vs. less)

Cocaine Use in Last 6 mths

(Yes vs. no)

Crack Use in Last $6 \mathrm{mths}$

(Yes vs. no)

ns 
Alcohol

(Yes vs. no)

ns

ns

ns

Bingeing

(Yes vs. no)

ns

nS

ns 
Table 13 Comparison of unadjusted sexual behavior odds ratios among different categories of age at first incident of sexual violence

\begin{tabular}{ccc}
\hline$\leq \mathbf{1 2}$ vs. never & $\mathbf{1 3 - 1 7}$ vs. never & $\mathbf{2 1 8}$ vs. never \\
$(U O R, 95 \% C I)$ & $(U O R, 95 \% C I)$ & $(U O R, 95 \% C I)$ \\
\hline
\end{tabular}

Age when respondent was first paid for sex

(Per year decrement) $\quad 0.90(0.85-0.95) \quad$ ns ns

Age at first consensual intercourse

(Per year decrement) $0.95(0.93-0.97) \quad$ ns ns

Sex trade in last 6 months

$\begin{array}{llll}\text { (Yes vs. no) } & 6.3(4.8-8.3) & 6.3(4.4-9.2) & 6.4(4.3-9.5)\end{array}$

Sex trade ever

$\begin{array}{lll}\text { (Yes vs. no) } \quad 5.2(4.0-6.8) & 5.1(3.5-7.3) \quad 7.1(4.7-10.7)\end{array}$

Condoms with opposite sex client

(Yes vs. no) $\quad 4.5(3.4-5.9) \quad 3.6(2.5-5.3) \quad 4.3(2.9-6.5)$

Number of lifetime sexual partners

(More than 20 vs less) $2.9(1.4-2.5) \quad$ ns $\quad 1.8(1.1-2.8)$

Regular opposite sex sexual partner

$\begin{array}{llll}\text { (Yes vs. no) } & \text { ns } & 1.6(1.1-2.4) & 1.8(1.2-2.7)\end{array}$

Casual opposite sex sexual partner

(Yesvs. no) ns ns ns

Condoms with regular opposite sex sexual partner

(Yes vs. no) ns ns

ns

Condoms with casual opposite sex sexual partner

(Yes vs. no) ns ns

ns 
Table 14 Comparison of unadjusted medical and health care utilization odds ratios among different categories of age at first incident of sexual violence

\begin{tabular}{ccc}
\hline$\leq 12$ vs. never & $\mathbf{1 3 - 1 7}$ vs. never & $\geq \mathbf{1 8 \text { vs. never }}$ \\
$(U O R, 95 \% \mathrm{CI})$ & $(U O R, 95 \% \mathrm{CI})$ & $(U O R, 95 \% \mathrm{CI})$ \\
\hline
\end{tabular}

Ever hospitalized for a mental disability (including suicide)
(Yes vs. no)
$4.6(3.4-6.1)$
$1.9(1.2-3.1)$
$3.4(2.2-5.4)$

Seriously thought about suicide

(Yes vs. no) $\quad 4.2(3.2-5.6)$

$2.8(1.9-4.2) \quad 3.1(2.0-4.9)$

Attempted suicide

(Yes vs. no)

$3.0(2.1-4.3)$

$2.0(1.2-3.3)$

$3.3(1.9-6.0)$

Ever any sexually transmitted diseases

$\begin{array}{llll}\text { (Yes vs. no) } \quad 2.6(2.0-3.4) & 1.9(1.3-2.7) & 2.0(1.3-3.0)\end{array}$

GP consult in past $6 \mathrm{mths}$
(Yes vs. no)
$2.3(1.7-3.3)$
$1.6(1.0-2.6)$
$2.6(1.5-4.7)$

Ever diagnosed with a mental disability/disorder
(Yes vs. no)
$2.4(1.8-3.2)$
ns
$1.8(1.2-2.9)$

Drug/Alcohol treatment ever

(Yes vs. no)

$2.4(1.7-3.3)$

$1.6(1.0-2.5)$

$1.8(1.1-3.0)$

Overnight Hospital Admission in past 6 mths

$\begin{array}{llll}\text { (Yes vs. no) } \quad 1.9(1.4-2.5) & 1.9(1.2-2.9) & 1.8(1.1-2.9)\end{array}$

Currently on methadone

(Yes vs. no)

ns

$2.4(1.4-4.0)$

$2.8(1.6-4.7)$

Ambulance attention in past $6 \mathrm{mths}$

(Yes vs. no) $\quad 1.4(1.0-1.8)$

ns $\quad 1.7(1.1-2.6)$

Current Drug/Alcohol treatment

$\begin{array}{lll}\text { (Yes vs. no) } \quad 1.5(1.1-2.1) & 1.9(1.3-3.0) & 2.4(1.5-3.8)\end{array}$

Emergency Dept. in past $6 \mathrm{mths}$

(Yes vs. no)

$1.4(1.1-1.8)$

ns

$1.7(1.1-2.6)$ 
Table 15 Univariate analyses comparing sociodemographic characteristics of individuals reporting first sexual violence at or before age 12 versus those who report never having experienced sexual violence $(n=1225)$.

\section{First Sexual Violence}

\begin{tabular}{crrrr} 
Never & $\leq 12$ yrs & Unadjusted & & \\
n, $(\%)$ & $\mathbf{n},(\%)$ & Odds Ratio & $(95 \%$ C.I. $)$ & p-value \\
$\mathbf{n}=919$ & $\mathbf{n = 3 0 6}$ & & & \\
\hline
\end{tabular}

\section{Gender}

Male $\quad 759(83 \%) \quad 119(39 \%)$

$\begin{array}{llllll}\text { Female } & 160(17 \%) & 187(61 \%) & 7.5 & (5.7-9.8) & <0.001\end{array}$

Born in Canada

$\begin{array}{llcccc}\text { No } & 167(18 \%) & 25(8 \%) & & & \\ \text { Yes } & 752(82 \%) & 281(92 \%) & 2.5 & (1.6-3.8) & <0.001\end{array}$

Ethnicity

$\begin{array}{llllll}\text { Other } & 725(79 \%) & 204(67 \%) & & & \\ \text { Aboriginal } & 194(21 \%) & 168(33 \%) & 1.9 & (1.4-2.5) & <0.001\end{array}$

Employment

\begin{tabular}{|c|c|c|}
\hline No & $857(93 \%)$ & $299(98 \%)$ \\
\hline Yes & $62(7 \%)$ & $7 \quad(2 \%)$ \\
\hline
\end{tabular}

Married or Common Law

$\begin{array}{llllll}\text { No } & 734(80 \%) & 224(73 \%) & & & \\ \text { Yes } & 185(20 \%) & 82(27 \%) & 1.5 & (1.1-2.0) & 0.014\end{array}$

$<$ High School Education

$\begin{array}{llllll}\text { No } & 760(83 \%) & 236(77 \%) & & & \\ \text { Yes } & 159(17 \%) & 70(23 \%) & 1.4 & (1.0-2.0) & 0.030\end{array}$

Welfare as Main Income

$\begin{array}{llllll}\text { No } & 268(29 \%) & 107(35 \%) & & & \\ \text { Yes } & 651(71 \%) & 199(65 \%) & 0.8 & (0.6-1.0) & 0.056\end{array}$

Housing

Stable $\quad 361(39 \%) \quad 110(36 \%)$

\begin{tabular}{llllll} 
Unstable & $558(61 \%)$ & $196(64 \%)$ & 1.2 & $(0.9-1.5)$ & 0.299 \\
\hline
\end{tabular} 
Table 16 Univariate analyses of drug use characteristics associated with first sexual violence at or before age 12 versus never experienced sexual violence $(n=1225)$.

\section{First Sexual Violence}

\begin{tabular}{lcll} 
Never & $\leq 12$ yrs & Unadjusted & \\
$n,(\%)$ & $n,(\%)$ & Odds Ratio $(95 \%$ C.I.) & p-value \\
$n=919$ & $n=306$ & & \\
\hline
\end{tabular}

Age when first fixed (years)
Median
19
17

IQR $16-25 \quad 14-22$
$<0.001$

\section{Ever Accidentally Overdosed}
No
$489(53 \%)$
$102(33 \%)$
Yes $\quad 430(47 \%) \quad 204(67 \%)$
$2.3 \quad(1.7-3.0)$
$<0.001$

Ever Knowingly Borrowed Needles from HIV-positive Person
No $\quad 879(96 \%) \quad 270(88 \%)$
Yes $\quad 40(4 \%) \quad 36(12 \%)$
$2.9 \quad(1.9-4.6) \quad<0.001$

Ever Lent Needles
No $626(68 \%) \quad 165(54 \%)$
Yes $293(32 \%) \quad 141(46 \%)$
$1.8 \quad(1.4-2.4) \quad<0.001$

Currently Borrowing Needles
No $\quad 604(66 \%) \quad 157(51 \%)$
Yes $\quad 315(35 \%) \quad 149(49 \%)$
$1.8 \quad(1.4-2.4) \quad<0.001$

Ever Borrowed Needles
No $\quad 350(38 \%)$
$85(28 \%)$
Yes $\quad 569(62 \%) \quad 221(72 \%)$
$1.6 \quad(1.2-2.1)<0.001$

Cocaine Use Frequency
$<1 /$ day $542(59 \%)$
$145(47 \%)$
$>1 /$ day $377(41 \%) \quad 161(53 \%)$
$1.6 \quad(1.2-2.1)<0.001$

Need Help Injecting
No $\quad 580(63 \%) \quad 163(53 \%)$
Yes $\quad 339(37 \%) \quad 143(47 \%)$
$1.5 \quad(1.2-1.9) \quad 0.002$ 


\section{Currently Smoke Cigarettes}

No $\quad 68(7 \%) \quad 10(3 \%)$

Yes $\quad 851(93 \%) \quad 296(97 \%)$

$2.4 \quad(1.2-4.6) \quad 0.010$

Heroin Use in Last 6 mths

No $\quad 243(26 \%) \quad 76(25 \%)$

Yes $\quad 676(74 \%) \quad 230(75 \%)$

$1.1 \quad(0.8-1.5) \quad 0.579$

Heroin Use Frequency
$<1 /$ day $545(59 \%)$
$173(57 \%)$
$>1 /$ day $374(41 \%)$
$133(43 \%)$
$1.1 \quad(0.9-1.5) \quad 0.395$

Cocaine Use in Last $6 \mathrm{mths}$

$\begin{array}{llllll}\text { No } & 155(17 \%) & 46(15 \%) & & & \\ \text { Yes } & 764(83 \%) & 260(85 \%) & 1.2 & (0.8-1.6) & 0.453\end{array}$

Crack Use in Last 6 mths

$\begin{array}{llllll}\text { No } & 527(57 \%) & 163(53 \%) & & & \\ \text { Yes } & 392(43 \%) & 143(47 \%) & 1.2 & (0.9-1.5) & 0.213\end{array}$

\section{Bingeing}

No $\quad 472(51 \%) \quad 143(47 \%)$

Yes $\quad 447(49 \%) \quad 163(53 \%)$

$1.2(0.9-1.6) \quad 0.161$

Alcohol

No $\quad 536(58 \%) \quad 185(60 \%)$

Yes $\quad 383(42 \%) \quad 121(40 \%)$

$0.9 \quad(0.7-1.2) \quad 0.511$ 
Table 17 Univariate analyses of sexual behaviors associated with first sexual violence at and before the age of 12 versus never experiencing sexual violence $(n=1225)$.

\section{First Sexual Violence}

$\begin{array}{lcccc}\text { Never } & \leq 12 \text { yrs } & \text { Unadjusted } & & \\ \mathbf{n},(\%) & \mathbf{n},(\%) & \text { Odds Ratio } & (95 \% \text { C.I. }) & \text { p-value } \\ \mathbf{n}=919 & \mathbf{n}=306 & & & \\ & & & & \end{array}$

Age when respondent was first paid for sex (years)
Median
19
16
Interquartile Range
$16-24$
$14-21$
$<0.001$
Age at first consensual intercourse (years)
Median $\quad 15 \quad 14$
$\begin{array}{llll}\text { Interquartile Range } & 13-16 & 13-16 & <0.001\end{array}$

Sex trade in last 6 months
No
$792(86 \%)$
$152(50 \%)$
Yes
$127(14 \%) \quad 154(50 \%)$
6.3
$(4.8-8.3)<0.001$

Sex trade ever

$\begin{array}{llllll}\text { No } & 704(77 \%) & 118(39 \%) & & & \\ \text { Yes } & 215(24 \%) & 188(61 \%) & 5.2 & (4.0-6.8) & <0.001\end{array}$

Condoms with opposite sex client

$\begin{array}{llllll}\text { No } & 766(83 \%) & 161(53 \%) & & & \\ \text { Yes } & 153(17 \%) & 145(47 \%) & 4.5 & (3.4-5.9) & <0.001\end{array}$

Number of lifetime sexual partners

$<20 \quad 353(38 \%) \quad 76(25 \%)$

$>20 \quad 566(62 \%) \quad 230(75 \%)$

$1.9 \quad(1.4-2.5) \quad<0.001$

Regular opposite sex sexual partner
No
$562(61 \%)$
$169(55 \%)$
Yes
$357(39 \%) \quad 137(45 \%)$
$1.3 \quad(1.0-1.7)$
0.067

Casual opposite sex sexual partner
No
$604(66 \%)$
$212(69 \%)$
Yes
$315(34 \%) \quad 94(31 \%)$
0.9
$(0.6-1.1) \quad 0.253$

Condoms with regular opposite sex sexual partner
No
$738(80 \%)$
$237(78 \%)$
Yes
$181(20 \%)$
$69(23 \%)$
1.2
$(0.9-1.6) \quad 0.283$

Condoms with casual opposite sex sexual partner
No
$690(75 \%) \quad 235(77 \%)$
Yes
$229(25 \%)$
$71(23 \%)$
0.9
$(0.7-1.2) \quad 0.545$ 
Table 18 Univariate analyses of health issues and medical utilization associated with first sexual violence at and before age 12 versus never experienced sexual violence $(n=1225)$.

\section{First Sexual Violence}

$\begin{array}{lcccc}\text { Never } & \leq 12 \text { yrs } & \text { Unadjusted } & & \\ n,(\%) & n,(\%) & \text { Odds Ratio } & (95 \% \text { C.I. }) & \text { p-value } \\ n=919 & n=306 & & & \end{array}$

Ever hospitalized for a mental disability (including suicide)
No $809(88 \%)$ $189(62 \%)$
Yes
$110(12 \%) \quad 117(38 \%)$
4.6
$(3.4-6.1)<0.001$

Seriously thought about suicide
No
$509(55 \%)$
$70(23 \%)$
Yes
$410(45 \%) \quad 236(77 \%)$
4.2
$(3.2-5.6)<0.001$

Attempted suicide
No
$199(49 \%) \quad 56(24 \%)$
Yes
$211(52 \%) \quad 180(76 \%)$
3.0
$(2.1-4.3)<0.001$

Ever any sexually transmitted diseases
No
$548(60 \%)$
$111(36 \%)$
Yes
$371(40 \%) \quad 195(64 \%)$
2.6
$(2.0-3.4)<0.001$

Ever diagnosed with a mental disability/disorder
No
$748(81 \%)$
$197(64 \%)$
Yes
$171(19 \%) \quad 109(36 \%)$
2.4
$(1.8-3.2)<0.001$

Drug/Alcohol treatment ever
No
$284(31 \%)$
$48(16 \%)$
Yes
$635(69 \%) \quad 258(84 \%)$
2.4
$(1.7-3.3)<0.001$

GP consult in past $6 \mathrm{mths}$
No
$269(29 \%)$
$46(15 \%)$
Yes
$650(71 \%) \quad 260(85 \%)$
2.3
$(1.7-3.3)<0.001$

Overnight Hospital Admission in past 6 mths
No
$759(83 \%) \quad 219(72 \%)$
Yes
$160(17 \%) \quad 87(28 \%)$
1.9
$(1.4-2.5) \quad<0.001$

Current Drug/Alcohol treatment
No
$764(83 \%) \quad 233(76 \%)$
Yes
$155(17 \%) \quad 73(24 \%)$
1.5
$(1.1-2.1) \quad 0.007$ 
Emergency Dept. in past $6 \mathrm{mths}$

$\begin{array}{llllll}\text { No } & 537(58 \%) & 155(51 \%) & & & \\ \text { Yes } & 382(42 \%) & 151(49 \%) & 1.4 & (1.1-1.8) & 0.017\end{array}$

Ambulance attention in past $6 \mathbf{m t h s}$

$\begin{array}{llllll}\text { No } & 672(73 \%) & 204(67 \%) & & & \\ \text { Yes } & 247(27 \%) & 102(33 \%) & 1.4 & (1.0-1.8) & 0.030\end{array}$

Currently on methadone

No $\quad 842(92 \%) \quad 270(88 \%)$

Yes $\quad 77(8 \%) \quad 36(12 \%)$

$1.5 \quad(1.0-2.2) \quad 0.076$ 
Table 19 Univariate analyses comparing sociodemographic characteristics of individuals reporting first sexual violence in adolescence (ages 13 through 17) versus those who report no lifetime sexual violence $(n=1036)$.

\section{First Sexual Violence}

\begin{tabular}{ccccc} 
Never & Adolescence & Unadjusted & & \\
$\mathbf{n},(\%)$ & $\mathbf{n},(\%)$ & Odds Ratio & $(95 \%$ C.I. $)$ & p-value \\
$\mathbf{n}=919$ & $\mathbf{n = 1 1 7}$ & & & \\
\hline
\end{tabular}

Gender

Male $\quad 759(83 \%) \quad 32(27 \%)$

Female $160(17 \%) \quad 85(73 \%)$

$12.6 \quad(8.7-18.3) \quad<0.001$

Born in Canada

$\begin{array}{llcccc}\text { No } & 167(18 \%) & 6(5 \%) & & & \\ \text { Yes } & 752(82 \%) & 111(95 \%) & 4.1 & (1.9-8.9) & <0.001\end{array}$

Married or Common Law

$\begin{array}{llllll}\text { No } & 734(80 \%) & 77(66 \%) & & & \\ \text { Yes } & 185(20 \%) & 40(34 \%) & 2.1 & (1.4-3.1) & <0.001\end{array}$

\section{Ethnicity}

Other $725(79 \%) \quad 81(69 \%)$

Aboriginal $194(21 \%) \quad 36(31 \%)$

$1.7 \quad(1.1-2.5) \quad 0.018$

Employment

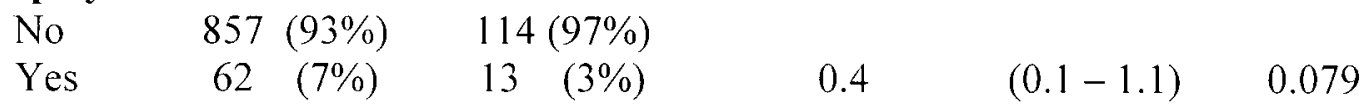

$<$ High School Education

No $\quad 760(83 \%) \quad 93(80 \%)$

$\begin{array}{llllll}\text { Yes } & 159(17 \%) & 24(20 \%) & 1.2 & (0.8-2.0) & 0.391\end{array}$

Welfare as Main Income
No
$268(29 \%)$
$40(34 \%)$
Yes
$651(71 \%) \quad 77(66 \%)$
0.8
$(0.5-1.2) \quad 0.263$

\section{Housing}

Stable $\quad 361(39 \%) \quad 47(40 \%)$

Unstable $558(61 \%) \quad 70(60 \%)$

$1.0 \quad(0.7-1.4) \quad 0.853$ 
Table 20 Univariate analyses of drug use characteristics associated with first sexual violence in adolescence (ages 13 through 17) versus those who report no sexual violence $(n=1036)$.

\section{First Sexual Violence}

$\begin{array}{lcccc}\text { Never } & \text { Adolescence } & \text { Unadjusted } & & \\ \mathbf{n},(\%) & \mathbf{n},(\%) & \text { Odds Ratio } & (95 \% \text { C.I. }) & \text { p-value } \\ \mathbf{n}=919 & \mathrm{n}=117 & & & \end{array}$

Need Help Injecting
No $580(63 \%) \quad 56(48 \%)$
Yes
$339(37 \%) \quad 61(52 \%)$
1.9
$(1.3-2.7)<0.001$

Ever Accidentally Overdosed
No
$489(53 \%) \quad 47(40 \%)$
Yes
$430(47 \%) \quad 70(60 \%)$
1.7
$(1.2-2.5) \quad 0.008$

Age when first fixed (years)
Median
19
18
IQR Range $\quad 16-25$
$15-23$
0.014

Ever Knowingly Borrowed Needles from HIV-positive Person
No
$879(96 \%) \quad 106(91 \%)$
Yes
$40(4 \%) \quad 11(9 \%)$
2.3
$(1.2-4.5)$
0.017

Ever Lent Needles
No
$626(68 \%) \quad 69(59 \%)$
Yes
$293(32 \%) \quad 48(41 \%)$
1.5
$(1.0-2.2)$
0.047

Currently Smoke Cigarettes
No
$68(7 \%)$
$3(3 \%)$
Yes
$851(93 \%) \quad 114(97 \%)$
3.0
$(1.0-9.3)$
0.051

Currently Borrowing Needles
No
$604(66 \%)$
$68(58 \%)$
Yes
$315(34 \%) \quad 49(42 \%)$
1.4
$(0.9-2.0)$
0.105

Ever Borrowed Needles
No
$350(38 \%) \quad 35(30 \%)$
Yes
$569(62 \%) \quad 82(70 \%)$
1.4
$(1.0-2.2)$
0.085

Cocaine Use Frequency
$<1 /$ day
$542(59 \%) \quad 65(56 \%)$
$>1 /$ day
$377(41 \%) \quad 52(44 \%)$
1.2
$(0.8-1.7)$
0.479 
Heroin Use in Last 6 mths
No
$243(26 \%) \quad 31(27 \%)$
Yes
$676(74 \%) \quad 86(73 \%)$
1.0
$(0.7-1.5) \quad 0.990$

Heroin Use Frequency
$<1 /$ day
$545(59 \%) \quad 65(56 \%)$
$>1 /$ day
$374(41 \%) \quad 52(44 \%)$
1.2
$(0.8-1.7) \quad 0.438$

Cocaine Use in Last 6 mths

No $\quad 155(17 \%) \quad 22(19 \%)$

Yes $\quad 764(83 \%) \quad 95(81 \%)$

$0.9 \quad(0.5-1.4) \quad 0.600$

\section{Crack Use in Last 6 mths}
No
$527(57 \%) \quad 66(56 \%)$
Yes
$392(43 \%) \quad 51(44 \%)$
1.0
$(0.7-1.5) \quad 0.847$

Alcohol

No $\quad 536(58 \%) \quad 69(59 \%)$

Yes $\quad 383(42 \%) \quad 48(41 \%)$

$1.0 \quad(0.7-1.4) \quad 0.893$

Bingeing
No
$472(51 \%) \quad 65(56 \%)$
Yes
$447(49 \%) \quad 52(44 \%)$
0.8
$(0.6-1.2) \quad 0.392$ 
Table 21 Univariate analyses of sexual behaviors associated with first sexual violence in adolescence (ages 13 through 17) versus no reported sexual violence $(n=1036)$.

\section{First Sexual Violence}

\begin{tabular}{lcccc} 
Never & Adolescence & Unadjusted & & \\
$\mathbf{n},(\%)$ & $\mathbf{n},(\%)$ & Odds Ratio & $(95 \%$ C.I. $)$ & p-value \\
$\mathbf{n = 9 1 9}$ & $\mathbf{n = 1 1 7}$ & & & \\
\hline
\end{tabular}

Age when respondent was first paid for sex (years)
Median
19
15
IQR
$16-24$
$14-20$
$<0.001$

Sex trade in last 6 months
No
$792(86 \%)$
$58(50 \%)$
Yes
$127(14 \%)$
$59(50 \%)$
6.3
$(4.4-9.2)$
$<0.001$

Sex trade ever

$\begin{array}{lll}\text { No } & 704(77 \%) & 46(39 \%) \\ \text { Yes } & 215(23 \%) & 71(61 \%)\end{array}$

$5.1 \quad(3.5-7.3)$

$<0.001$

Condoms with opposite sex client
No
$766(83 \%)$
$68(58 \%)$
Yes
$153(17 \%)$
$49(42 \%)$
3.6
$(2.5-5.3)$
$<0.001$

Regular opposite sex sexual partner
No
$562(61 \%)$
$58(50 \%)$
Yes
$357(39 \%)$
$59(50 \%)$
1.6
$(1.1-2.4)$
0.016

Number of lifetime sexual partners
$<20$
$353(38 \%)$
$35(30 \%)$
$>20$
$566(62 \%)$
$82(70 \%)$
$1.5 \quad(1.0-2.2)$
0.074

Age at first consensual intercourse (years)
Median
15
IQR
$13-16$
15
$14-16$

0.456

Casual opposite sex sexual partner
No
$604(66 \%)$
$82(70 \%)$
Yes
$315(34 \%) \quad 35(30 \%)$
$0.8 \quad(0.5-1.2)$
0.347

Condoms with regular opposite sex sexual partner
No
$738(80 \%)$
$89(76 \%)$
Yes
$181(20 \%)$
$28(24 \%)$
$1.3(0.8-2.0)$
0.282

Condoms with casual opposite sex sexual partner

\begin{tabular}{llllll} 
No & $690(75 \%)$ & $93(79 \%)$ & & & \\
Yes & $229(25 \%)$ & $24(21 \%)$ & 0.8 & $(0.5-1.2)$ & 0.296 \\
\hline
\end{tabular}


- Table 22 Univariate analyses of health issues and medical utilization associated with first sexual violence in adolescence versus no reported sexual violence $(n=1036)$.

First Sexual Violence

$\begin{array}{ccccc}\text { Never } & \text { Adolescence } & \text { Unadjusted } & & \\ \mathbf{n},(\%) & \mathbf{n},(\%) & \text { Odds Ratio } & (95 \% \text { C.I. }) & \text { p-value } \\ \mathbf{n}=\mathbf{9 1 9} & \mathbf{n}=117 & & & \\ & & & & \end{array}$

Seriously thought about suicide
No
$509(55 \%)$
$36(31 \%)$
Yes
$410(45 \%)$
$81(69 \%)$
2.8
$(1.9-4.2)<0.001$

Currently on methadone
No
$842(92 \%)$
$96(82 \%)$
Yes
$77(8 \%)$
$21(18 \%)$
2.4
$(1.4-4.0) \quad<0.001$

Attempted suicide
No
$199(49 \%) \quad 26(32 \%)$
Yes
$211(51 \%) \quad 55(68 \%)$
2.0
$(1.2-3.3)$
0.007

Overnight Hospital Admission in past 6 mths
No
$759(83 \%)$
$84(72 \%)$
Yes
$160(17 \%) \quad 33(28 \%)$
1.9
$(1.2-2.9)$
0.005

Current Drug/Alcohol treatment
No
$764(83 \%)$
$84(72 \%)$
Yes
$155(17 \%) \quad 33(28 \%)$
1.9
$(1.3-3.0) \quad 0.003$

Ever any sexually transmitted diseases
No
$548(60 \%)$
$52(44 \%)$
Yes
$371(40 \%) \quad 65(56 \%)$
1.9
$(1.3-2.7) \quad 0.002$

Ever hospitalized for mental illness
No
$809(88 \%)$
$93(79 \%)$
Yes
$110(12 \%)$
$24(21 \%)$
1.9
$(1.2-3.1)$
0.009

GP consult in past $6 \mathrm{mths}$
No
$269(29 \%)$
$24(21 \%)$
Yes
$650(71 \%)$
$93(79 \%)$
1.6
$(1.0-2.6)$
0.048

Drug/Alcohol treatment ever
No
$284(31 \%)$
$26(22 \%)$
Yes
$635(69 \%)$
$91(78 \%)$
1.6
$(1.0-2.5)$
0.053 
Ever diagnosed with a mental disability/disorder

No $\quad 748(81 \%) \quad 91(78 \%)$

Yes $\quad 171(19 \%) \quad 26(22 \%)$

$1.3 \quad(0.8-2.0) \quad 0.348$

Ambulance attention in past 6 mths

No $\quad 672(73 \%) \quad 77(66 \%)$

Yes $\quad 247(27 \%) \quad 40(34 \%)$

$1.4 \quad(0.9-2.1) \quad 0.096$

Emergency Dept. in past 6 mths No $\quad 537(58 \%) \quad 60(51 \%)$

$\begin{array}{llllll}\text { Yes } & 382(42 \%) & 57(49 \%) & 1.3 & (0.9-2.0) & 0.140\end{array}$ 
Table 23 Univariate analyses comparing sociodemographic characteristics of individuals reporting first sexual violence in childhood (age at or under 12) versus adolescence (aged 13 through 17) $(n=423)$.

\begin{tabular}{|c|c|c|c|c|c|}
\hline \multicolumn{6}{|c|}{ First Sexual Violence } \\
\hline & $\begin{array}{c}13-17 y \text { rs } \\
n,(\%) \\
n=117\end{array}$ & $\begin{array}{c}\leq 12 \text { yrs } \\
\mathrm{n},(\%) \\
\mathrm{n}=\mathbf{3 0 6}\end{array}$ & $\begin{array}{l}\text { Unadjusted } \\
\text { Odds Ratio }\end{array}$ & (95\% C.I.) & p-value \\
\hline \multicolumn{6}{|l|}{ Gender } \\
\hline Male & $32(28 \%)$ & $119(39 \%)$ & & & \\
\hline Female & $85(73 \%)$ & $187(61 \%)$ & 0.6 & $(0.4-0.9)$ & 0.027 \\
\hline \multicolumn{6}{|c|}{ Born in Canada } \\
\hline No & $6(5 \%)$ & $25(8 \%)$ & & & \\
\hline Yes & $111(95 \%)$ & $281(92 \%)$ & 0.6 & $(0.2-1.5)$ & 0.283 \\
\hline \multicolumn{6}{|l|}{ Ethnicity } \\
\hline Other & $81(69 \%)$ & $204(67 \%)$ & & & \\
\hline Aboriginal & $36(31 \%)$ & $102(33 \%)$ & 1.1 & $(0.7-1.8)$ & 0.615 \\
\hline \multicolumn{6}{|c|}{ Married or Common Law } \\
\hline No & $77(66 \%)$ & $224(73 \%)$ & & & \\
\hline Yes & $40(34 \%)$ & $82(27 \%)$ & 0.7 & $(0.5-1.1)$ & 0.133 \\
\hline \multicolumn{6}{|l|}{ Employment } \\
\hline No & $114(97 \%)$ & $299(98 \%)$ & & & \\
\hline Yes & $3(3 \%)$ & $7(2 \%)$ & 0.9 & $(0.2-3.5)$ & 0.867 \\
\hline \multicolumn{6}{|c|}{$<$ High School Education } \\
\hline No & $93(80 \%)$ & $236(77 \%)$ & & & \\
\hline Yes & $24(20 \%)$ & $70(23 \%)$ & 1.2 & $(0.7-1.9)$ & 0.601 \\
\hline \multicolumn{6}{|c|}{ Welfare as Main Income } \\
\hline No & $40(34 \%)$ & $107(35 \%)$ & & & \\
\hline Yes & $77(66 \%)$ & $199(65 \%)$ & 1.0 & $(0.6-1.5)$ & 0.880 \\
\hline \multicolumn{6}{|l|}{ Housing } \\
\hline Stable & $47(40 \%)$ & $110(36 \%)$ & & & \\
\hline Unstable & $70(61 \%)$ & $196(64 \%)$ & 1.2 & $(0.7-1.9)$ & 0.421 \\
\hline
\end{tabular}


Table 24 Univariate analyses comparing drug use characteristics of individuals reporting first sexual violence in childhood (age at or under 12) versus adolescence (aged 13 through 17$)(n=423)$.

\section{First Sexual Violence}

\begin{tabular}{ccccc}
$13-17 y r s$ & $\leq 12$ yrs & Unadjusted & & \\
$n,(\%)$ & $n,(\%)$ & Odds Ratio & $(95 \%$ C.I.) & p-value \\
$n=117$ & $n=306$ & & & \\
\hline
\end{tabular}

Age when first fixed (years)

Median

Interquartile Range

Ever Knowingly Borrowed Needles from HIV-positive Person
No
$106(91 \%) \quad 270(88 \%)$
Yes
$11(9 \%) \quad 36(12 \%)$
1.3
$(0.6-2.6)$
0.489

Currently Smoke Cigarettes
No
$3(3 \%)$
$10(3 \%)$
Yes
$114(97 \%) \quad 296(97 \%)$
0.8
$(0.2-2.9)$
0.708

Ever Accidentally Overdosed

$\begin{array}{llllll}\text { No } & 47(40 \%) & 102(33 \%) & & & \\ \text { Yes } & 70(60 \%) & 204(67 \%) & 1.3 & (0.9-2.1) & 0.188\end{array}$

Ever Lent Needles

$\begin{array}{llllll}\text { No } & 69(59 \%) & 165(54 \%) & & & \\ \text { Yes } & 48(41 \%) & 141(46 \%) & 1.2 & (0.8-1.9) & 0.350\end{array}$

Currently Borrowing Needles
No
$68(58 \%)$
$157(51 \%)$
Yes
$49(42 \%)$
$149(49 \%)$
1.3
$(0.9-2.0)$
0.209

Ever Borrowed Needles
No
$35(30 \%)$
$85(28 \%)$
Yes
$82(70 \%) \quad 221(72 \%)$
1.1
$(0.7-1.8)$
0.663

Need Help Injecting

$\begin{array}{lll}\text { No } & 56(48 \%) & 163(53 \%) \\ \text { Yes } & 61(52 \%) & 143(47 \%)\end{array}$

$\begin{array}{lll}0.8 & (0.5-1.2) \quad 0.320\end{array}$

Cocaine Use Frequency
$<1 /$ day
$65(56 \%)$
$145(47 \%)$
$>1 /$ day
$52(44 \%) \quad 161(53 \%)$

$1.4 \quad(0.9-2.1)$

0.133 


\section{Heroin Use in Last 6 mths}

$\begin{array}{lll}\text { No } & 31(27 \%) & 76(25 \%) \\ \text { Yes } & 86(73 \%) & 230(75 \%)\end{array}$

$1.1 \quad(0.7-1.8) \quad 0.725$

Heroin Use Frequency

$<1$ day $\quad 65(56 \%) \quad 173(57 \%)$

$>1 /$ day $\quad 52(44 \%) \quad 133(43 \%)$

$1.0 \quad(0.6-1.5) \quad 0.856$

Cocaine Use in Last 6 mths

$\begin{array}{llcccc}\text { No } & 22(19 \%) & 46(15 \%) & & & \\ \text { Yes } & 95(81 \%) & 260(85 \%) & 1.3 & (0.7-2.3) & 0.345\end{array}$

Crack Use in Last 6 mths

No $\quad 66(56 \%) \quad 163(53 \%)$

Yes $\quad 51(44 \%) \quad 143(47 \%)$

$1.1 \quad(0.7-1.7) \quad 0.562$

Alcohol

No $\quad 69(59 \%) \quad 185(60 \%)$

Yes $\quad 48(41 \%) \quad 121(40 \%)$

$0.9 \quad(0.6-1.5) \quad 0.781$

Bingeing

No

$65(56 \%) \quad 143(47 \%)$

Yes

$52(44 \%) \quad 163(53 \%)$

1.4

$(0.9-2.2)$

0.104 
Table 25 Univariate analyses comparing sexual behavior characteristics of individuals reporting first sexual violence in childhood (age at or under 12) versus adolescence (aged 13 through 17) $(n=423)$.

\section{First Sexual Violence}

\begin{tabular}{ccccc}
$13-17 y r s$ & $\leq 12$ yrs & Unadjusted & & \\
$n,(\%)$ & $n,(\%)$ & Odds Ratio & $(95 \%$ C.I. $)$ & p-value \\
$n=117$ & $n=306$ & & & \\
\hline
\end{tabular}

Sex trade in last 6 months
No
$58(50 \%)$
$152(50 \%)$
Yes
$59(50 \%)$
$154(50 \%)$
1.0
$(0.7-1.5)$
0.985

Sex trade ever
No
$46(39 \%)$
$118(39 \%)$
Yes
$71(61 \%)$
$188(61 \%)$
1.0
$(0.7-1.6) \quad 0.887$

Condoms with opposite sex client
No
$68(58 \%)$
$161(53 \%)$
Yes
$49(42 \%)$
$145(47 \%)$
$1.3(0.8-1.9)$
0.309

Number of lifetime sexual partners
$<20$
$35(30 \%)$
$76(25 \%)$
$>20$
$82(70 \%)$
$230(75 \%)$
$1.3(0.8-2.1)$
0.288

Regular opposite sex sexual partner
No
$58(50 \%)$
$169(55 \%)$
Yes
$59(50 \%)$
$137(45 \%)$
0.8
$(0.5-1.2)$
0.297

Casual opposite sex sexual partner
No
$82(70 \%)$
$212(69 \%)$
Yes
$35(30 \%)$
$94(31 \%)$
1.0
$(0.7-1.7)$
0.872

Condoms with regular opposite sex sexual partner
No
$89(76 \%)$
$237(77 \%)$
Yes
$28(24 \%)$
$69(23 \%)$
0.9
$(0.6-1.5)$
0.762

Condoms with casual opposite sex sexual partner
No
$93(80 \%)$
$235(77 \%)$
Yes
$24(20 \%)$
$71(23 \%)$
1.2
$(0.7-2.0)$
0.553 
Table 26 Univariate analyses comparing medical and health care utilization characteristics of individuals reporting first sexual violence in childhood (age at or under 12) versus adolescence (aged 13 through 17$)(n=423)$.

First Sexual Violence

\begin{tabular}{ccccc}
$13-17 y r s$ & $\leq 12$ yrs & Unadjusted & & \\
$n,(\%)$ & $n,(\%)$ & Odds Ratio & $(95 \%$ C.I. $)$ & p-value \\
$n=117$ & $n=306$ & & & \\
\hline
\end{tabular}

Ever hospitalized for a mental disability (including suicide)
No
$93(80 \%)$
$189(62 \%)$
Yes
$24(20 \%)$
$117(38 \%)$
2.4
$(1.5-3.9)<0.001$

Ever diagnosed with a mental disability/disorder
No
$91(78 \%)$
$197(64 \%)$
Yes
$26(22 \%)$
$109(29 \%)$
1.9
$(1.2-3.2) \quad 0.008$

Seriously thought about suicide

$\begin{array}{llllll}\text { No } & 36(31 \%) & 70(23 \%) & & & \\ \text { Yes } & 81(69 \%) & 236(77 \%) & 1.5 & (0.9-2.4) & 0.094\end{array}$

Attempted suicide

$\begin{array}{llclll}\text { No } & 26(32 \%) & 56(24 \%) & & & \\ \text { Yes } & 55(68 \%) & 180(76 \%) & 1.5 & (0.9-2.6) & 0.138\end{array}$

Ever any sexually transmitted diseases
No
$52(44 \%)$
$111(36 \%)$
Yes
$65(56 \%)$
$195(64 \%)$
$1.4(0.9-2.2)$
0.122

GP consult in past $6 \mathrm{mths}$
No
$24(21 \%)$
$46(15 \%)$
Yes
$93(80 \%)$
$260(85 \%)$
$1.5(0.9-2.5)$
0.175

Drug/Alcohol treatment ever

$\begin{array}{llcccc}\text { No } & 26(22 \%) & 48(16 \%) & & & \\ \text { Yes } & 91(78 \%) & 258(36 \%) & 1.5 & (0.9-2.6) & 0.113\end{array}$

Overnight Hospital Admission in past 6 mths
No
$84(72 \%)$
$219(72 \%)$
Yes
$33(28 \%)$
$87(28 \%)$
1.0
$(0.6-1.6)$
0.963

Currently on methadone
No
$96(82 \%)$
$270(88 \%)$
Yes
$21(18 \%)$
$36(12 \%)$
0.6
$(0.3-1.1)$
0.096 
Ambulance attention in past $6 \mathbf{m t h s}$

\begin{tabular}{|c|c|c|c|c|c|}
\hline No & $77(66 \%)$ & $204(67 \%)$ & & & \\
\hline Yes & $40(34 \%)$ & $102(33 \%)$ & 1.0 & $(0.6-1.5)$ & 0.868 \\
\hline \multicolumn{6}{|c|}{ irrent Drug/Alcohol treatment } \\
\hline No & $84(72 \%)$ & $233(76 \%)$ & & & \\
\hline Yes & $33(28 \%)$ & $73(24 \%)$ & 0.8 & $(0.5-1.3)$ & 0.256 \\
\hline \multicolumn{6}{|c|}{ nergency Dept. in past $6 \mathrm{mths}$} \\
\hline No & $60(51 \%)$ & $155(51 \%)$ & & & \\
\hline Yes & $57(49 \%)$ & $151(49 \%)$ & 1.0 & $(0.7-1.6)$ & 0.908 \\
\hline
\end{tabular}


Table 27 Univariate analyses comparing sociodemographic characteristics of individuals reporting first sexual violence in adulthood (aged 18 and over) versus those who report no lifetime sexual violence $(n=1014)$.

First Sexual Violence

$\begin{array}{ccccc}\text { Never } & \text { Adulthood } & \text { Unadjusted } & & \\ \mathbf{n},(\%) & \mathrm{n},(\%) & \text { Odds Ratio } & (95 \% \text { C.I. }) & \text { p-value } \\ \mathbf{n = 9 1 9} & \mathbf{n = 9 5} & & & \end{array}$

\section{Gender}

$\begin{array}{llllll}\text { Male } & 759(83 \%) & 22(23 \%) & & & \\ \text { Female } & 160(17 \%) & 73(77 \%) & 15.7 & (10.4-23.8) & <0.001\end{array}$

Married or Common Law

$\begin{array}{llllll}\text { No } & 734(80 \%) & 60(63 \%) & & & \\ \text { Yes } & 185(20 \%) & 35(37 \%) & 2.3 & (1.5-3.6) & <0.001\end{array}$

\section{Ethnicity}

Other $\quad 725(79 \%) \quad 65(68 \%)$

Aboriginal $194(21 \%) \quad 30(32 \%)$

$1.7 \quad(1.1-2.7) \quad 0.019$

Welfare as Main Income

$\begin{array}{llllll}\text { No } & 268(29 \%) & 16(17 \%) & & & \\ \text { Yes } & 651(71 \%) & 79(83 \%) & 2.0 & (1.2-3.5) & 0.011\end{array}$

\section{Born in Canada}

$\begin{array}{llllll}\text { No } & 167(18 \%) & 9(10 \%) & & & \\ \text { Yes } & 752(82 \%) & 86(90 \%) & 2.1 & (1.1-4.2) & 0.033\end{array}$

Employment
No
$857(93 \%) \quad 92(97 \%)$
0.5
$(0.1-1.4)$
0.174
Yes
$62(7 \%) \quad 3(3 \%)$

$<$ High School Education

$\begin{array}{llllll}\text { No } & 760(83 \%) & 79(83 \%) & & & \\ \text { Yes } & 159(17 \%) & 16(17 \%) & 1.0 & (0.6-1.7) & 0.910\end{array}$

Housing

Stable $\quad 361(39 \%) \quad 40(42 \%)$

Unstable $558(61 \%) \quad 55(58 \%)$

$0.9 \quad(0.6-1.4) \quad 0.592$ 
Table 28 Univariate analyses comparing drug use characteristics of individuals reporting first sexual violence in adulthood (aged 18 and over) versus those who report no lifetime sexual violence $(n=1014)$.

\section{First Sexual Violence}

\begin{tabular}{lcccc} 
Never & Adulthood & Unadjusted & & \\
n, $(\%)$ & $n,(\%)$ & Odds Ratio & $(95 \%$ C.I. $)$ & p-value \\
$\mathbf{n = 9 1 9}$ & $\mathbf{n = 9 5}$ & & & \\
\hline
\end{tabular}

Need Help Injecting
No
$580(63 \%)$
$45(47 \%)$
Yes
$339(37 \%)$
$50(52 \%)$
1.9
$(1.3-2.9)$
0.003

Ever Lent Needles
No
$626(68 \%) \quad 52(55 \%)$
Yes
$293(32 \%) \quad 43(45 \%)$
1.8
$(1.2-2.7)$
0.008

Age when first fixed (years)

$\begin{array}{lcc}\text { Median } & 19 & 20 \\ \text { IQR } & 16-25 & 17-26\end{array}$

0.694

Ever Knowingly Borrowed Needles from HIV-positive Person
No
$879(96 \%)$
$87(92 \%)$
Yes
$40(4 \%)$
$8(8 \%)$
2.0
$(0.9-4.4)$
0.075

Currently Smoke Cigarettes
No
$68(7 \%)$
$5(5 \%)$
Yes
$851(93 \%)$
$90(95 \%)$
1.4
$(0.6-3.6)$
0.443

Ever Accidentally Overdosed
No
$489(53 \%)$
$47(50 \%)$
Yes
$430(47 \%) \quad 58(50 \%)$
1.2
$(0.8-1.8)$
0.487

Currently Borrowing Needles
No
$604(66 \%)$
$57(60 \%)$
Yes $\quad 315(34 \%) \quad 38(40 \%)$
1.3
$(0.8-2.0)$
0.265

Ever Borrowed Needles
No
$350(38 \%)$
$28(29 \%)$
Yes
$569(62 \%)$
$67(71 \%)$
1.5
$(0.9-2.3)$
0.098 
- Cocaine Use Frequency

$<1$ per day $542(59 \%) \quad 49(52 \%)$

$>1$ per day $377(41 \%) \quad 46(48 \%)$

1.4

$(0.9-2.1)$

0.164

Heroin Use in Last 6 mths
No
$243(26 \%)$
$24(25 \%)$
Yes
$676(74 \%)$
$71(75 \%)$
1.1
$(0.7-1.7)$
0.804

Heroin Use Frequency
$<1 /$ day
$545(59 \%)$
$57(60 \%)$
$>1 /$ day $374(41 \%) \quad 38(40 \%)$
1.0
$(0.6-1.5)$
0.895

Cocaine Use in Last 6 mths

No $\quad 155(17 \%) \quad 12(13 \%)$

Yes $\quad 764(83 \%) \quad 83(87 \%)$

$1.4 \quad(0.8-2.6)$

0.289

Crack Use in Last 6 mths

No $\quad 527(57 \%) \quad 52(55 \%)$

Yes $\quad 392(43 \%) \quad 43(45 \%)$

$\begin{array}{lll}1.1 & (0.7-1.7) & 0.625\end{array}$

Alcohol

No $\quad 536(58 \%) \quad 58(61 \%)$

Yes $\quad 383(42 \%) \quad 37(39 \%)$

$0.9 \quad(0.6-1.4)$

0.607

Bingeing

\begin{tabular}{llllll} 
No & $472(51 \%)$ & $53(56 \%)$ & & & \\
Yes & $447(49 \%)$ & $42(44 \%)$ & 0.8 & $(0.5-1.3)$ & 0.411 \\
\hline
\end{tabular}


Table 29 Univariate analyses comparing sexual behavior characteristics of individuals reporting first sexual violence in adulthood (aged 18 and over) versus those who report no lifetime sexual violence $(n=1014)$.

\section{First Sexual Violence}

Never Adulthood Unadjusted

n, $(\%) \quad$ n, $(\%) \quad$ Odds Ratio $\quad(95 \%$ C.I. $) \quad$ p-value

$\mathrm{n}=919 \quad \mathrm{n}=95$

Sex trade in last 6 months
No
$792(86 \%) \quad 47(49 \%)$
Yes
$127(14 \%) \quad 48(51 \%)$
6.4
$(4.3-9.5)<0.001$

Sex trade ever

$\begin{array}{lccccl}\text { No } & 704(77 \%) & 30(32 \%) & & & \\ \text { Yes } & 215(23 \%) & 65(68 \%) & 7.1 & (4.7-10.7) & <0.001\end{array}$

Condoms with opposite sex client
No
$766(83 \%) \quad 51(54 \%)$
Yes
$153(17 \%) \quad 44(46 \%)$
$4.3 \quad(2.9-6.5) \quad<0.001$

Age at first consensual intercourse (years)

Median $15 \quad 15$

Interquartile Range $\quad 13-16 \quad 14-17$

0.008

Regular opposite sex sexual partner

$\begin{array}{llllll}\text { No } & 562(61 \%) & 45(47 \%) & & & \\ \text { Yes } & 357(39 \%) & 50(53 \%) & 1.8 & (1.2-2.7) & 0.009\end{array}$

Number of lifetime sexual partners

$\begin{array}{llllll}<20 & 353(38 \%) & 25(26 \%) & & & \\ >20 & 566(62 \%) & 70(74 \%) & 1.8 & (1.1-2.8) & 0.020\end{array}$

Casual opposite sex sexual partner
No
$604(66 \%) \quad 70(74 \%)$
Yes
$315(34 \%) \quad 25(26 \%)$
$\begin{array}{lll}0.7 & (0.4-1.1) \quad 0.118\end{array}$

Condoms with regular opposite sex sexual partner

No

Yes
$738(80 \%) \quad 75(79 \%)$

$181(20 \%) \quad 20(21 \%)$
1.1
$(0.7-1.8)$
0.752 
Condoms with casual opposite sex sexual partner

$$
\text { No } \quad 690(75 \%) \quad 78(82 \%)
$$

Yes $\quad 229(25 \%) \quad 17(18 \%)$

0.7

$(0.4-1.1)$

0.128

Age when respondent was first paid for sex (years)

Median

19

Interquartile Range

$16-24$

20

$17-27$

0.339 
Table $30 \quad$ Univariate analyses comparing medical and health care utilization characteristics of individuals reporting first sexual violence in adulthood (aged 18 and over) versus those who report no lifetime sexual violence $(\mathrm{n}=1014)$.

\section{First Sexual Violence}

Never Adulthood Unadjusted

$n,(\%) \quad n,(\%) \quad$ Odds Ratio $\quad(95 \%$ C.I. $) \quad$ p-value $\mathrm{n}=919$ $\mathrm{n}=95$.

Ever hospitalized for a mental disability (including suicide)
No
$809(88 \%)$
$65(68 \%)$
Yes
$110(12 \%)$
$30(32 \%)$
3.4
$(2.2-5.4)<0.001$

Seriously thought about suicide
No
$509(55 \%)$
$27(28 \%)$
Yes
$410(45 \%)$
$68(72 \%)$
3.1
$(2.0-4.9)$
$<0.001$

Attempted suicide

$\begin{array}{llllll}\text { No } & 199(49 \%) & 15(22 \%) & & & \\ \text { Yes } & 211(51 \%) & 53(78 \%) & 3.3 & (1.9-6.0) & <0.001\end{array}$

GP consult in past $6 \mathrm{mths}$
No
$269(29 \%)$
$13(14 \%)$
Yes
$650(71 \%)$
$82(86 \%)$
2.6
$(1.5-4.7)<0.001$

Currently on methadone
No
$842(92 \%)$
$76(80 \%)$
Yes
$77(8 \%)$
$19(20 \%)$
2.8
$(1.6-4.7) \quad<0.001$

\section{Current Drug/Alcohol treatment}
No
$764(83 \%)$
$64(67 \%)$
$155(17 \%) \quad 31(33 \%)$
2.4
$(1.5-3.8)$
$<0.001$

Ever any sexually transmitted diseases
No
$548(60 \%)$
$41(43 \%)$
Yes
$371(40 \%)$
$54(57 \%)$
2.0
$(1.3-3.0)$
0.002

Ever diagnosed with a mental disability/disorder
No
$748(81 \%)$
$67(71 \%)$
Yes
$171(19 \%)$
$28(29 \%)$
1.8
$(1.2-2.9)$
0.011 


\section{Drug/Alcohol treatment ever}

$\begin{array}{llllll}\text { No } & 284(31 \%) & 19(20 \%) & & & \\ \text { Yes } & 635(69 \%) & 76(80 \%) & 1.8 & (1.1-3.0) & 0.027\end{array}$

Overnight Hospital Admission in past 6 mths

$\begin{array}{llllll}\text { No } & 759(83 \%) & 69(73 \%) & & & \\ \text { Yes } & 160(17 \%) & 26(27 \%) & 1.8 & (1.1-2.9) & 0.017\end{array}$

Ambulance attention in past 6 mths

$\begin{array}{llllll}\text { No } & 672(73 \%) & 59(62 \%) & & & \\ \text { Yes } & 247(27 \%) & 36(38 \%) & 1.7 & (1.1-2.6) & 0.023\end{array}$

Emergency Dept. in past 6 mths
No
$537(58 \%)$
$43(45 \%)$
Yes
$382(42 \%)$
$52(55 \%)$
1.7
$(1.1-2.6) \quad 0.014$ 
2. Table 31 Univariate analyses comparing sociodemographic characteristics of individuals reporting first sexual violence at or before age 12 versus those who report sexual violence after age $12(n=518)$.

\begin{tabular}{|c|c|c|c|c|c|}
\hline \multicolumn{6}{|c|}{ First Sexual Violence } \\
\hline & $\begin{array}{c}>12 \text { yrs } \\
n,(0 \%) \\
n=212\end{array}$ & $\begin{array}{c}\leq 12 \text { yrs } \\
n,(0) \\
n=306\end{array}$ & $\begin{array}{l}\text { Unadjusted } \\
\text { Odds Ratio }\end{array}$ & (95\% C.I.) & p-value \\
\hline \multicolumn{6}{|l|}{ Gender } \\
\hline Male & $54(25 \%)$ & $119(39 \%)$ & & & \\
\hline Female & $158(75 \%)$ & $187(61 \%)$ & 0.5 & $(0.4-0.8)$ & $<0.001$ \\
\hline \multicolumn{6}{|c|}{ Married or Common Law } \\
\hline No & $137(65 \%)$ & $224(73 \%)$ & & & \\
\hline Yes & $75(35 \%)$ & $82(27 \%)$ & 0.7 & $(0.5-1.0)$ & 0.037 \\
\hline \multicolumn{6}{|c|}{ Welfare as Main Income } \\
\hline No & $56(26 \%)$ & $107(35 \%)$ & & & \\
\hline Yes & $156(74 \%)$ & $199(65 \%)$ & 0.7 & $(0.5-1.0)$ & 0.039 \\
\hline \multicolumn{6}{|c|}{ Born in Canada } \\
\hline No & $15(7 \%)$ & $25(8 \%)$ & & & \\
\hline Yes & $197(93 \%)$ & $281(92 \%)$ & 0.9 & $(0.4-1.7)$ & 0.646 \\
\hline \multicolumn{6}{|l|}{ Ethnicity } \\
\hline Other & $146(69 \%)$ & $204(67 \%)$ & & & \\
\hline Aboriginal & $66(31 \%)$ & $168(33 \%)$ & 1.1 & $(0.8-1.6)$ & 0.599 \\
\hline \multicolumn{6}{|l|}{ Employment } \\
\hline No & $206(97 \%)$ & $299(98 \%)$ & & & \\
\hline Yes & $6(3 \%)$ & $7 \quad(2 \%)$ & 0.8 & $(0.3-2.4)$ & 0.698 \\
\hline \multicolumn{6}{|c|}{$<$ High School Education } \\
\hline No & $172(81 \%)$ & $236(77 \%)$ & & & \\
\hline Yes & $40(19 \%)$ & $70(23 \%)$ & 1.3 & $(0.8-2.0)$ & 0.273 \\
\hline \multicolumn{6}{|l|}{ Housing } \\
\hline Stable & $156(41 \%)$ & $110(36 \%)$ & & & \\
\hline Unstable & $125(59 \%)$ & $196(64 \%)$ & 1.2 & $(0.9-1.8)$ & 0.241 \\
\hline
\end{tabular}


Table 32 Univariate analyses of drug use characteristics associated with first sexual violence at or before age 12 versus over $12(n=518)$.

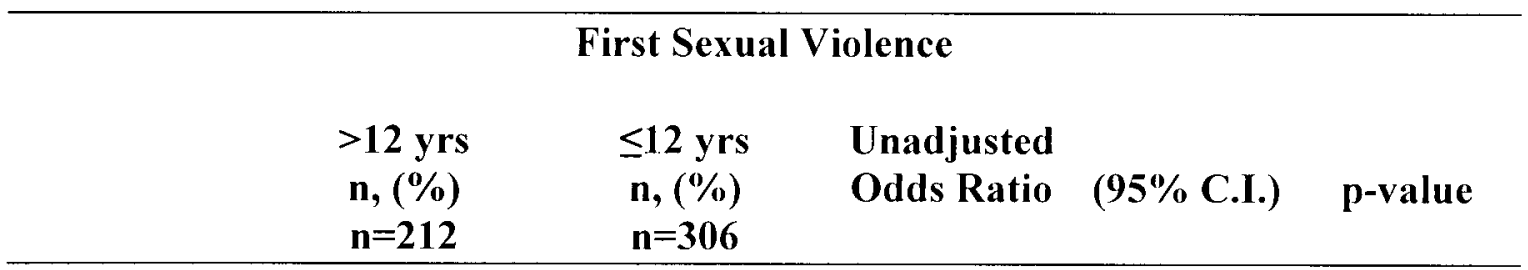

Ever Accidentally Overdosed

$\begin{array}{lccccc}\text { No } & 94(44 \%) & 102(33 \%) & & & \\ \text { Yes } & 118(56 \%) & 204(67 \%) & 1.6 & (1.1-2.3) & 0.011\end{array}$

Bingeing

$\begin{array}{llllll}\text { No } & 118(56 \%) & 143(47 \%) & & & \\ \text { Yes } & 94(44 \%) & 163(53 \%) & 1.4 & (1.0-2.0) & 0.046\end{array}$

Ever Knowingly Borrowed Needles from HIV-positive Person
No
$193(91 \%) \quad 270(88 \%)$
Yes
$19(9 \%)$
$36(12 \%)$
$1.4(0.8-1.7)$
0.309

Currently Smoke Cigarettes
No
$8(4 \%)$
$10(3 \%)$
Yes $\quad 204(96 \%) \quad 296(97 \%)$
$1.2(0.5-3.0)$
0.757

Ever Lent Necdles
No
$121(57 \%)$
$165(54 \%)$
Yes
$91(43 \%) \quad 141(46 \%)$
$1.1 \quad(0.8-1.6)$
0.478

Currently Borrowing Needles
No
$125(59 \%)$
$157(51 \%)$
Yes
$87(41 \%)$
$149(49 \%)$
1.4
$(1.0-1.9)$
0.086

Ever Borrowed Needles
No
$63(30 \%)$
$85(28 \%)$
Yes
$149(70 \%)$
$221(72 \%)$
$1.1 \quad(0.7-1.6)$
0.631

Need Help Injecting
No
$101(48 \%)$
$163(53 \%)$
Yes
$111(52 \%)$
$143(47 \%)$
0.8
$(0.6-1.1)$
0.208

Cocaine Use Frequency
$<1 /$ day
$114(54 \%)$
$145(47 \%)$
$\geq 1 /$ day
$98(46 \%)$
$161(53 \%)$
$1.3 \quad(0.9-1.8)$
0.153 
Heroin Use in Last $6 \mathrm{mths}$

$\begin{array}{lccccc}\text { No } & 55(26 \%) & 76(25 \%) & & & \\ \text { Yes } & 157(74 \%) & 230(75 \%) & 1.1 & (0.7-1.6) & 0.776\end{array}$

Heroin Use Frequency

$\begin{array}{lccccc}<1 / \text { day } & 122(58 \%) & 173(57 \%) & & & \\ \geq 1 / \text { day } & 90(42 \%) & 133(43 \%) & 1.0 & (0.7-1.5) & 0.819\end{array}$

Cocaine Use in Last $6 \mathrm{mths}$

No

$34(16 \%)$

$46(15 \%)$

Yes

$178(84 \%) \quad 260(85 \%)$

$\begin{array}{lll}1.1 & (0.7-1.8) & 0.756\end{array}$

Crack Use in Last 6 mths
No
$118(56 \%)$
$163(53 \%)$
Yes
$94(44 \%)$
$143(47 \%)$
$1.1 \quad(0.8-1.6) \quad 0.591$

Alcohol

No

$127(60 \%) \quad 185(60 \%)$

Yes

$85(40 \%)$

$121(40 \%)$

1.0

$(0.7-1.4) \quad 0.900$ 
Table 33 "Univariate analyses of sexual behaviors associated with first sexual violence at and before the age of 12 versus over age $12(n=518)$.

\begin{tabular}{cccc}
\hline \multicolumn{5}{c}{ First Sexual Violence } \\
& & & \\
$>12$ yrs & $\leq 12$ yrs & Unadjusted & \\
$n,(\%)$ & $n,(\%)$ & Odds Ratio & $(95 \%$ C.I. $) \quad$ p-value \\
$n=212$ & $n=306$ & & \\
\hline
\end{tabular}

Sex trade in last 6 months
No
$105(50 \%)$
$152(50 \%)$
Yes
$107(50 \%)$
$154(50 \%)$
1.0
$(0.7-1.4) \quad 0.974$

Sex trade ever
No
$76(36 \%)$
$118(39 \%)$
Yes
$136(64 \%)$
$188(61 \%)$
0.9
$(0.6-1.3) \quad 0.530$

Condoms with opposite sex client

$\begin{array}{llllll}\text { No } & 119(56 \%) & 161(53 \%) & & & \\ \text { Yes } & 93(44 \%) & 145(47 \%) & 1.2 & (0.8-1.6) & 0.430\end{array}$

Number of lifetime sexual partners
$<20$
$60(28 \%)$
$76(25 \%)$
$>20$
$152(72 \%)$
$230(75 \%)$
1.2
$(0.8-1.8) \quad 0.378$

Regular opposite sex sexual partner
No
$103(49 \%)$
$169(55 \%)$
Yes
$109(51 \%)$
$137(45 \%)$
0.8
$(0.5-1.1) \quad 0.137$

\section{Casual opposite sex sexual partner}
No
$152(77 \%)$
$212(69 \%)$
Yes
$48(28 \%)$
$94(31 \%)$
1.1
$(0.7-1.7) \quad 0.554$

Condoms with regular opposite sex sexual partner
No
$164(77 \%)$
$237(78 \%)$
Yes
$48(23 \%)$
$69(23 \%)$
1.0
$(0.7-1.5) \quad 0.980$

Condoms with casual opposite sex sexual partner
No
$171(81 \%)$
$235(77 \%)$
Yes
$41(19 \%)$
$71(23 \%)$
1.3
$(0.8-1.9)$
0.294 
$\therefore$ Table 34 Univariate analyses of health issues and medical utilization associated with first sexual violence at and before age 12 versus over $12(n=518)$.

\section{First Sexual Violence}

\begin{tabular}{lcccc}
$>12$ yrs & $\leq 12$ yrs & Unadjusted & & \\
$\mathbf{n},(\%)$ & $\mathbf{n},(\%)$ & Odds Ratio & $(95 \%$ C.I. $)$ & p-value \\
$\mathbf{n}=\mathbf{2 1 2}$ & $\mathrm{n}=\mathbf{3 0 6}$ & & & \\
\hline
\end{tabular}

Ever hospitalized for a mental disability (including suicide)
No
$158(75 \%)$
$189(62 \%)$
Yes
$54(25 \%)$
$117(38 \%)$
1.8
$(1.2-2.7)$
0.002

Ever diagnosed with a mental disability/disorder

$\begin{array}{lccccc}\text { No } & 158(75 \%) & 197(64 \%) & & & \\ \text { Yes } & 54(25 \%) & 109(36 \%) & 1.6 & (1.1-2.4) & 0.014\end{array}$

Currently on methadone
No
$172(81 \%)$
$270(88 \%)$
Yes
$40(19 \%)$
$36(12 \%)$
$0.6 \quad(0.4-0.9)$
0.025

Seriously thought about suicide
No
$63(30 \%)$
$70(23 \%)$
Yes
$149(70 \%) \quad 236(77 \%)$
1.4
$(1.0-2.1)$
0.080

Attempted suicide
No
$41(28 \%)$
$56(24 \%)$
Yes
$108(72 \%) \quad 180(76 \%)$
$1.2(0.8-2.0)$
0.404

Ever any sexually transmitted diseases
No
$93(44 \%)$
$111(36 \%)$
Yes
$119(56 \%) \quad 195(64 \%)$
1.4
$(1.0-2.0)$
0.082

GP consult in past $6 \mathrm{mths}$

$\begin{array}{llllll}\text { No } & 37(18 \%) & 46(15 \%) & & & \\ \text { Yes } & 175(83 \%) & 260(85 \%) & 1.2 & (0.7-1.9) & 0.460\end{array}$

Drug/Alcohol treatment ever

$\begin{array}{llllll}\text { No } & 45(21 \%) & 48(16 \%) & & & \\ \text { Yes } & 167(79 \%) & 258(84 \%) & 1.5 & (0.9-2.3) & 0.106\end{array}$

Overnight Hospital Admission in past $6 \mathbf{m t h s}$
No
$153(72 \%)$
$219(72 \%)$
Yes
$59(28 \%)$
$87(28 \%)$
$1.0 \quad(0.7-1.5)$
0.881 
Ambulance attention in past 6 mths

$\begin{array}{lccccc}\text { No } & 136(64 \%) & 204(67 \%) & & & \\ \text { Yes } & 76(36 \%) & 102(33 \%) & 0.9 & (0.6-1.3) & 0.553\end{array}$

Current Drug/Alcohol treatment

$\begin{array}{llllll}\text { No } & 148(83 \%) & 233(76 \%) & & & \\ \text { Yes } & 64(30 \%) & 73(24 \%) & 0.7 & (0.5-1.1) & 0.108\end{array}$

Emergency Dept. in past $6 \mathrm{mths}$
No
$103(49 \%)$
$155(51 \%)$
Yes
$109(51 \%)$
$151(49 \%)$
0.9
$(0.6-1.3) \quad 0.643$ 
Table 35 Adjusted odds ratios across age categories of first sexual violence related to important HIV risk factors and other self-destructive behaviors*

Outcome

ever vs. never $\geq 18$ vs. never $13-17$ vs. never $\leq 12$ vs. never $(A O R, 95 \% C I) \quad(A O R, 95 \% C I) \quad(A O R, 95 \% C I) \quad(A O R, 95 \% C I)$

Age entered sex trade

$(\leq 15$ vs. $\geq 16)$

$1.2(0.95-1.6)$

$0.79(0.47-1.3) 1.0(0.66-1.6)$

$1.6(1.1-2.2)$

Sex trade ever

(Yes vs. no)

$3.7(2.8-4.9) \quad 2.7(1.6-4.7)$

$2.7(1.8-4.3)$

$4.1(3.0-5.8)$

Borrowing from HIV+ people

(Yes vs. no)

$$
1.7(1.3-2.3)
$$

$1.7(0.99-3.0)$

$1.3(0.78-2.1)$

$2.0(1.4-2.8)$

Attempted suicide

(Yes vs. no)

$1.7(1.2-2.3)$

$1.7(0.96-3.1)$

$2.0(1.2-3.3)$

$1.6(1.1-2.3)$

Accidental overdoses

(Yes vs. no)

$$
1.3(0.99-1.6) 0.96(0.58-1.6) 0.93(0.61-1.4)
$$

Diagnosed mental disorder

(Yes vs. no)

$$
2.0(1.6-2.6) \quad 1.6(0.97-2.8)
$$

$1.6(1.1-2.5)$

Ever borrowed needles/rigs

(Yes vs. no)

$$
0.98(0.6-1.4) \quad 1.2(0.53-2.6) \quad 0.66(0.31-1.4) 0.98(0.62-1.5)
$$

\section{Cocaine frequency}

$(\geq 1 /$ day vs. $<1) \quad 0.83(0.67-1.1) 0.5(0.29-0.86) \quad 0.72(0.47-1.1) 0.87(0.64-1.2)$

Need help injecting

$\begin{array}{lllll}\text { (Yes vs. no) } & 1.2(0.85-105) & 1.5(0.86-2.8) & 0.84(0.54-1.3) & 1.3(0.93-1.8)\end{array}$

*All variables adjusted for gender, age at baseline, education, ethnicity, and place of birth. 
$\because$ Table 36 Adjusted odds ratios across age categories at first experience of sexual $\quad$ violence for health care utilization $* * *$

Outcome evervs. never $\geq 18$ vs. never $13-17$ vs. never $\leq 12$ vs. never $(A O R, 95 \% C I) \quad(A O R, 95 \% C I) \quad(A O R, 95 \% C I) \quad(A O R, 95 \% C I)$

GP consultation in past six months

$($ Yes vs. no) $\quad \mathbf{1 . 9}(\mathbf{1 . 1}-\mathbf{3 . 5}) \quad 1.2(0.43-3.3) \quad 2.7(0.79-9.2) \quad 1.9(0.94-4.0)$

Ambulance use in past six months

(Yes vs. no) $\quad 1.2(0.94-1.6) \quad \mathbf{1 . 9}(\mathbf{1 . 1}-\mathbf{3 . 2}) \quad 1.0(0.64-1.6) \quad 1.2(0.87-1.6)$

Admitted to hospital at least overnight in past six months

$\begin{array}{llll}\text { (Yes vs. no) } \quad 1.2(0.94-1.6) & 1.2(0.70-1.9) & 1.2(0.72-1.8) & 1.2(0.91-1.6)\end{array}$

Emergency Dept. use in past six months

(Yes vs. no) $\quad \mathbf{1 . 8}(\mathbf{1 . 3}-\mathbf{2 . 4}) \quad 1.2(0.59-2.3) \quad 1.2(0.68-2.0) \quad \mathbf{1 . 9}(\mathbf{1 . 3}-\mathbf{2 . 9})$

Ever hospitalized for a mental disorder/disability (including suicide)

(Yes vs. no) $\quad \mathbf{1 . 5}(\mathbf{1 . 1}-\mathbf{1 . 9}) \quad 1.8(0.98-3.1) \quad 1.4(0.87-2.2) \quad \mathbf{1 . 7}(\mathbf{1 . 2}-\mathbf{2 . 4})$

*** All variables adjusted for gender, age at baseline, education, ethnicity, and place of birth. 